\title{
Response and time allocation on concurrent variable -interval schedules of signaled and unsignaled reinforcement
}

\author{
Jeffrey Everly \\ West Virginia University
}

Follow this and additional works at: https://researchrepository.wvu.edu/etd

\section{Recommended Citation}

Everly, Jeffrey, "Response and time allocation on concurrent variable -interval schedules of signaled and unsignaled reinforcement" (2007). Graduate Theses, Dissertations, and Problem Reports. 2562.

https://researchrepository.wvu.edu/etd/2562

This Dissertation is protected by copyright and/or related rights. It has been brought to you by the The Research Repository @ WVU with permission from the rights-holder(s). You are free to use this Dissertation in any way that is permitted by the copyright and related rights legislation that applies to your use. For other uses you must obtain permission from the rights-holder(s) directly, unless additional rights are indicated by a Creative Commons license in the record and/ or on the work itself. This Dissertation has been accepted for inclusion in WVU Graduate Theses, Dissertations, and Problem Reports collection by an authorized administrator of The Research Repository @ WVU.

For more information, please contact researchrepository@mail.wvu.edu. 
Response and Time Allocation on Concurrent Variable-Interval Schedules of Signaled and Unsignaled Reinforcement

\author{
Jeffrey Everly
}

Dissertation submitted to the Eberly College of Arts and Sciences

at West Virginia University in partial fulfillment of the requirements

for the degree of

Doctor of Philosophy

in

Psychology

Michael Perone, Ph.D., Chair

Kennon A Lattal, Ph.D.

Karen G. Anderson, Ph.D.

JoNell Strough, Ph.D.

Joseph J. Donovan, Ph.D.

Department of Psychology

Morgantown, West Virginia

2007

Keywords: choice, matching law, local model of choice, concurrent schedules, fix and sample, pigeon 


\begin{abstract}
Response and Time Allocation on Concurrent Variable-Interval Schedules of Signaled and Unsignaled Reinforcement

Jeffrey Everly
\end{abstract}

The present experiments were designed to evaluate accounts of how behavior is allocated on concurrent variable-interval (VI) VI schedules. The generalized matching law assumes that the proportion of behavior allocated to the two schedules will match the proportion of reinforcers obtained on the two schedules (Baum, 1974). An alternate view holds that under ideal conditions, behavior should "fix" almost exclusively at the richer schedule. The leaner schedule is only visited, or "sampled", when a reinforcer becomes available on that schedule (Houston \& McNamara, 1981). Attempts were made to create optimal conditions for producing an ideal fixand-sample response pattern. Pigeons were exposed to a series of concurrent VI VI schedules with and without signals for the availability of reinforcement. In Experiment 1, reinforcers at the lean alternative were signaled, which produced a robust tendency to fix at the rich schedule. In Experiment 2, reinforcers at the rich schedule were signaled, and the allocation of behavior shifted in favor of the lean schedule. No evidence of an ideal fix-and-sample pattern was found in either experiment, but a less extreme form of the pattern was observed in both experiments, regardless of the presence or absence of signals. Results were consistent with other research indicating that less extreme fix-and-sample patterns may be a fundamental characteristic of behavior engender by concurrent schedules (e.g., Aparicio \& Baum, 2006). Although the present data were well described by the generalized matching equation, they were better described by a model that captures the way in which reinforcers are obtained by fix-and-sample response patterns (MacDonall, 2005). 


\section{Acknowledgements}

I would like to thank the members of my committee, Drs. Mike Perone, Andy Lattal, Karen G. Anderson, JoNell Strough, and Joe Donovan, for their thought-provoking and helpful comments. I especially thank my advisor, Dr. Mike Perone, for his many years of guidance. I have never ceased to be amazed at what Mike Perone has taught me about research, writing, and teaching. I thank members of the Perone Lab, past and present, for their assistance and inspiration. I thank my mother, father, sister, and grandparents for their enthusiasm and assistance throughout my graduate career. Finally, I thank Jessica Long. The completion of this document was much easier with Jessica’s constant encouragement, patience, and support. Thank you for everything. 
Table of Contents

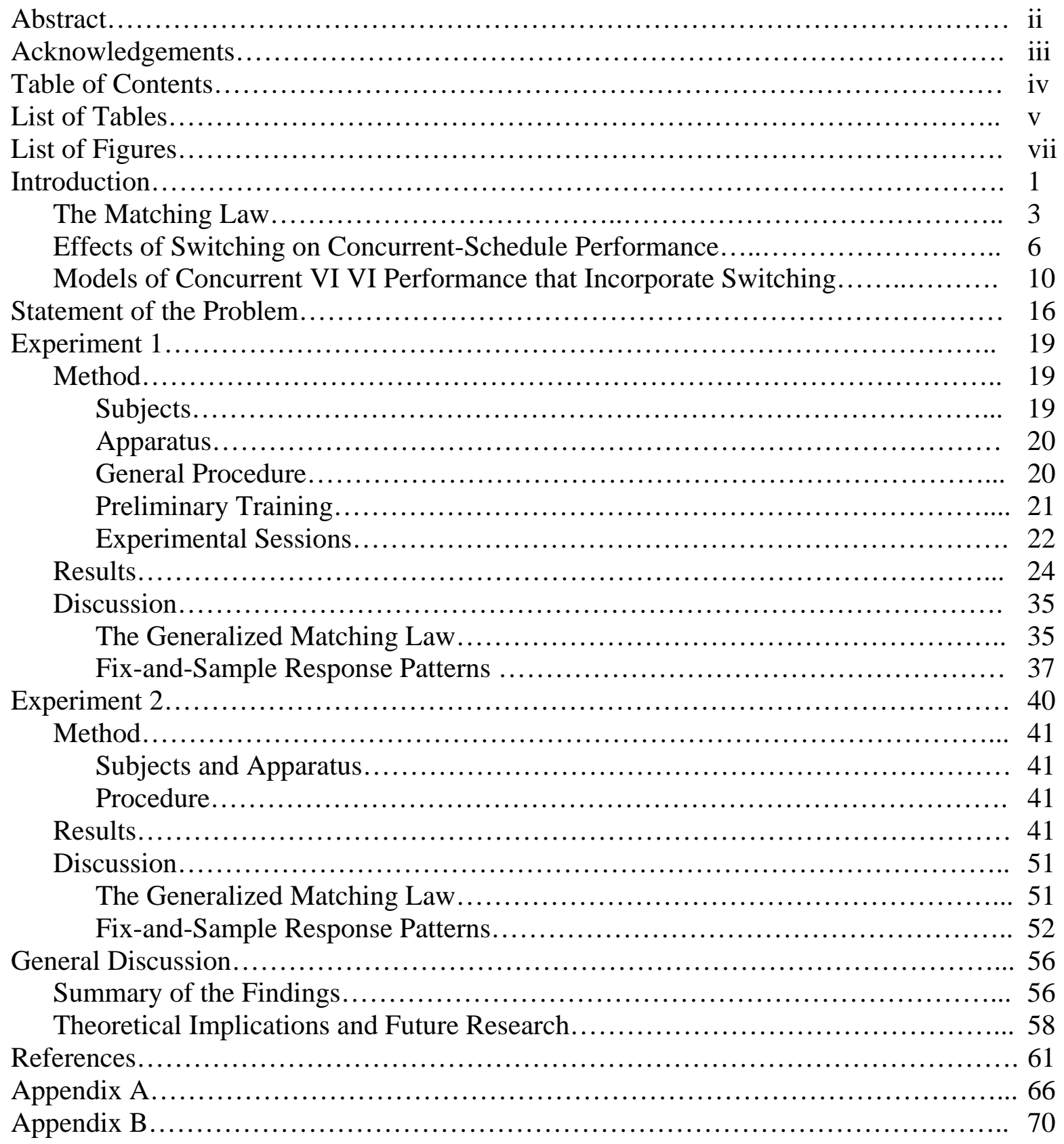




\section{List of Tables}

Table A1 (Experiment 1). Responses per minute for the left and right keys..............66

Table A2 (Experiment 1). Obtained reinforcers per minute for the left and right keys, and the overall obtained reinforcers per minute.

Table A3 (Experiment 1). Total time, total number of responses, and

total number of switches. Each measure is shown for the left and right keys............. 68

Table A4 (Experiment 1). Total number of reinforcers obtained by staying at

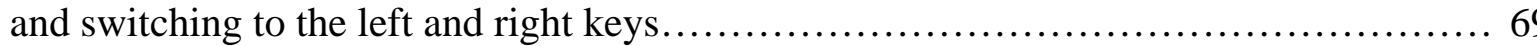

Table B1 (Experiment 2). Responses per minute for the left and right keys in the unsignaled and signaled conditions

Table B2 (Experiment 2). Obtained reinforcers per minute for the left and right keys, and the overall obtained reinforcers per minute.

Table B3 (Experiment 2). Total time, total number of responses, and total number of switches. Each measure is shown for the left and right keys

Table B4 (Experiment 2). Total number of reinforcers obtained by staying at and switching to the left and right keys...

Table 1 (Experiment 1). The ratio of reinforcers, number of reinforcers per session, the order of conditions, and the number of sessions in each condition...

Table 2 (Experiment 1). Slopes, intercepts, proportions of explained variance, and standard errors of the estimates for the data shown in Figure 1

Table 3 (Experiment 1). Slopes for obtaining and earning reinforcers, intercepts, proportions of explained variance, and standard errors of the estimates for data shown in Figure 9.

Table 4 (Experiment 1). Values of the Akaike Information Criterion for Equations 3 and 6.

Table 5 (Experiment 2). The ratio of reinforcers, number of reinforcers per session, the order of conditions, and the number of sessions in each condition.... 78

Table 6 (Experiment 2). Slopes, intercepts, proportions of explained variance, and standard errors of the estimates for the data shown in Figure 10 


\section{List of Tables (continued)}

Table 7 (Experiment 2). Slopes for obtaining and earning reinforcers, intercepts, proportions of explained variance, and standard errors of the estimates for data

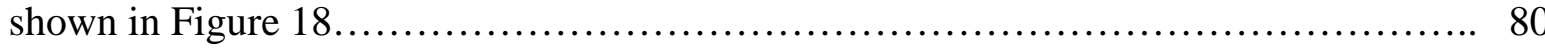

Table 8 (Experiment 2). Values of the Akaike Information Criterion for

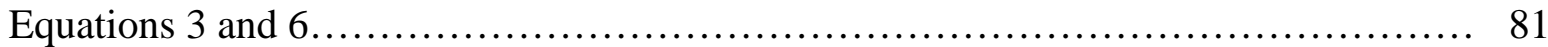




\section{List of Figures}

Figure 1 (Experiment 1). Log response ratios and log time ratios as a function of the $\log$ reinforcer ratios.

Figure 2 (Experiment 1). Switches per minute as a function of the log

reinforcer ratios.

Figure 3 (Experiment 1). Run lengths on the left and right keys as a

function of the log reinforcer ratios.

Figure 4 (Experiment 1). Visit durations on the left and right keys as a function of the log reinforcer ratios.

Figure 5 (Experiment 1). Responses per reinforcer at the lean alternative as a function of the log reinforcer ratios.

Figure 6 (Experiment 1). Obtained visit durations as a function of predicted visit durations.

Figure 7 (Experiment 1). Proportion of reinforcers obtained by staying at the left key and switching to the left key..... 88

Figure 8 (Experiment 1). Proportion of reinforcers obtained by staying at the right key and switching to the right key....

Figure 9 (Experiment 1). Log response ratios and log time ratios as a function of the sum of the log ratios for obtaining and earning reinforcers.

Figure 10 (Experiment 2). Log response ratios and log time ratios as a function of log obtained reinforcer ratios.

Figure 11 (Experiment 2). Switches per minute as a function of the log reinforcer ratios.

Figure 12 (Experiment 2). Run lengths on the left and right keys as a function of the log reinforcer ratios.

Figure 13 (Experiment 2). Visit durations on the left and right keys as a function of the log reinforcer ratios.

Figure 14 (Experiment 2). Responses per reinforcer at the rich alternative as a function of the log reinforcer ratios....

Figure 15 (Experiment 2). Obtained visit durations as a function of predicted visit durations. 


\section{List of Figures (continued)}

Figure 16 (Experiment 2). Proportion of reinforcers obtained by staying at the left key and switching to the left key.................................... 97

Figure 17 (Experiment 2). Proportion of reinforcers obtained by staying at the right key and switching to the right key....................................... 98

Figure 18 (Experiment 2). Log response ratios and log time ratios as a function of the sum of the $\log$ ratios for obtaining and earning reinforcers..................... 99 


\section{Introduction}

The chief concern of behavior analysis is how the environment influences the likelihood that a particular behavior will occur. One source of environmental influence is the consequence that follows a behavior. The consequence has the potential to increase (reinforce) or decrease (punish) the probability of future occurrences of that behavior. In the laboratory, the reinforcing effects of consequences are typically studied with small animals. For example, a pigeon that has been deprived of food for several hours is placed in a chamber containing response keys that the bird can peck at any time. This arrangement allows for a well-controlled examination of how behavior, usually measured as responses on the keys, is influenced by the consequence of receiving food (a reinforcer). Changes in the rate of responding are typically used as a measure of changes in the probability that responses will occur (Ferster \& Skinner, 1957).

Another way in which the environment influences behavior is through various stimuli that occur before and during the emission of responses. For example, if reinforcement is available when the response key is lit green, but unavailable when the key is lit red, the pigeon will eventually come to respond only when the key is green. The color of the key is said to function as a discriminative stimulus.

An abundance of research in behavior analysis has focused on schedules of reinforcement, which are rules that specify which instances of behavior are reinforced. Schedules allow for an analysis of how behavior is affected by the intermittent delivery of reinforcers. A commonly studied schedule is the variable-interval (VI) schedule, which arranges reinforcers after different intervals of time have elapsed. The duration of the intervals vary around some mean value. Once a reinforcer is arranged, it is held until a response is emitted, after which the reinforcer is delivered and the next interval begins. Although responses during 
the interval have no programmed effect, VI schedules typically maintain steady rates of responding. Manipulations of various aspects of VI schedules have been shown to produce systematic changes in response rates. For example, increases in the mean interval duration results in decreases in response rates (e.g., Catania \& Reynolds, 1968).

Several schedules can be arranged concurrently. Consider a pigeon that is presented with two response keys. Pecking either key is occasionally reinforced by food delivery. On one key, a reinforcer is made available every 30 s on average (i.e., a VI 30-s schedule is in effect). On the other key, reinforcers are made available every 60 s on average (i.e., a VI 60-s schedule is in effect). Because both VI schedules are continuously operating and simultaneously available, the pigeon is said to be working on a concurrent VI 30-s VI 60-s schedule.

Because concurrent schedules allow for the allocation of behavior to two or more alternatives (i.e., response keys), they are conceptualized as a means for studying choice. Of interest is whether ongoing patterns of "choices" can be determined by the way in which the reinforcers are arranged at the two alternatives. For example, if the pigeon responds exclusively at the VI 30-s alternative, the number of reinforcers it earns will be twice the number earned if it responded exclusively at the VI 60-s alternative (2 reinforcers per minute vs. 1 reinforcer per minute). Because reinforcers on both schedules become available with the passage of time, it is possible for the pigeon to obtain up to 3 reinforcers per minute by allocating behavior to both alternatives. Research has shown that animals almost always allocate behavior to both alternatives when exposed to concurrent VI VI schedules. In addition, the allocation of behavior has shown a striking regularity that has lead to several theoretical and quantitative accounts (e.g., see Davison \& McCarthy, 1988, and Herrnstein, 1997 for reviews).

The present discussion will focus on various quantitative and theoretical accounts of 
concurrent-schedule performances, particularly the more traditional view embodied in the matching law. The matching law describes choice in terms of the proportion of behavior allocated to each alternative in relation to the proportion of reinforcers obtained at each alternative. One aspect of concurrent-schedule performance that is not addressed by the matching law is switching between the alternatives. Research will be discussed that suggests that understanding switching may be crucial to understanding concurrent-schedule performance. Finally, alternate theoretical and quantitative models that emphasize the role of switching will be discussed. Based on theoretical and empirical work, it will be argued that the matching law may ignore crucial variables that control concurrent-schedule performance, thereby mischaracterizing the way in which behavior is allocated among the schedules.

\section{The Matching Law}

Herrnstein (1961) exposed pigeons to a series of concurrent VI VI schedules. The programmed reinforcement rate at each of the two alternatives was varied across the conditions of the experiment, but the overall reinforcement rate (the combined reinforcement rate of the two alternatives) was always held constant at 1.5 reinforcers per minute. The fact that reinforcers on VI schedules become available with the passage of time makes it possible that a reinforcer can be obtained at an alternative as soon as the pigeon switches to that alternative, thus increasing the likelihood of the reinforcement of switching. Because Herrnstein was interested in how reinforcement affected responding at the two alternatives rather than switching between them, he programmed a changeover delay (COD) that prevented reinforcers from being obtained for $1.5 \mathrm{~s}$ following a switch from one alternative to the other.

Herrnstein (1961) found that changes in relative response rates (the proportion of the total responses allocated to each alternative) directly corresponded to changes in relative 
reinforcement rates (the proportion of the total reinforcers obtained at each alternative). For all of the concurrent schedules studied, the relative response rates were equal to, or matched, the relative reinforcement rates. Herrnstein expressed his finding in the following equation that has become known as the matching law:

$$
\frac{B_{1}}{B_{1}+B_{2}}=\frac{R_{1}}{R_{1}+R_{2}}
$$

where $B_{1}$ and $B_{2}$ are responses emitted at alternatives 1 and 2 , and $R_{1}$ and $R_{2}$ are reinforcers obtained at the two alternatives.

Although Equation 1 provided a good fit to data from concurrent VI VI schedules with a COD in effect (e.g., Davison \& McCarthy, 1988; Herrnstein, 1961), subsequent research began to reveal deviations from this strict matching relation. Baum (1974) proposed that most concurrent-schedule data were more generally described by the following power function:

$$
\frac{B_{1}}{B_{2}}=k\left(\frac{R_{1}}{R_{2}}\right)^{a}
$$

where $B_{x}$ is behavior (either responses or time) allocated to alternative $x$, and $R_{x}$ is the number of reinforcers obtained at alternative $x$. The multiplier $k$ and the exponent $a$ are fitted parameters that are derived from data. Transformed logarithmically, Equation 2 yields the linear function:

$$
\log \left(\frac{B_{1}}{B_{2}}\right)=a \log \left(\frac{R_{1}}{R_{2}}\right)+\log k
$$

where $a$ is the slope, and $\log k$ is the intercept (e.g., Baum, 1974; Davison \& McCarthy, 1998).

Matching (Equation 1) is a special case of Equation 3 where $a=1$ and $\log k=0$. Hence, in Equation 3, the generalized matching law, deviations from matching can be identified by values of $a$ that differ from 1 and values of $\log k$ that differ from 0 . Two types of deviation are captured by the fitted parameters. The parameter log $k$ represents a bias towards one of the 
alternatives, or a constant preference for that alternative that is not predicted by the matching law. Baum (1974) suggested that bias can be the result of uncontrolled preferences for a particular side of the chamber or a particular key color. Bias can also be produced by either programmed or uncontrolled asymmetries on the two alternatives. For example, different reinforcer magnitudes and different types of reinforcers (e.g., food reinforcer on one alternative and water on the other) can produce bias. Different types of schedules can also produce a bias. For example, Trevett, Davison, and Williams (1972) found that pigeons showed a clear bias towards a VI schedule when the other schedule was a fixed-interval (FI; a schedule that arranges reinforcers after fixed periods) schedule.

In Equation 3, the parameter $a$ is an index of sensitivity to changes in the reinforcement rates delivered by the two schedules. Values of $a$ that are less than 1 indicate undermatching, whereas values of $a$ that are greater than 1 indicate overmatching. In the case of undermatching, changes in the behavior ratio $\left(\mathrm{B}_{1} / \mathrm{B}_{2}\right)$ occur at lower rate than changes in the reinforcer ratio $\left(r_{1} / r_{2}\right)$. In overmatching, changes in the behavior ratio occur at higher rate than changes in the reinforcer ratio (Baum, 1974; Davison \& McCarthy, 1988). Baum suggested three factors as potentially affecting sensitivity. One is the level of food deprivation. In behavior-analytic research, animals are deprived of food to ensure that it will function as a reinforcer. Sensitivity increases the less the animal is food deprived. A second factor is the extent to which the two schedules are discriminated. Sensitivity increases as differences between the two alternatives become more discriminable (e.g., Davison \& Jenkins, 1985; Madden \& Perone, 2003). A third factor is the duration of the COD. Increases in the COD reduce the severity of undermatching, thereby yielding a value of $a$ that is closer to 1 (e.g., Baum, 1974, 1979).

Equation 3 provides an excellent fit to data from a variety of concurrent-schedule 
arrangements across a variety of species (Davison \& McCarthy, 1988; Herrnstein, 1997;

McDowell, 2005). Animals’ performances on concurrent VI VI schedules are typically characterized by slight undermatching for both response and time allocation (Baum, 1979;

Mullins, Agunwamba, \& Donohoe, 1982; Myers \&Myers, 1977; Wearden \& Burgess, 1982).

Baum evaluated data from 23 different studies, and found that the median value of $a$ was 0.83 for response allocation and 0.92 for time allocation. An examination of Baum's report suggests that bias is negligible, with many of the values of $\log k$ falling between -0.1 and 0.1 . The generalized matching law provides a reliable quantitative description of the overall allocation of responses and time at each alternative, but it ignores the relation between reinforcement and switching between the alternatives.

\section{Effects of Switching on Concurrent-Schedule Performance}

For behavior to be allocated to both concurrently available alternatives, the subject must periodically switch from one alternative to the other. To understand the impact of switching, MacDonall (e.g., 1998, 1999, 2000) distinguishes between earning and obtaining reinforcers on concurrent schedules. As MacDonall sees it, on interval schedules responses are required to obtain reinforcers, but reinforcers are earned with the passage of time independently of the subject's behavior. For example, an interval of $50 \mathrm{~s}$ would require the passage of $50 \mathrm{~s}$ to earn the reinforcer and, at that point in time, 1 response to obtain it. It is important to recognize that, on concurrent interval schedules, reinforcers are simultaneously earned at both alternatives regardless of which alternative is capturing the subject's behavior, making it possible that a reinforcer is obtained as soon as the subject switches from one alternative to the other. The result is an increased likelihood of reinforcement for a sequence of behavior that begins when the subject leaves one alternative and ends with the first response at the other alternative. Thus, it 
can be argued that concurrent interval schedules contain a contingency of reinforcement for switching.

The contingency for earning and obtaining reinforcers on ratio schedules is somewhat different. A ratio schedule arranges reinforcers after a specified number of responses have been emitted. The number can either be fixed [i.e. a fixed-ratio (FR) schedule] or vary around some mean value [i.e., a variable-ratio (VR) schedule]. On ratio schedules the subject must emit the specified number of responses to both earn and obtain reinforcers. For example, on an FR 50

schedule, a reinforcer would be earned by the emission of 50 responses, and obtained by the $50^{\text {th }}$ response. On concurrent ratio schedules, the subject can only earn and obtain reinforcers from a given alternative while responding at that alternative. Reinforcers at the other alternative also must be earned by responding, so the contingency of reinforcement for switching is much weaker than on concurrent interval schedules. It is optimal for the subject to allocate all of its behavior to the richer of the two ratio alternatives because responding at the leaner alternative wastes effort and switching will be reinforced rarely. Consistent with this assumption is the common finding that on concurrent FR FR and concurrent VR VR schedules, animals typically respond almost exclusively at the richer alternative with little switching between the alternatives (Herrnstein \& Loveland, 1974; MacDonall, 1988).

Results from several experiments suggest that the contingencies of reinforcement for switching play an important role in concurrent-schedule performance. For example, MacDonall (1988) exposed rats to two concurrent VR VR arrangements that differed in terms of the contingencies for earning reinforcers. In some cases, the two VR schedules were arranged independently (the standard concurrent ratio arrangement where responses at an alternative only advanced the ratio at that alternative). This resulted in nearly exclusive responding at the rich 
alternative. In other cases, the schedules were arranged such that responses at either alternative advanced the ratios at both alternatives (dependent concurrent VR VR schedules). This arrangement resulted in frequent switching between the two alternatives with response allocations approximating matching.

MacDonall’s (1988) results are noteworthy because the contingencies for earning reinforcers on dependent concurrent VR VR schedules are comparable to those on concurrent VI VI schedules. In both procedures, reinforcers are simultaneously earned at the two alternatives, thus increasing the likelihood that reinforcers are obtained immediately following switches between the alternatives. When reinforcers at an alternative can only be earned by responding at that alternative, as is the case with independent concurrent-ratio schedules, the likelihood of obtaining reinforcement following a switch is reduced, and switching is virtually eliminated.

Crowley and Donahoe (2004) explored contingencies for switching by using a multipleschedule procedure. In a multiple schedule, two or more schedules are periodically alternated, and only one schedule is in effect at a time. The effective schedule is signaled by a discriminative stimulus, in this case, the color of the response key. An important difference between multiple and concurrent schedules is that switches between schedules are programmed by the experimenter on multiple schedules, whereas switches are under the control of the subject on concurrent schedules. After extensive training on each of several multiple VI VI schedules, probe trials were inserted in which the stimuli (key colors) that accompanied the various VI schedules were presented concurrently. During the probe trials, two keys were lit, but responding was not reinforced. Pigeons allocated their behavior almost exclusively to the stimulus that was correlated with the richer schedule. In subsequent conditions, the same VI schedules that comprised the multiple schedules were presented concurrently, and switching 
between the schedules gradually emerged. Eventually, the allocation of behavior approximated matching, leading Crowley and Donahoe to conclude that switching is an acquired behavior that must be taken into account if concurrent-schedule performance is to be fully understood.

Shahan and Lattal (2000) found that a crucial determinant of the frequency of switching is the interval of time between the last response on the switched-from alternative and the first reinforcer on the switched-to alternative. The frequency of switching decreased as this interval increased. Shull, Spear, and Bryson (1981) arranged a procedure in which pigeons could either respond on a VI 2-min schedule or switch to an alternate schedule. Once the alternate schedule was accessed, it remained in effect for a fixed period of time, after which the VI 2-min schedule was reinstated. Only one reinforcer was delivered per visit to the alternate schedule, and various delays between the onset of the alternate schedule and the delivery of the reinforcer were studied. The frequency of switching to the alternate schedule was directly related to the delay to the reinforcer following the switch.

The studies by MacDonnal (1988) and Crowley and Donahoe (2004) suggest that switching between concurrently available alternatives is more likely when a contingency of reinforcement for switching exists. Results from Shahan and Lattal (2000) and Shull et al. (1981) suggest that the frequency of switching between two concurrently available VI schedules is sensitive to the time to reinforcement following the switch - a time period that can be affected by the duration of the COD. Taken together, these results suggest that switching, and the contingencies of reinforcement that govern it, should be part of a comprehensive account of concurrent-schedule performance. 


\section{Models of Concurrent VI VI Performance that Incorporate Switching}

Consider the earlier example of a pigeon responding on a concurrent VI 30-s VI 60-s

schedule. The traditional view embodied in the matching law holds that the pigeon is faced with a choice to respond at either the VI 30-s alternative or the VI 60-s alternative. An alternate view holds that the pigeon's choice is to either stay at the current alternative or switch to the other alternative (Houston \& McNamara, 1981; MacDonall, 1998, 1999, 2000, 2005). According to this view, the VI schedule at each alternative is not a single schedule of reinforcement, but rather a pair of schedules: a stay schedule and a switch schedule. Suppose that the pigeon is currently working at the VI 30-s alternative. Staying is reinforced every $30 \mathrm{~s}$ on average. Meanwhile, the VI 60-s schedule continues to operate and, if it arranges a reinforcer, the reinforcer will be held until the pigeon switches and obtains it. Thus, while earning and obtaining reinforcers at the VI 30-s alternative, reinforcers are also earned according to the VI 60-s schedule and obtained immediately following a switch. Responding at the VI 30-s alternative, then, can be viewed as a choice between a VI 30-s stay schedule and a VI 60-s switch schedule. Once the pigeon switches, the VI 60-s schedule becomes the stay schedule and the VI 30-s schedule becomes the switch schedule. By this analysis, concurrent VI VI schedules are composed of two pairs of stay and switch schedules with only one pair in effect at a time.

In a series of experiments, MacDonall $(1998,1999,2000,2003)$ exposed rats to pairs of explicitly programmed stay and switch schedules. In a typical procedure, the stay and switch schedules operated simultaneously. When stay-schedule reinforcers became available, they could be obtained by responses on a stay lever. Responses on a second lever, the switch lever, stopped both schedules and produced a switch-schedule reinforcer if one was available. Both schedules resumed following a switch back to the stay lever. 
Across experiments, MacDonall used a variety of stay and switch schedules including dependent VR schedules (1998, 1999), random-interval schedules (2000), and VI schedules (1998, 2003). MacDonall analyzed run lengths (the number of stay-lever responses between switch-lever responses) and visit durations (the time allocated to the stay lever between switchlever responses). Both measures were well described by the following power function of the ratio of stay- and switch-schedule reinforcers (MacDonall et al., 2006, p. 284, Equation 2):

$$
\frac{B}{C}=k^{\prime}\left(\frac{R t / C}{R w / C}\right)^{l^{\prime}}
$$

where $B$ is behavior (i.e., responses or time) on the stay lever, $C$ is the number of switches, $R t$ is the number of stay-schedule reinforcers, $R w$ is the number of switch-schedule reinforcers, $k^{\prime}$ is a parameter indicating a bias towards staying, and l' is a parameter indicating the sensitivity to changes in the ratio of reinforcement for staying and switching. Equation 4 states that the run length or visit duration $(B / C)$ is a function of the ratio of reinforcement for staying and switching $[(R t / C) /(R w / C)]$. Equation 4 provided good fits for the data in all of MacDonall's aforementioned procedures.

Equation 4 is a description of performance on a single stay and switch schedule. Equation 4 can be extended to accommodate concurrent schedules, which are composed of a pair of stay and switch schedules (e.g., MacDonall 1998, 1999; MacDonall et al., 2006). This extension, which MacDonall calls the local model of choice, can be expressed logarithmically as follows:

$$
\log \frac{B_{1}}{B_{2}}=l \log \left(\frac{R t_{1} / R w_{1}}{R t_{2} / R w_{2}}\right)+\log k
$$

The left side of Equation 5 is the ratio of run lengths (or visit durations) at Alternatives 1 and 2. The right side of Equation 5 is the ratio of reinforcers obtained per visit to each 
alternative. The numerator is the ratio of reinforcers obtained for staying at Alternative $1\left(R t_{1}\right)$ and switching from Alternative $1\left(R w_{1}\right)$. The denominator is the ratio of reinforcers obtained by staying at Alternative $2\left(R t_{2}\right)$ and switching from Alternative $2\left(R w_{2}\right)$. The parameter $l$ is an estimate of the sensitivity to reinforcers obtained at each alternative, and the parameter $\log k$ is an estimate of bias towards staying at one alternative or the other. Equation 5 states that the ratio of run lengths or visit durations is a function of the ratio of reinforcers obtained for staying at and switching to each alternative.

Note that the term $C$, the number of switches, appears in Equation 4, but not in Equation 5. Including the number of switches is problematic because it would appear on both sides of the equation. This is less than optimal because part of the behavior to be predicted (the left side of Equations 4 and 5) would included in the predictor (the right side of Equations 4 and 5). If the switches from an each alternative were included in Equation 5, they would be divided out of each term on both sides of the equation. However, MacDonall has noted (MacDonall, 1998, 1999, 2005) that in a given experimental session, the numbers of switches from the two alternatives are approximately equal and large (e.g., greater than 100); hence they cancel out of Equation 5.

The right side of Equation 5 is the ratio of the rates at which reinforcers are obtained by staying at an alternative and switching from the alternative. MacDonall (2005) argues that behavior might also be sensitive to the rates at which reinforcers are earned at the two alternatives. Recall that concurrent schedules can be conceptualized as a symmetrical pair of stay and switch schedules (MacDonall, 1998, 1999, 2000). On symmetrical pairs of stay and switch schedules, reinforcers are earned at the same rate at both alternatives. Consider a concurrent schedule where a VI 30-s schedule is programmed at Alternative 1 and a VI 60-s 
schedule is programmed at Alternative 2. At Alternative 1, the VI 30-s schedule arranges 2 reinforcers per minute for staying, and the VI 60-s schedule arranges 1 reinforcer per minute for switching. Hence, the subject can earn 3 reinforcers per minute while responding at Alternative 1. Once the subject switches to Alternative 2, the contingencies are reversed; the VI 60-s schedule arranges 1 reinforcer per minute for staying, and the VI 30-s schedule arranges 2 reinforcers per minute for switching. Therefore, 3 reinforcers per minute are also earned while responding at Alternative 2 .

Although standard concurrent schedules arrange the same rate of reinforcement for staying and switching at the two alternatives, asymmetries in concurrent schedules can alter the rate at which reinforcers are earned (MacDonall, 2005; MacDonall et al., 2006). Consider the following example of an asymmetrical pair of stay and switch schedules. Alternative 1 arranges reinforcers for staying and switching according to a VI 30-s schedule, and Alternative 2 arranges reinforcers for staying and switching according to a VI 60-s schedule. Under this arrangement, the rate of earning reinforcers at Alternative 1 is twice as high as the rate of earning reinforcers at Alternative 2, and a bias towards Alternative 1 might be expected. To capture sensitivity to asymmetries in the rates of earning reinforcers, MacDonall et al. added a second term to the right side of Equation 5 (MacDonall et al., 2006, Equation 5, p. 284):

$$
\log \frac{B_{1}}{B_{2}}=l \log \left(\frac{R t_{1} / R w_{1}}{R t_{2} / R w_{2}}\right)+m \log \left(\frac{R t_{1}+R w_{1}}{R t_{2}+R w_{2}}\right)+\log k
$$

The term on the left side of Equation 6 is the same as in Equation 5. The first term on the right side of Equation 6 is also the same as in Equation 5, and will be hereafter referred to as the term for obtaining reinforcers. The second term on the right side of Equation 6 is the sum of reinforcers earned at Alternative $1\left(R t_{1}+R w_{1}\right)$ divided by the sum of reinforcers earned at Alternative $2\left(R t_{2}+R w_{2}\right)$. The parameter $m$ captures sensitivity to changes in the rate of earning 
reinforcers. The second term will hereafter be referred to as the term for earning reinforcers.

Several experiments have shown the validity of Equation 6 (MacDonall, 2005;

MacDonall et al., 2006). Rats were exposed to a series of concurrent schedules that arranged symmetrical and asymmetrical pairs of stay and switch schedules. The generalized matching law (Equation 3, p. 4) described data from the symmetrical schedules, but could not describe the combination of symmetrical and asymmetrical schedules. By contrast, Equation 6 provided an excellent fit to the combination of schedules, indicating that concurrent schedules are better described by an equation that accounts for reinforcement of both staying and switching.

Previous analyses are consistent with MacDonall’s (e.g.,1998, 1999, 2000) conceptualization of reinforcement of staying and switching. Houston and McNamra (1981) conducted a mathematical analysis of various response patterns an organism could emit on concurrent VI VI schedules. The goal of the analysis was to identify an optimal pattern of responding for maximizing the overall obtained reinforcement rate. They determined that when the programmed reinforcement rates at the two alternatives are unequal, the optimal strategy is to respond almost exclusively at the rich alternative. Responses should only be allocated to the lean alternative to obtain reinforcers as soon as they become available. Houston and McNamara called this pattern of responding stay/switch, and concluded that it is the optimal response pattern for a large range of possible concurrent VI VI values, including those commonly studied in experiments. Note that in a stay/switch response pattern, reinforcers at the rich alternative would be obtained by staying, whereas reinforcers at the lean alternative would be obtained by a switch. When the generalized matching equation (Equation 3) is fitted to a stay/switch response pattern, the resulting allocation of behavior would show extreme overmatching because behavior at the lean alternative is reduced to the minimum amount necessary to obtain the reinforcers at 
that alternative (i.e., single responses in the form a switch to that alternative). Deviations from the stay/switch response pattern, in the form of more frequent switches, will eventually lead to matching, with further increases in switching leading to undermatching (Baum, Schwendiman, \& Bell, 1999; Houston \& McNamara, 1981).

Several empirical studies have shown tendencies towards a stay/switch response pattern (e.g., Aparicio \& Baum, 2006; Baum \& Aparicio, 1999; Baum \& Davison, 2004; Baum, Schwendiman, \& Bell, 1999). For example, Baum et al. (1999) exposed pigeons to a series of concurrent VI VI schedules where the ratio of reinforcers programmed for the left key and the right key ranged from 256:1 and 1:256. The allocation of behavior approximately matched the ratio of obtained reinforcers. An interesting finding came from analyses of local (i.e., shortterm) response patterns. For all concurrent schedules studied, run lengths at each alternative were estimated. Across conditions, run lengths at the lean alternatives were brief, often averaging less than 2 responses per visit. By contrast, run lengths at the rich alternative increased as that alternative became richer. Baum et al. referred to this pattern of responding as fix and sample because pigeons tended to fix (stay) at the rich alternative and frequently sample (i.e, switch to) the lean alternative.

The fix-and-sample response pattern is noteworthy for two reasons. First, staying (fixing) only occurs at the rich alternative. Because run lengths at the lean alternative averaged little more than 1 response per visit (sampling), and because the first response at an alternative is essentially the response that completes the switch to that alternative, then it must be the case that almost all the behavior allocated to the lean alternative is in the form of switches. Furthermore, if only switches are allocated to the lean alternative, then reinforcers at that alternative are obtained by switching. 
A second noteworthy feature of the fix-and-sample response pattern is that it is essentially a less extreme version of Houston and McNamara’s (1981) stay/switch response pattern. Sampling of the lean alternative is frequent because the availability of reinforcers for sampling is unpredictable. If the availability of reinforcement at the lean alternative could be discriminated, then sampling would only occur to obtain the lean-alternative reinforcer, the result of which would be near-exclusive fixing at the rich alternative. Essentially, the stay/switch response pattern is an ideal fix-and-sample response pattern.

\section{Statement of the Problem}

The theoretical assumption behind the generalized matching law is that strict matching is an outcome of control by concurrent VI VI schedules. Deviations from strict matching, such as bias and undermatching, are the result of uncontrolled sources of variation or programmed asymmetries in the schedules (e.g., Baum, 1974; Davison \& McCarthy, 1988). Although allocation of behavior to both alternatives necessarily requires switching, excessive switching is considered a nuisance that interferes with an assessment of the relation between behavior at the two alternatives and obtained reinforcement rates (e.g., Herrnstein, 1961). This is often addressed procedurally by the inclusion of a COD, which is used to prevent rapid switching between the alternatives.

It is also possible that an ideal fix-and-sample pattern of behavior is a natural outcome of control by concurrent VI VI schedules. If so, then concurrent-schedule performance is characterized by a tendency towards almost exclusive allocation of behavior to the rich alternative. How frequently a subject samples the lean alternative may depend upon the discriminability of reinforcement at that alternative. When the availability of reinforcement at the lean alternative can be discriminated, sampling of the lean alternative only occurs to obtain 
the reinforcer, and the remainder of the behavior is fixed at the rich alternative. Such an allocation of behavior would result in overmatching rather than matching. When switching is sufficiently frequent, the allocation of behavior shifts from near-exclusive responding at the rich alternative to a distribution that often favors the lean alternative (which would result in undermatching). According to this view, matching is not a natural outcome of control by concurrent schedules, but is instead a deviation from an ideal fix-and-sample pattern.

The possibility that an ideal fix-and-sample response pattern is an outcome of control by concurrent-interval schedules has not been investigated. An ideal fix-and-sample response pattern as one in which responding occurs almost exclusively at the rich alternative. Responding at the lean alternative only occurs at the moment a reinforcer becomes available at that alternative. For such a pattern of behavior to occur, the subject must discriminate two features of concurrent schedules - the richer of the two alternatives, and the availability of reinforcement on the lean alternative. The fact that a greater proportion of behavior is typically allocated to the alternative with the higher obtained reinforcement rate implies that the richer of the two alternatives is discriminated. Discriminating the availability of reinforcement at the lean alternative is difficult because reinforcement delivery is unsignaled and occurs at varying points in time. The availability of reinforcement on the lean alternative could be discriminated, however, if it were accompanied by a discriminative stimulus.

The goal of the present research was to create the optimal conditions for an ideal fix-andsample response pattern to emerge. This was accomplished by exposing pigeons to various concurrent VI VI schedules with signals accompanying the availability of reinforcement. A COD was not used. In Experiment 1, the availability of reinforcement on the lean alternative was signaled, which was expected to produce an ideal fix-and-sample response pattern: the pigeon 
should respond at the rich alternative except when the availability of a reinforcer is signaled at the lean alternative. Although such results would support the notion that an ideal fix-and-sample response pattern is an outcome of control by concurrent VI VI schedules that are unconstrained by a COD, it is also possible that the results would be an artifact of the procedure. By functioning as a cue for the optimal time to respond, it is possible that the reinforcement signal will reduce responding regardless of which alternative is signaled.

The possibility that expected results in Experiment 1 could be an artifact of the procedure was addressed in Experiment 2 by signaling the availability of reinforcement at the rich alternative. If an ideal fix-and-sample pattern was an artifact of the procedure, the pigeon should respond at the lean alternative except when the availability of a reinforcer is signaled at the rich alternative. A different pattern of results should emerge if an ideal fix-and-sample response pattern is an outcome of control by concurrent VI VI schedules. Although it may be expected that responding will be reduced at the rich (signaled) alternative, the pigeon should still allocate most of its time at that alternative. Because the availability of reinforcement at the lean alternative cannot be discriminated, switching to the lean alternative should be frequent; resulting in an approximation of matching for time allocation.

A secondary goal of the present research was to compare two quantitative models; the generalized matching law (Equation 3, p. 4) and the local model (Equation 6, p. 13). Because fix and sample suggests a critical distinction between reinforcement for staying at the rich alternative and switching to the lean alternative, then Equation 6, which makes the distinction, should better describe the present data. 


\section{Experiment 1}

The likely conditions for an ideal fix-and-sample response pattern to emerge were arranged in Experiment 1. Pigeons were exposed to a variety of concurrent VI VI schedules twice, once with signals correlated with reinforcement on the lean schedule, and once without signals. Reinforcers were distributed among the left and right keys according to a predetermined ratio that varied across conditions. Lean-schedule reinforcers were signaled by turning on the house light $1 \mathrm{~s}$ prior to the availability of reinforcement. A COD was not used.

Several studies have shown that, using procedures similar to the one described above, signaling reinforcement reduces response rates to very low levels on the signaled alternative (e.g., Catania, 1963; Catania, Silverman, \& Stubbs, 1974; Marcucella \& Margolius, 1978; Pliskoff \& Green, 1972; Wilkie, 1973). The extent to which data from these studies indicate an ideal fix-and-sample response pattern is difficult to discern for two reasons. First, the alternative on which reinforcement was signaled contained the rich schedule in some conditions and the lean schedule in other conditions. Second, because the topics of interest in these studies differed substantially from the present research, the data necessary to identify an ideal fix-and-sample response pattern (e.g., run lengths and visit durations) were not reported.

Method

\section{Subjects}

Four male White Carneau pigeons with various experimental histories served as subjects. Each pigeon was maintained at $80 \%(+/-2 \%)$ of their free-feeding body weights by mixed grain that was delivered during the session and, as necessary, supplemental feedings delivered at least one halfhour after the session ended. The pigeons were housed individually in a temperature-controlled room with a 12:12 hour light/dark cycle. Water and grit were freely accessible in the pigeons' home cages. 


\section{Apparatus}

Experimental sessions were conducted in four operant chambers. The front panels of the chambers were constructed of stainless steel, and the walls were constructed of either wood or fiberglass and plexiglas (depending on the chamber). Each chamber contained three response keys, which were approximately $2 \mathrm{~cm}$ in diameter, and could be illuminated from behind with various colors. The response keys were situated in a row on the front panel, and were approximately $9 \mathrm{~cm}$ apart (from the centers of the keys) and $24 \mathrm{~cm}$ from the floor. General illumination could be provided by house lights that were situated on either the front panel or the ceiling of the chamber. Ventilation fans, which were located on the back wall of the chambers, were used to mask extraneous sounds. Reinforcers, which consisted of mixed grain, were delivered by a hopper that was accessible via a $5 \mathrm{~cm}$ x $6 \mathrm{~cm}$ square aperture (which could illuminated) located on the front panel approximately $11 \mathrm{~cm}$ below the center key. Control and recording of experimental events were arranged with microcomputers located in an adjacent room.

\section{General Procedure}

Sessions were conducted at approximately the same time each day, 5 to 6 days per week. To allow the pigeons time to recover from handling, each session was preceded by a 3-min delay during which the chamber was dark. Following the delay, the appropriate keys (described below) were illuminated with white light. Throughout preliminary training and experimental sessions, the pigeons were exposed to a variety of VI schedules (described below) that consisted of 10 intervals derived from Fleshler and Hoffman's (1962) distribution. Responses that met the schedule requirement initiated the reinforcement period, which consisted of darkening of the keys, illumination of the food aperture, and raising of the food hopper for $3 \mathrm{~s}$. Sessions lasted until a specified number of reinforcers were obtained (shown in Table 1) or until 2 hr elapsed. 


\section{Preliminary Training}

Pigeons were initially trained to peck the center key on which a VI schedule was effect. The mean interval of the VI schedule was increased across several sessions until a VI 60-s schedule was reached. Then, to facilitate responding on the side keys, the VI 60-s schedule was alternated between the left and right keys in 3-min blocks. At the start of each session, the key on which the VI 60-s schedule was initially arranged (active key) was randomly determined ( $p=.5$ ). The active key was illuminated and the other two keys were dark and inoperative. This phase of training continued until response rates on both left and right keys showed no upward or downward trend for three consecutive sessions as determined by visual inspection.

Next, the schedule arrangement was changed to a concurrent schedule. Reinforcers were arranged on either the left or right key. At any given time, only one key was active and illuminated. The other key was dark and inoperative. Responses on the center key, the switching key (Findley, 1958) changed the active key. The switching key was illuminated with green light until pecked, at which point it became dark and inoperative. The switching key remained dark and inoperative until a response was made on the newly activated key. Because no changeover delay was programmed, any peck on the active key was eligible for reinforcement, even if it occurred immediately after a peck on the switching key.

Following the lead of Stubbs \& Pliskoff (1969) the distribution of reinforcers on the left and right keys was arranged so that obtained reinforcement rates were likely to match programmed rates. A single VI 60-s schedule was in effect. Reinforcers arranged by the VI 60-s schedule were randomly assigned (on a reinforcer-by-reinforcer basis) to either the left or right key with equal probability (i.e., a reinforcement ratio of 1:1), which results in a fairly equal distribution of reinforcers between the two keys. Once a reinforcer was assigned to a key, the VI 60-schedule was suspended until the reinforcer was collected. Training on the concurrent schedules continued until response rates on the left and right keys were approximately equal and showed no upward or 
downward trend for 3 consecutive sessions as determined by visual inspection, at which point preliminary training was completed.

Experimental Sessions

Throughout the experiment proper, pigeons were exposed to concurrent VI VI schedules as described above. Across conditions, the programmed ratio of reinforcers assigned to each key was manipulated. After a few of the pigeons completed the first experimental condition, it was discovered that randomly assigning reinforcers had the potential to result in moderate discrepancies between programmed and obtained reinforcer ratios. To prevent large discrepancies, reinforcers were subsequently assigned to the keys according to a random, pre-determined sequence that ensured the programmed and obtained reinforcer ratios were identical.

Table 1 summarizes the conditions in Experiment 1. The two leftmost columns show the ratio of reinforcers assigned to the left and right keys, and the number of reinforcers per session. Each reinforcer ratio was in effect for an entire experimental condition. Across conditions, the ratio of reinforcers assigned to the two keys ranged from 2:1 to 1:10 (left key to right key). The rich schedule was arranged on the left key in half of the conditions and on the right key in the other half. Each session lasted until a specified number of reinforcers was delivered. The number of reinforcers per session was kept as close as possible to 50 reinforcers while maintaining the specified reinforcer ratio.

The remaining columns of Table 1 show, for each pigeon, the order of conditions and the number of sessions in each condition. Each reinforcer ratio was in effect for two consecutive conditions; an unsignaled (denoted by "U” in Table 1) and a signaled condition (denoted by "S" in Table 1). The reinforcer ratios were presented according to two different sequences. For Pigeons 1024 and 1163, the intermediate reinforcer ratios (1:5 and 4:1) were presented first, followed by the most extreme ratios (9:1 and 1:10) followed by the least extreme ratios (1:3 and 
2:1). For Pigeons 9980 and 6890, the most extreme reinforcer ratios were presented first, followed by the intermediate ratios, followed by the least extreme ratios. Only one manipulation (either a change of the signaling or a change of the reinforcer ratio) was made each time a condition was changed.

Unsignaled and signaled conditions were arranged as follows. In the unsignaled conditions, the delivery of reinforcers was not accompanied by a discriminative stimulus. In the signaled conditions, the availability of reinforcement at the lean alternative was signaled by turning on the house light $1 \mathrm{~s}$ before the end of the interval. The house light remained on until the reinforcer was obtained. The signal was started before the end of the interval to ensure that it was contacted if even if the pigeon was responding on the lean alternative at the moment a reinforcer became available.

In the current experiment, stability was assessed by using the following mathematical criterion. The proportion of time spent at the rich alternative (time at the rich alternative / time at both alternatives) was calculated for each session. The median of these proportions was calculated for successive 5-session blocks. Starting with the $15^{\text {th }}$ session, the medians of the five most recent 5-session blocks (e.g., the median for Sessions 7-11, Sessions 8-12, Sessions 9-13, etc.) were compared. Once the range of these five medians was no greater than 0.05 , the behavior was considered stable (cf., Davison \& McCarthy, 1988; Shahan \& Lattal, 2000).

After the first few conditions, it became apparent that although the data were stable according to the mathematical criterion, other measures varied. To compensate, a second stability criterion was added involving visual inspection of plots of time ratios (time allocated to the left key / time allocated to the right key). When time ratios showed no increasing or decreasing trend over the most recent 5 sessions, and the mathematical criterion was met, the behavior was considered stable, and the condition was ended. 


\section{Results}

All analyzed data are from the last five (stable) sessions of each condition. For figures showing fits of equations and proportions, data were summed across the stable sessions. For all other figures, data are means of the stable sessions. Data expressed as rates used total session time minus time in the reinforcement period.

Tables in Appendix A show summary measures and raw data from each condition for each pigeon. All data are taken from the stable sessions. Table A1 shows mean responses per minute (standard deviations in parentheses). Table A2 shows mean obtained reinforcers per minute (including overall reinforcers per minute). Table A3 shows total time in seconds (minus reinforcement time) spent at each alternative, the total number of responses, and the total number of switches. Table A4 shows the total number of reinforcers obtained by staying and switching. In each table, all measures are shown for the left and right keys in the unsignaled and signaled conditions. All subsequent results were derived from the raw data shown in Tables A3 and A4.

Figure 1 shows fits of the logarithmic generalized matching equation (Equation 3, p. 4). The logarithms (base 10) of the response ratios $\left(B_{L} / B_{R}\right)$ and time ratios $\left(T_{L} / T_{R}\right)$ are plotted as a function of the logarithms of the obtained reinforcer ratios $\left(R_{L} / R_{R}\right)$. Ratios were calculated by dividing the measures for the left key by measures for the right key (denoted by the subscripts L and $\mathrm{R}$, respectively). In each panel of Figure 1, the (light) dashed diagonal line depicts matching of behavior ratios to reinforcer ratios. Open circles depict results from the unsignaled conditions and filled circles depict results from the signaled conditions. Solid lines and heavy dashes are the least-squares regression lines for the unsignaled and signaled conditions, respectively. Note that the scales of the y-axes differ among the individual panels.

Panels in the left column of Figure 1 show fits for response ratios and panels in the right column show fits for time ratios. Fits of Equation 3 were similar for both measures. In the 
unsignaled conditions, three pigeons approximately matched behavior ratios to reinforcer ratios. The exception was Pigeon 1163, as evidenced by severe undermatching. In the signaled conditions, slopes of the regression lines increased for all four pigeons. All pigeons but Pigeon 1163 showed severe overmatching.

Table 2 shows the slopes, intercepts, the proportions of explained variance $\left(r^{2}\right)$, and standard errors of the estimate for the slopes and intercepts for the fits shown in Figure 1. Fits for the response ratios are shown in the top half of Table 2. In the unsignaled conditions, slopes of the regression lines approximated 1.00 for Pigeons 9980 and 6890 which, given the absence of bias, indicates matching. Slight undermatching was evident for Pigeon 1024 (slope $=0.82$ ) and severe undermatching was evident for Pigeon 1163 (slope = 0.54). For Pigeons 1024, 9980, and 6890, intercepts ranged from -0.06 to 0.02, suggesting negligible bias. Pigeon 1163 showed a bias towards the right key as indicated by an intercept of -0.35. Equation 3 explained nearly all of the variance in the data. Values of $\mathrm{r}^{2}$ ranged from .89 to .99 , and standard errors of the slopes and intercepts were small.

In the signaled conditions, the slopes of the regression lines are higher for all four pigeons. Slopes for Pigeons 1024, 9980, and 6890 ranged from 1.60 to 2.42, indicating severe overmatching. The slope for Pigeon 1163 was 1.00. Pigeon 1024 showed a bias towards the left key (intercept $=0.26$ ), and Pigeon 1163 showed a bias towards the right key (intercept $=-0.36$ ) The fits of Equation 3 were not as good relative to the unsignaled conditions. For Pigeons 1024, 9980, and 6890, values of $\mathrm{r}^{2}$ were high, but slightly less than in the unsignaled conditions. The fit for Pigeon 1163 was poor $\left(r^{2}=.67\right)$. For all four pigeons, standard errors for the slopes were small, but the standard errors for the intercepts were high relative to the actual values of the intercepts. 
The bottom half of Table 2 shows fits for time ratios. In the unsignaled conditions, time ratios tended towards undermatching as indicated by slopes ranging from 0.67 to 0.90 . Only Pigeon 1024 showed a key bias (intercept of -0.24). Fits of Equation 3 were good. Values of $\mathrm{r}^{2}$ ranged from .95 to .99 , and standard errors for the slopes and intercepts were small. In the signaled conditions, overmatching was evident for Pigeons 1024, 9980, and 6890, but the steepness of the slopes were less extreme than the slopes of response ratios. Intercepts ranged from -0.05 to 0.14 , suggesting negligible bias for all four pigeons. Fits of Equation 3 were good, but less so than in the unsignaled conditions. For Pigeons 1024, 9980, and 6890, values of $\mathrm{r}^{2}$ ranged from .90 to .93. The fit for Pigeon 1163 was poor $\left(r^{2}=.65\right)$. For all four pigeons, standard errors for the slopes were relatively small, but standard errors for the intercepts were large compared to the value of the intercepts.

Generally speaking, both response and time allocation were well described by Equation 3, particularly in the unsignaled conditions. For three of four pigeons, response ratios approximated matching in the unsignaled conditions, whereas overmatching was evident in the signaled conditions. The exception was Pigeon 1163, for which severe undermatching was evident in the unsignaled condition, and the slope approximated 1.00 in the signaled conditions. Time allocation was similar in most respects except that the slopes were lower in both the unsignaled and signaled conditions (with the exception of Pigeon 1163).

It was expected that by signaling the availability of reinforcement at the lean alternative, switching to that alternative should only occur in the presence of the signal. The extent to which switching was reduced is examined in Figure 2, which shows mean switches per minute as a function of log programmed reinforcer ratios. Error bars extend one standard deviation above and below the mean. In the unsignaled conditions, switching rates are low at the most extreme 
reinforcer ratios, and increase as the reinforcer ratios become less extreme. In the signaled conditions, switching rates are at near-zero levels and show very little change across reinforcer ratios. The exception is Pigeon 1163 for which switching rates in the unsignaled and signaled conditions tended to increase as the reinforcer ratios increased.

Recall that a fix-and-sample pattern is characterized by a tendency to respond primarily at the rich alternative. Responding at the lean alternative involves little more than the switch to that alternative - that is, the lean alternative is “sampled”. Fix-and-sample patterns can be identified by examining the amount of behavior allocated to each alternative per visit. Per-visit analyses of responses are shown in Figures 3, and per-visit analyses of time are shown in Figure 4.

Figure 3 shows the mean number of responses per visit (run lengths) to an alternative as a function of the log programmed reinforcer ratio. Panels in the left column show run lengths on the left key and panels in the right column show run lengths on the right key. The shaded regions encompass conditions in which the key is the lean alternative. The results for the left and right keys are similar. When a key was the lean alternative, run lengths frequently averaged less than 2 responses per visit. Additionally, run lengths were equally short in the unsignaled and signaled conditions. When a key was the rich alternative, run lengths were longer, and tended to increase as the key became progressively richer. Additionally, run lengths on the rich key were longer in the signaled conditions than in the unsignaled conditions. The exception was Pigeon 1163, whose run lengths on the left key were extremely short at nearly all reinforcer ratios.

Figure 4 shows mean visit durations as a function of the log reinforcer ratio. Patterns of visit durations were identical to patterns of run lengths in almost every respect. Visit durations at the lean alternative were short, often averaging only a few seconds. Visit durations at the rich 
alternative tended to increase as the alternatives became richer, and visits were longest in the signaled conditions.

A fix-and-sample response pattern is evident in Figures 3 and 4. At the lean alternatives, run lengths and visit durations were short. At the rich alternative, run lengths and visit durations were longer and tended to increase as the alternative became richer. At the rich alternative, run lengths were longest in the signaled conditions, which is a likely outcome of the decrease in the frequency of switching. In the signaled conditions, increased run lengths and visit durations at the rich alternative are noteworthy because they would be expected in an ideal fix-and-sample pattern. The ideal fix-and-sample pattern is characterized by almost exclusive responding at the rich alternative. Sampling of the lean alternative should only involve the single response necessary to obtain the reinforcer at that alternative. The result of the ideal fix-and-sample pattern would be extreme fixes at the rich alternative that would shift the allocation of behavior towards extreme overmatching (see Figure 1).

There are other, more specific, indicators of an ideal-fix-and sample pattern. If the pigeon only samples the lean alternative when a reinforcer is signaled, then the number of responses at the lean alternative should approximately equal the number of reinforcers obtained at that alternative, that is, the response-reinforcer ratio should approximately equal 1 . Responsereinforcer ratios are examined in Figure 5. Another indicator of an ideal fix-and-sample pattern is the duration of the visit to the rich alternative. If a switch to the lean alternative only occurs when a reinforcer becomes available, then average duration of a visit to the rich alternative should equal the average interreinforcer interval at the lean alternative. For example, on a concurrent VI 30-s 60-s schedule, reinforcement at the lean alterative will become available every 60-s on average. Thus, the predicted average visit duration at the rich alternative is 60-s. 
A comparison of observed and predicted visit durations is shown in Figure 6.

Figure 5 shows the mean number of responses per reinforcer at the lean alternative as a function of the log programmed reinforcer ratios. With few exceptions, pigeons emitted more responses per reinforcer in the unsignaled conditions than in the signaled conditions. In the unsignaled conditions, the responses per reinforcer tended to decrease as the response ratios became less extreme. A similar pattern can be seen in the signaled conditions, although Pigeons 1024 and 6890 emitted very few responses per reinforcer at several of the most extreme reinforcer ratios. Despite the clear effect of the signal, the pigeons generally emitted more responses per reinforcer than required for an ideal fix-and-sample pattern. Pigeons 1024, 9980, and 6890 approximated 1 response per reinforcer in some conditions, but emitted as many as 10 responses per reinforcer in other conditions.

As seen in Figure 5, pigeons emitted excess responses at the lean alternative in the signaled conditions. If the pigeons only switched to the lean alternative in the presence of the signal, then the responses per reinforcer would be also be a measure of the run lengths. Considering that run lengths often averaged less than 2 responses per visit (see Figure 3), and that pigeons emitted as many as 10 responses per reinforcer, it must be the case that most of the excess responding was in the form of switches.

Figure 6 shows, for the signaled conditions, the mean obtained visit durations at the rich alternative as a function of the predicted visit durations at the rich alternative. Visit durations for the lean alternative are not shown because there is no predictable value in an ideal fix-andsample pattern. The predicted visit durations are calculated by dividing session time (excluding reinforcement time) by the number of reinforcers programmed for the lean alternative. The time measures are in seconds. The dashed diagonal lines depict the points at which the obtained visit 
durations equal the predicted visit durations. Note the different $y$-axis for Pigeon 1163 . The relation between predicted and obtained visit duration offer little evidence of an ideal fix-andsample pattern. In several conditions, the visit durations for Pigeon 1024 approximated the predicted visit duration. For the other three pigeons, obtained visit durations consistently fell short of predicted visit duration.

In the signaled conditions, the ratios of behavior became more extreme as evidenced by overmatching and low switching rates (Figures 1 and 2; Table 2). However, the allocation of behavior fell short of an ideal fix-and-sample response pattern. At the lean alternative, pigeons emitted a greater-than-predicted number of responses (Figure 5). Visit durations at the rich alternative were shorter than predicted (Figure 6). Although the fix-and-sample pattern was robust in both unsignaled and signaled conditions. The present procedure failed to produce good evidence of an ideal fix-and-sample pattern.

That an ideal fix-and-sample pattern was not obtained should not overshadow the fact that fix and sample was evident in both the unsignaled and signaled conditions. The fix-andsample pattern raises questions regarding the way in which reinforcers were obtained. The “sample” response at the lean alternative is most likely the same response that completes a switch from the rich alternative. Because the switch to the lean alternative encompasses most of the behavior allocated to that alternative, it follows that most reinforcers at that alternative will be obtained by a switch. Conversely, run lengths at the rich alternative are longer, meaning that most rich-alternative responses are "stay" responses. As such, it is likely that reinforcers obtained at the rich alternative will be obtained by a stay response. Reinforcement of staying and switching is also a key component of MacDonall’s $(1998,2005)$ conceptualization of concurrent schedules as pairs of stay and switch schedule. Therefore, it is worthwhile to 
examine how reinforcers were obtained across conditions.

Figure 7 shows the proportion of reinforcers obtained for staying on the left key and switching to the left key as a function of the log programmed reinforcer ratios. The shaded regions encompass conditions in which the left key was lean. The left panel shows results from the unsignaled conditions. A clear and consistent pattern of results can be seen for Pigeons 1024, 9980, and 6890. When the left key is lean, reinforcers are almost never obtained by stay responses. Instead, reinforcers are obtained by switching to the left key. The proportion of reinforcers obtained by switches increases as the reinforcer ratio becomes less extreme. A different pattern is evident when the left key is rich. Staying is reinforced, and the proportion of stay reinforcers increases as the reinforcer ratio increases. Switching to the left key continues to be reinforced, but the proportion decreases as the reinforcer ratio increases. It is worth noting that at the least extreme reinforcer ratio, a greater proportion of reinforcers are obtained by switching than by staying, despite the fact that the left key is rich.

The right column of Figure 7 shows results from the signaled conditions. When the left key is lean the results are identical to the unsignaled conditions. No reinforcers are obtained by staying, and the proportion of reinforcers obtained by switching increase as the reinforcer ratio become less extreme. When the left key is rich, a very small proportion of the reinforcers are obtained by switching. Instead, reinforcers are obtained by staying, and the proportion of reinforced stay responses increases as the reinforcer ratio increases. The exception in both the unsignaled and signaled conditions is Pigeon 1163, for which the proportion of reinforcers obtained by switches increases as the reinforcer ratio increases, and the proportion of reinforcers obtained by staying does not vary in a meaningful fashion.

Figure 8 shows the proportion of reinforcers obtained by staying at the right key and 
switching to the right key. Patterns of changes in reinforcement of staying and switching are nearly identical to those seen on the left key (Figure 7). Staying is almost never reinforced when the right key is lean. All of the reinforcers are obtained by switching, and the proportion increases as the reinforcer ratio becomes less extreme. When the right key is rich, the proportions of stay and switch reinforcers depend upon the presence or absence of the signal. In the unsignaled conditions, reinforcement of staying increases as reinforcement of switching decreases. In the signaled conditions, reinforcement of staying increases, whereas reinforcement of switching drops to very low levels.

Results shown in Figures 7 and 8 are consistent with the notion that response and time allocation are directly related to reinforcement of staying and switching (e.g., MacDonall, 1998, 1999, 2005, 2006). The pattern of changes in the proportion of reinforcers obtained by staying (Figures 7 and 8) closely corresponds to changes in run lengths and visit durations (Figures 7 and 8). When an alternative is lean, it is the sampled alternative hence staying is rarely reinforced. As an alternative becomes richer, run lengths, visit durations, and the proportion of reinforcers obtained by a switch all tend to increase. Conversely, in the unsignaled conditions, there is a close correspondence between the rate of switching (Figure 2) and the proportion of reinforcers obtained by switching (Figures 7 and 8). Switching rates and reinforcement of switching increase as the reinforcer ratio becomes less extreme. Additionally, nearly all reinforcers obtained at the lean alternative (i.e., the sampled alternative) are obtained by switches.

The present results indicate that the allocation of behavior on concurrent schedules is orderly at the level of visits to the alternatives. Fix and sample is evident, and run lengths and visit durations correspond with changes in the proportion of reinforcers obtained by staying and switching. The local model (Equation 6, p. 13) describes the allocation of behavior in terms of 
the rates at which reinforcers are earned and obtained by staying at one alternative and switching to the other alternative. As such, Equation 6 should provide a good fit to the present data.

Figure 9 shows fits of Equation 6. The log of the response ratios (left column) and time ratios (right column) are plotted as a function of the sum of the log reinforcer ratios. Recall that the right side of Equation 6 contains two terms; a term for the rate at which reinforcers are obtained and a term for the rate at which reinforcers are earned. Each term has it's own sensitivity parameter. The two terms were fit to the data using multiple linear regression, then summed to get the term plotted on the x-axes in Figure 9. Because the predictions made by Equation 6 did not produce a straight line, the predicted values were plotted as squares. Circles depict the observed behavior ratios. Open symbols depict data from the unsignaled conditions and filled symbols depict data from the signaled conditions.

As seen in Figure 9, the results are similar for response and time allocation. For all pigeons data are separated into clusters at the extreme ends of the x-axes. The clusters show a somewhat linear pattern, although it is difficult to ascertain the slopes and intercepts of the clusters. The most noteworthy feature of Figure 9 is that without exception, there is close correspondence between the predicted and observed behavior ratios, indicating a good fit for Equation 6.

Table 3 shows the fits for the data shown in Figure 9. Included in Table 3 are the slopes for the ratios of obtained reinforcers and earned reinforcers (the two terms that were summed in Figure 9), the intercept, the proportion of explained variance $\left(r^{2}\right)$, and standard errors of the estimates of the slopes and intercepts. The top half of Table 3 shows results for response allocation. Slopes for obtained reinforcers were low in the unsignaled conditions (ranging from 0.16 to 0.24 ), and showed little change in the signaled conditions. By contrast, slopes for 
earning reinforcers were higher in the unsignaled conditions (ranging from 0.42 to 1.10 ), and in most cases, increased in the signaled conditions. Intercepts were typically small and negligible in both the unsignaled and signaled conditions. Fits of Equation 6 were good. In the unsignaled conditions, values of $\mathrm{r}^{2}$ ranged from .93 to .99. Standard errors of the slopes were small, but in several cases, standard errors of the intercepts were large compared to the actual estimates. In the signaled conditions, values of $r^{2}$ ranged from .96 to .99. Standard errors of the slopes were small, but standard errors of the intercepts were somewhat large in several instances.

The bottom half of Table 3 shows fits for time allocation. Fits for time allocation were similar to fits for response allocation. Slopes for obtained reinforcers were low in both the unsignaled and signaled conditions. Slopes for earned reinforcers were higher in the unsignaled conditions, and increased in the signaled conditions. Fits of Equation 6 were good, with values of $\mathrm{r}^{2}$ at or exceeding .96 in both the signaled and unsignaled conditions. Additionally, standard errors for the slopes and intercepts were small.

Assumptions about the goodness of fit for Equation 6 should be taken with caution. A problem with fitting Equation 6 to the present data is that there were many conditions in which no reinforcers were obtained by staying at the lean alternative or by switching to the rich alternative. Including values of 0 in Equation 6 would result in reinforcer ratios with a value of 0, or reinforcer ratios that are undefined. To compensate, 1 was added to all reinforcer totals. This technique is justified because MacDonall et al. (2006) used the same technique for the same reasons. Nonetheless, the adjustments may have influenced the fit.

Both the generalized matching law (Equation 3, p. 4) and Equation 6 provided good descriptions of the present data. It may be tempting to compare the two based on goodness of fit, but values of $r^{2}$ were high for both models (cf. Tables 2 and 3), and $r^{2}$ is not an appropriate 
statistic when comparing models with different numbers of free parameters. A better statistic is the Akaike Information Criterion (AIC). The AIC adjusts for the number of free parameters in an equation in its assessment of goodness of fit. When using the AIC to compare models, the model with the lower values is the preferred model (MacDonall et al., 2006).

Table 4 shows AIC values for Equations 3 and 6 for both the unsignaled and signaled conditions. The top half of Table 4 shows values for response allocation and the bottom half shows values for time allocation. For time allocation in the unsignaled conditions, Equation 3 had lower AIC values than Equation 6. For Equation 6, values of AIC were lower for response allocation in the unsignaled conditions, and for both response and time allocation in the signaled conditions. Overall, Equation 6 provided a better description of the present data.

\section{Discussion}

\section{The Generalized Matching Law}

Response and time allocation were well described by the generalized matching law (Equation 3, p. 4). In the unsignaled conditions, three of four pigeons showed close approximations to matching. Slopes of the regression lines were at or near values that are typical of concurrent VI VI schedules (Baum, 1979; Mullins et al., 1982; Myers \& Myers, 1977; Wearden \& Burgess, 1982). In the signaled conditions, the reduction in switching resulted in increased slopes for all four pigeons, with three pigeons showing severe overmatching. Fits of Equation 3 were good for both unsignaled and, to a lesser extent, signaled conditions.

In the unsignaled conditions, the close approximations to matching raise issues about the COD. A COD is typically used to prevent adventitious reinforcement of switching by preventing a reinforcer from being delivered until several seconds elapse following a switch (e.g., Baum, 1979; Baum et al., 1999; Herrnstein, 1961, 1970; Shahan \& Lattal, 1998, 2000). It is assumed that when most of the reinforcers are obtained by switching between alternatives, the subject is behaving as if 
the concurrent schedule involves one behavior (i.e., switching) instead of two separate behaviors (staying at the two alternatives). The COD is effective at reducing switching (Brownstein \& Pliskoff, 1968; Pliskoff, 1971; Stubbs, Pliskoff \& Reid, 1977; Shahan \& Lattal, 1998, 2000), and changes in switching rates are often evident in estimates of sensitivity. Excessive switching causes behavior ratios to fall towards equality, which can cause estimates of sensitivity to fall towards severe undermatching. Conversely, reductions in switching can result in longer visits to each of the alternatives, which can result in increased estimates of sensitivity and closer approximations to matching (Baum, 1974, 1979; Baum et al., 1999).

Evidence suggests that the COD does more than simply reduce the frequency of switching. Local analyses have shown that a distinctive pattern of responding occurs immediately following a switch. At the beginning of the visit to an alternative, subjects emit a burst of high-rate responding that continues throughout the duration of the COD. Following the COD, response rates decrease to a level that is fairly consistent for the remainder of the visit. With the bursts of high-rate responding, the allocation of behavior approximates matching. When the bursts of high-rate responding are removed from the data, overmatching is the result (Baum et al, 1999; Shahan \& Lattal, 1998, 2000; Silberberg \& Fantino, 1970). If the extraction of the response burst results in higher estimates of sensitivity, then it follows that the burst engendered by the COD reduces sensitivity.

The COD appears to engender two changes in behavior that have opposite effects on sensitivity. The COD reduces switching and engenders a burst of high-rate responding. The reduction in switching increases sensitivity, whereas the response burst decreases sensitivity. Despite the complex effects of the COD, it has been argued that the matching relation may be partly dependent on it (e.g., Baum, 1974, 1979; Herrnstein, 1961, 1970; Silberberg \& Fantino, 1970). It is curious, then, that matching was obtained in the present study despite the absence of a COD. Others have also reported matching without a COD (Baum et al., 1999; Heyman, 1979), which suggests that a COD may not be necessary to ensure sensitivity of behavior to changes in relative reinforcement 
rates. The COD is particularly problematic because it inhibits brief and frequent sampling of the lean alternative, making it difficult to determine the generality of fix-and-sample response patterns.

\section{Fix-and-Sample Response Patterns}

The present procedure produced a robust fix-and-sample response pattern. At the lean alternative, run lengths typically averaged less than 2 responses per visit, regardless of the presence or absence of a signal. At the rich alternative, run lengths were longer, particularly in the signaled conditions. The duration of visits to the lean alternative typically lasted a few seconds in both unsignaled and signaled conditions. Visits durations at the rich alternative were longer, particularly in the signaled conditions. The present results extend the findings that on concurrent schedules, animals tend to allocate their behavior by fixing at the rich alternative and sampling the lean alternative (Aparicio \& Baum, 2006; Baum \& Aparicio, 1999; Baum et al., 1999; Baum \& Davison, 2004).

In the signaled conditions, run lengths and visit durations were extended, but not to the point that would be expected of an ideal fix-and-sample response pattern. The number of responses allocated to the lean alternative should have equaled the number of reinforcers programmed for that alternative, but the pigeons often emitted considerably more responses than necessary to obtain reinforcers. The visit duration at the rich alternative should have equaled the mean interreinforcer interval at the lean alternative. Instead, visit durations at the rich alternative were shorter than expected.

Deviations from an ideal fix-and-sample pattern could be the result of excessive switching or excessive stay responses at the lean alternative. Any excessive responding is curious in the present procedure. At the lean alternative, reinforcement was only available in the presence of the signal; hence the absence of a signal should have functioned as a discriminated period of non-reinforcement. Perhaps reinforcement for switching back to the rich alternative 
caused a general increase in the tendency to switch, or perhaps reinforcement for staying at the lean alternative caused a slight increase in run lengths and visit durations at that alternative, but reinforcers were rarely obtained in either fashion. Perhaps the reinforcement signal controlled the allocation of behavior, but only in a limited sense.

Recent research on “preference pulses” might shed some light on excessive responding in the signaled conditions (e.g., Baum \& Davison, 2004; Davison \& Baum, 2006; Krageloh, Davison, \& Elliffe, 2005; Landon, Davison, \& Elliffe, 2002). In several studies, subjects were exposed to a variety of concurrent VI VI schedules, and the allocation of behavior was examined in several different ways. Response ratios were calculated for data aggregated across the stable sessions. As is typically the case, response ratios favored the rich alternative. The allocation of behavior was also examined at local levels. Response ratios were calculated on a reinforcer-byreinforcer basis, or for each of the first several responses following reinforcers. Local response ratios showed a temporary shift in favor of the just-reinforced alternative. These local shifts in preference, or "preference pulses”, occurred at both alternatives, regardless of how rich or lean the alternatives were.

Preference pulses might explain the deviation from an ideal fix-and-sample response pattern. When pigeons obtain a reinforcer for switching to the lean alternative, a preference pulse might occur in the form of either a temporary increase in stay responses or, because the reinforcer was obtained by a switch, a temporary increase in switches. If a preference pulse produced an increased tendency to stay at the lean alternative, run lengths would necessarily average more than 1 response per visit. Excessive responding at the lean alternative would also occur if a preference pulse produced an increased tendency to switch. Either form of the preference pulse would necessarily reduce time spent at the rich alternative. 
Analyses of preference pulses involve aggregations of much more data that was collected in the present experiment. (e.g., Baum \& Davison, 2004; Krageloh, et al., 2005). As such, a sufficient analysis of preference pulses may not be possible, and assumptions about their influence must remain speculative. The possibility that preference pulses disrupted an ideal fixand-sample response pattern is provocative because it suggests that the pattern may be impossible to obtain, and that present assumptions about the pattern are necessarily false. In the absence of the signal, responding at the lean alternative must occur because reinforcers reliably engender responses after they are delivered (i.e., a preference pulse).

The present results are noteworthy despite the failure to obtain an ideal fix-and-sample response pattern. In the unsignaled conditions, the pigeons' behavior approximately matched the distribution of reinforcers by fixing at the rich alternative and sampling the lean alternative. In the signaled conditions, overmatching occurred when the tendency to fix and sample was exaggerated. These findings extend and support the literature suggesting that fix and sample may be a fundamental process, and that studies of concurrent schedules will benefit from local analyses of run lengths and visit durations (Aparicio \& Baum, 2006; Baum \& Aparicio, 1999; Baum et al., 1999).

The present results also support the notion that concurrent schedules can be conceptualized as a schedules that reinforce staying at one alternative and switching to the other alternative (MacDonall, 1998, 1999, 2000, 2003, 2005; MacDonall et al, 2006). In both the unsignaled and signaled conditions, a switch obtained almost all reinforcers arranged at the lean alternative. Additionally, the frequency of switching and the proportion of reinforcers obtained by switching were directly related. At the rich alternative, run lengths and visit duration tended to increase as the proportion of reinforcers obtained for staying increased. Although reinforcement of staying and switching were not explicitly manipulated in the present procedure, the correspondence between stay and switch responses and reinforcers obtained by staying and 
switching was clear.

Given the correspondence between the allocation of behavior and reinforcement of staying and switching, it is not surprising that the present data were well described by the local model (Equation 6, p 13.). Given the advantage of local analysis of concurrent-schedule performances, the local model may be preferable to the generalized matching law (Equation 3, p.

4) as a description of those performances. The local model describes run lengths and visit durations in terms of reinforcement of staying and switching at each of the alternatives. Additionally, the local model distinguishes between how reinforcers are obtained and earned. The generalized matching law, which is a global description, is silent on the way in which reinforcers earned and obtained by staying and switching. The generalized matching law has the advantage of simplicity, but Equation 6 may be preferable because of its specificity. Additionally, Equation 6 was generally better at describing the present data as indicated by values of the AIC statistic.

\section{Experiment 2}

Experiment 1 assessed whether signaling the availability of reinforcers on the leaner of two concurrent schedules would produce an ideal fix-and-sample response pattern. Although fairly extreme fix-and-sample patterns were observed in the signaled conditions, the patterns fell short of the ideal. Experiment 2 assessed the extent to which extreme fix-and-sample patterns were an artifact of the reinforcement signal. This was accomplished by signaling the availability of reinforcement at the rich alternative. If the fix-and-sample pattern is governed by a tendency to favor the rich alternative to the point that the lean alternative is only sampled, then signaling rich reinforcers was expected to have a minimal effect on the allocation of behavior. Although the reinforcement signal should reduce responding at the rich alternative, the allocation of time to that alternative should not be affected. Because the availability of reinforcement at the lean 
alternative could not be discriminated, it was expected that sampling of the lean alternative would be equally frequent in the unsignaled and signaled conditions. Hence, severe undermatching was expected in the unsignaled conditions because responding at the rich alternative should be reduced. However, time allocation should be comparable in both the unsignaled and signaled conditions.

Method

\section{Subjects and Apparatus}

Four male White Carneau pigeons with various experimental histories served as subjects. The pigeons were different than those used in Experiment 1. Care of the pigeons and the apparatus was the same as described in Experiment 1.

Procedure

All procedural details were the same as described in Experiment 1 with the exception that, in the signaled conditions, the availability of reinforcement at the rich alternative (but not the lean alternative) was signaled. Table 5 shows the reinforcer ratios, the number of reinforcers per session, and for each pigeon, the order of conditions and the number of sessions in each condition. As in Experiment 1, the reinforcer ratios were presented according to two different sequences. Pigeons 1034 and 1146 were exposed to the intermediate, most extreme, and least extreme reinforcer ratios (in that order). Pigeons 9297 and 2417 were exposed to the most extreme, intermediate, and least extreme reinforcer ratios (in that order).

Results

All analyses include means or sums of data from the last five (stable) sessions of each condition. Tables in Appendix B show summary measures and raw data from each condition for each pigeon. All data are taken from the stable sessions. Table B1 shows mean responses per 
minute (standard deviations in parentheses). Table B2 shows mean obtained reinforcers per minute (including overall reinforcers per minute). Table B3 shows total time in seconds (minus reinforcement time) spent at each alternative, the total number of responses, and the total number of switches. Table B4 shows the total number of reinforcers obtained by staying and switching. In each table, all measures are shown for the left and right keys in the unsignaled and signaled conditions. All subsequent results were derived from the raw data shown in Tables B3 and B4.

Figure 10 shows log response and time ratios as a function of log obtained reinforcer ratios (fits of Equation 3, p. 4). Note that the scales of the y-axis are different for Pigeon 1146. The left column of Figure 10 shows results for response ratios, and right column shows results for time ratios. The allocation of time and responses were similar. In the unsignaled conditions, Pigeons 1034, 9297, and 1146 show close approximations to matching, whereas Pigeon 2417 shows severe undermatching. In the signaled conditions, slopes of the regression line are negative, and the data points are widely dispersed around the line.

Table 6 shows results of the least-squares regression analyses. The top half of Table 6 shows results for response ratios. In the unsignaled conditions, Pigeons 9297 and 1146 show matching, as indicated by slopes of 1.02 and 1.05, respectively. Pigeon 1024 undermatched (slope $=0.71)$ and Pigeon 2417 severely undermatched $($ slope $=0.36)$. Equation 3 provided a good fit for data in the unsignaled conditions. Values of $\mathrm{r}^{2}$ ranged from .87 to .98 , and standard errors for slopes and intercepts were fairly small.

In the signaled conditions, slopes of the regression line reversed in direction. All four pigeons show negative slopes ranging from -0.29 to -1.15 . Pigeon 1034 showed a bias towards the left key (intercept $=0.37$ ). Fits of Equation 3 were poor. Values of $r^{2}$ ranged from .66 to .78 . Standard errors for slopes and intercepts were fairly large. 
The bottom half of Table 6 shows result for time ratios. In the unsignaled conditions, undermatching was evident for Pigeons 1034, 9297, and 2417 as indicated by slopes ranging from 0.64 to 0.76 . It is worth noting that undermatching for Pigeon 2417 was less severe than in the unsignaled conditions. Pigeon 1146 overmatched, as indicated by a slope of 1.26. Fits of Equation 3 were good. Values of $r^{2}$ ranged from .96 to .98 . Standard errors for the slopes were small, but standard errors for the intercepts were fairly large compared to the actual estimates.

In the signaled conditions, the slopes of the regression lines were negative for all four pigeons. However, the steepness of the slopes was less extreme than slope in the unsignaled conditions. Fits of Equation 3 were poor. Values of $\mathrm{r}^{2}$ ranged from .40 to .62, and standard errors for the slopes and intercepts were large.

Equation 3 provided a good description of the data from the unsignaled conditions. For response allocation, two pigeons' behavior approximated matching, and two other pigeons undermatched. For time allocation, deviations from matching were more robust, as indicated by severe undermatching in three pigeons, and overmatching in the fourth pigeon. Additionally, fits of Equation 3 were good, as indicated by high proportion of explained variance and, in most cases, small standard error for the slopes and intercepts.

In the signaled conditions, negative slopes were observed for both response and time allocation, although the slopes for time allocation were not as steep. Fits of Equation 3 were poor, as indicated by intermediate values of $\mathrm{r}^{2}$, and large standard errors of the slopes and intercepts. The negative slopes contradict assumptions about ideal fix-and-sample response patterns. It was expected that primary effect of the signal would be to reduce responding at the rich alternative, resulting in undermatching. Time allocation should not have been affected. Most of the pigeons' time should have been allocated to the rich alternative, and because the 
availability of reinforcement at the lean alternative could not be discriminated, switching between the two alternatives should have been equally frequent in the unsignaled and signaled conditions. Instead, response and time allocation were similarly affected by the signal. When the log reinforcer ratio was negative (i.e., the right key was rich), behavior ratios were positive. When the reinforcer ratios were positive (i.e., the left key was rich), behavior ratios were negative. The negative slopes indicate that a larger proportion of responses and time were allocated to the lean alternative.

Figure 11 shows switches per minute as a function of the log programmed reinforcer ratios. In the unsignaled conditions, switching rates were lowest at the most extreme reinforcer ratios, and increase as the reinforcer ratios become less extreme. Although Pigeon 1146 showed the typical pattern of switching rates, the rates were fairly low across all reinforcer ratios. In the signaled conditions, switching rates drop to low levels. For Pigeons 9297 and 1146, switching rates show little variation across reinforcer ratios. For Pigeons 1034 and 2417, switching rates were low at the most extreme reinforcer ratios and increased as the reinforcer ratios became less extreme. The signal was clearly effective at reducing switching. However, the reduced switching rates contradict assumptions about an ideal fix-and-sample response pattern because it was predicted that switching rates would be equal in the unsignaled and signaled conditions.

Figure 12 shows mean run lengths as a function of the log programmed reinforcer ratio. Panels in the left column show run lengths for the left key, and panels in the right column show run lengths for the right key. Shaded regions encompass the conditions in which the keys were the lean alternative. The results are nearly identical for the left and right keys. In the unsignaled conditions, run lengths averaged less than two responses per visit when the key was lean. When the key was rich, run lengths tended to increase as the reinforcer ratio became more extreme. 
For Pigeon 2417, run lengths were fairly short overall - a likely outcome of high switching rates (see Figure 11). Results for the left and right keys indicate a fix-and-sample pattern. Run lengths generally averaged less than two responses per visit at the lean alternative. At the rich alternative, run lengths tended to increase as the reinforcer ratio became more extreme.

An opposite pattern of run lengths is evident in the signaled conditions. Run lengths were longest when the key was lean. As the reinforcer ratio became more extreme, run lengths tended to increase, then level off or decrease at the most extreme reinforcer ratio. When the key was rich, run lengths averaged less than two responses per visit. There were two exceptions. For Pigeon 1034, run lengths on the left key increased well above two responses per visit as the reinforcer ratio increased. For Pigeon 2417, run lengths on the right key averaged less than two responses per visit regardless of whether the key was rich or lean.

Fix-and-sample patterns are evident in Figure 13. In the unsignaled conditions, run lengths at the lean alternative were short. At the rich alternative, run lengths were considerably longer. Results from the signaled conditions were unusual because pigeons tended to fix at the lean alternative and sample the rich alternative. As seen in Figure 10, behavior ratios shifted in favor of the lean alternative in the signaled conditions. Perhaps fix-and-sample patterns are better characterized as a tendency to fix at the preferred alternative (in this case, the lean alternative) and sample the non-preferred alternative (in this case, the rich alternative).

Figure 13 shows mean visit durations on the left and right keys as a function of the log programmed reinforcer ratio. Visit durations are similar to run lengths in many respects. In the unsignaled conditions, a standard fix-and-sample pattern is evident. When a key is lean, visit durations average a few seconds. When a key is rich, visit durations increase as the reinforcer ratio becomes more extreme. In the signaled conditions, visit durations are generally longer at 
the lean alternative than at the rich alternative. At the rich alternative, visit durations are often equally as long in the unsignaled and signaled conditions, and increase as the reinforcer ratio becomes more extreme.

In the signaled conditions, pigeons fixed at the lean (preferred) alternative and sampled the rich (non-preferred) alternative. Hence, it is worth exploring the possibility that pigeons approximated an ideal fix-and-sample pattern. Given the reversal in preference, it would be expected that the pigeons should only switch to the rich alternative when a reinforcer becomes available at that alternative, that is, the response-reinforcer ratio should be 1 . The responsereinforcer ratio is examined in Figure 14. Also, the average visit duration at the lean alternative should equal the average interreinforcer interval at the rich alternative, which is examined in Figure 15.

Figure 14 shows the mean number of responses per reinforcer at the rich alternative plotted as a function of the log programmed reinforcer ratio. For all pigeons, responses per reinforcer were higher in the unsignaled conditions than in the signaled conditions. In the signaled conditions, only Pigeon 1146 consistently emitted close to 1 response per reinforcer, although the response-reinforcer ratio for Pigeon 9297 was low across conditions. By contrast, Pigeons 1034 and 2417 emitted far more responses than necessary to obtain reinforcers at the rich alternative.

Figure 15 shows, for the signaled conditions, the mean obtained visit durations at the lean alternative as a function of the predicted visit durations at the lean alternative. Visit durations for the rich alternative are not shown because there is no predictable value for the ideal fix-andsample pattern. The predicted visit durations are calculated by dividing session time (excluding reinforcement time) by the number of reinforcers programmed for the rich alternative. The time 
measures are in seconds. The dashed diagonal lines depict the points at which the obtained visit durations equal the predicted visit durations. The data points in Figure 15 tend to be tightly clustered, indicating small differences in the range of predicted interreinforcer intervals. The obtained visit durations for Pigeons 1034, 9297, and 1146 closely approximated the predicted visit durations. By contrast, obtained visit durations for Pigeon 2417 fell short of the predicted values.

Taken together, Figures 14 and 15 indicate that a few of the pigeons approximated an ideal pattern of fixing at the preferred (lean) alternative and sampling the non-preferred (rich) alternative, but the results were not consistent across pigeons or analyses. For example, the obtained visit durations for Pigeon 1034 were close to the predicted visit durations (Figure 15), but the response-reinforcer ratios were too large (Figure 14). Hence, it is safe to assert that the present data provide little support for assumptions about an ideal fix-and-sample pattern. Nonetheless, fix-and-sample responding was evident in both signaled and unsignaled conditions, which makes it worthwhile to explore that way in which reinforcers were obtained.

Figure 16 shows the proportion of reinforcers obtained for staying at the left key and switching to the left key. The shaded regions encompass conditions in which the left key was lean. In the unsignaled conditions, staying was almost never reinforced when the left key was lean. When the left key was rich, staying was reinforced, and the proportion of reinforcers increased as the reinforcer ratio became more extreme. The proportions of reinforcers obtained by switching were lowest at the most extreme reinforcer ratios, and increased as the reinforcer ratios became less extreme. Although Pigeon 2417 showed the same general pattern, more reinforcers were obtained by switching at all but the largest reinforcer ratio.

In the signaled conditions, the proportions of reinforcers obtained by staying were low in 
all conditions. When the left key was lean, reinforcers obtained by staying increased as the reinforcer ratios became less extreme. As the left key became rich, reinforcement of staying tended to decrease somewhat, then increase again at the largest ratio. When the left key was lean, a very small proportion of reinforcers were obtained by switching. When the left key was rich, most of the reinforcers were obtained by switches.

Figure 17 shows the proportion of reinforcers obtained for staying at the right key and switching to the right key. In most respects, patterns of reinforcement on the right key are similar to those on the left key. In the unsignaled conditions, staying was rarely reinforced when the right key was lean, but was frequently reinforced when the right key was rich. Reinforcement of switching tended to increase as the reinforcer ratios became more extreme. A noteworthy exception is that Pigeon 2417 obtained the majority of reinforcers by switching, regardless of whether the right key was rich or lean. In the signaled conditions, the proportions of reinforcers obtained by staying were small across all reinforcer ratios, although there was a slight increase at the smallest reinforcer ratio (when the right key was rich). Reinforcement of switching increased as the right key became richer, with some decreases at the smallest reinforcer ratios.

In the unsignaled conditions, the relation between visit patterns and the way in which reinforcers were obtained is identical to the relation seen in Experiment 1. Staying at the lean alternative was rarely reinforced, whereas staying at the rich alternative was frequently reinforced. Likewise, run lengths and visit durations were brief at the lean alternative, and were longer at the rich alternative (see Figures 12 and 13). Reinforcement of switching tended to increase as the reinforcer ratios became less extreme, which corresponds with the pattern of switching rates shown in Figure 11. 
In the signaled conditions, the proportions of reinforcers obtained by staying were low across reinforcer ratios. By contrast, run lengths and visits durations were shorter at the rich alternative and longer at the lean alternative. The proportions of reinforcers obtained by switching were low at the lean alternative and high at the rich alternative - despite the fact that switching rates were fairly low across all reinforcer ratios. Although results for the signaled conditions may seem discrepant, they reveal a more complex relation between obtained reinforcers and visit patterns. The pigeons tended to sample the rich alternative, which means that staying would not often be reinforced. Because the programmed reinforcement rate is high at the rich alternative, a large proportion of reinforcers will be obtained by switches. By contrast, pigeons fixed at the lean alternative where the programmed rate of reinforcement is low. The result is that very few stays or switches would be reinforced.

Despite the more complex relations between run lengths and visit durations, and reinforcement of staying and switching, the local model (Equation 6, p. 13) should be able to describe the relations. Figure 18 shows the log response ratios (left column) and log time ratios (right column) as a function of the sum of the log ratios of obtaining reinforcers and earning reinforcers. Circles depict observed behavior ratios and squares depict predicted behavior ratios. Open symbols depict results from the unsignaled conditions and filled symbols depict results from the signaled conditions. Results for response and time allocation are nearly identical. Data from the unsignaled conditions tend to be clustered at the extreme ends of the x-axis, and show a fairly linear trend. By contrast, data for the signaled conditions tend fall near the center, and are separated into two clusters above and below the log behavior ratio of 0 . Regardless of where the data are clustered, observed behavior ratios are in close proximity to predicted behavior ratios in almost every case. 
Table 7 shows the fits for the data shown in Figure 9. The top half of Table 7 shows fits for response allocation. For Pigeons 1034, 9297, and 1146, slopes for obtained reinforcers were low in the unsignaled conditions (ranging from 0.07 to 0.23 ), and dropped to negative values in the signaled conditions. Slopes for earning reinforcers were high in the unsignaled conditions (ranging from 1.12 to 1.20), and showed little change in the signaled conditions. For Pigeon 2417, the slope for obtained reinforcers was small in the unsignaled conditions and decreased somewhat in the signaled conditions. The slope for earned reinforcers was small in the unsignaled conditions and increased in the signaled conditions. The fits were good for all pigeons. Values of $\mathrm{r}^{2}$ ranged from .91 to 1.00 in the unsignaled conditions, and from .89 to .99 in the signaled conditions. Standard errors for the slopes were generally small, but standard errors of the intercepts were large in some cases.

The bottom half of Table 7 shows fits for time allocation. Slopes for obtained reinforcers were small in the unsignaled conditions, and decreased in the signaled conditions. Slopes for earned reinforcers varied over a wide range in the unsignaled conditions (-0.06 to 0.74$)$, but were considerably higher in the signaled conditions. Fits of Equation 6 were generally good. Values of $r^{2}$ ranged from .93 to 1.00 in the unsignaled conditions. In the signaled conditions, values of $r^{2}$ were .99 for all pigeons but Pigeon $2417\left(r^{2}=.70\right)$. Standard errors for the slopes were generally small, but standard errors of the intercepts were large relative to the actual value of the intercept.

The present data were well described by Equation 6. A direct comparison of Equation 6 to the generalized matching law (Equation 3, p. 4) is made in Table 8, which shows the AIC values for Equations 3 and 6. Recall that the better model is the one with the lower AIC value. The generalized matching law was the better descriptor of time allocation in the unsignaled 
conditions. However, in nearly all other cases, AIC values for Equation 6 were lower, indicating that Equation 6 provided a better fit to the present data.

\section{Discussion}

\section{The Generalized Matching Law}

The extent to which the generalized matching law (Equation 3) adequately described the data depended upon the presence or absence of the reinforcement signal. In the unsignaled conditions, Equation 3 provided a good fit for both response and time allocation. For response allocation three of four pigeons showed close approximations of matching, as indicated by estimates of sensitivity within the typical range (Baum, 1979; Mullins et al., 1982; Myers \& Myers, 1977; Wearden \& Burgess, 1982). For time allocation, three pigeons undermatched, and one pigeon overmatched. Fits of Equation 3 were good for all four pigeons.

In the signaled conditions, pigeons showed a tendency to allocate a larger proportion of responses and time to the lean alternative, which resulted in negative slopes for the regression line. The negative slopes were interesting because it suggests a reversed sensitivity to changes in the reinforcer ratios. Interpretations about fits of Equation 3 are less certain, however, given the poor fits for both response and time allocation.

Results from the unsignaled conditions are noteworthy in two respects. As in Experiment 1, three pigeons approximated matching despite the absence of a COD. Perhaps matching was obtained because of some unusual aspect of the procedure, or because of the range of the reinforcer ratios studies, but neither seems likely. The findings in the Experiment 1 and 2 are consistent with Baum et al. (1999) and Heyman (1979), in suggesting that a COD may not be necessary to produce matching (cf. Baum, 1974, 1979; Herrnstein, 1961, 1970). The other interesting feature of the unsignaled conditions was that estimates of sensitivity were lower for time allocation than response allocation. Typically, the opposite is usually the case; time 
allocation more closely approximates matching (e.g., Baum, 1979, Wearden \& Burgess, 1982). Fix-and-Sample Response Patterns

As defined in the present study, an ideal fix-and-sample response pattern involves two discriminations; the richer of the two alternatives, and the moment that a reinforcer is available at the lean alternative. Animals typically allocate most of their behavior to the rich alternative, so discrimination of that alternative was assumed. An implicit assumption about an ideal fix-andsample response pattern is that the richer alternative is always preferred, and should almost exclusively capture the subject's behavior. The only reason that behavior is allocated to the lean alternative is because the switch to that alternative is reinforced.

In the present experiment, assumptions about ideal fix-and-sample response patterns were clearly violated. It was expected that signaling the availability of reinforcement at the rich alternative would only reduce responding at that alternative. Because the availability of reinforcement at the lean alternative could not be discriminated, responses to that alternative were expected to be the same in both the unsignaled and signaled conditions, and the rate of switching was not expected to have changed. Furthermore, because the rich alternative should still be preferred, most of the pigeons' time should have been allocated to that alternative. Instead, pigeons tended to allocate a larger proportion of both time and responding to the lean alternative, and the rate of switching between the two alternatives was substantially reduced.

Analyses of local response patterns were fairly consistent with shifts in preference captured by Equation 3. As in Experiment 1, a clear fix-and-sample pattern was evident in the unsignaled conditions. Run lengths and visit durations at the lean alternative were brief. At the rich alternative, run lengths and visit durations were longer and tended to increase as the reinforcer ratios became more extreme. In the signaled conditions, run lengths and visit 
durations were reversed. At the rich alternative, run lengths typically averaged between 1 and 2 responses per visit. At the lean alternative, run lengths were longer, but tended to decrease at the most extreme reinforcer ratios (when that alternative was leanest). Visit durations at the rich alternative were generally shorter than visit durations at the lean alternative. Additionally, visit durations at the rich alternative were nearly equal in the unsignaled and signaled conditions.

The allocation of behavior in the signaled conditions is interesting for several reasons. It was suspected that the pigeons might have engaged in a "reversed" form of the ideal fix-andsample pattern characterized by near-exclusive responding at the lean alternative that is only interrupted by switches that obtain reinforcers at the rich alternative. If so, then the duration of the visits to the lean alternative should have equaled the interreinforcer interval at the rich alternative, and the number of responses per reinforcer at the rich alternative should have equaled 1 . Three of the pigeons' visit durations at the lean alternative approximated the interreinforcer interval at the rich alternative. Likewise, two of the pigeons emitted close to 1 response per reinforcer at the rich alternative. The problem was that the results were inconsistent across pigeons in the two analyses. Regardless of how it may be interpreted, none of the analyses show evidence of an ideal fix-and-sample response pattern.

In the signaled conditions, run lengths were brief at the rich alternative and extended at the lean alternative. The response pattern is similar to fix and sample, but not in the usual way. By the definition used throughout the present study, fixing occurs at the rich alternative and sampling occurs at the lean alternative. Perhaps the definition is too narrow. If the alternative that captures the majority of the subject's behavior is considered the preferred alternative, then the definitional problem can be resolved - subjects fix at the preferred alternative and sample the non-preferred alternative (cf. Aparicio \& Baum, 2006; Baum \& Aparicio, 1999; Baum et al., 
1999). The definition is appropriate because it allows for a more uniform description of behavior in both experiments.

The most unusual finding in the signaled conditions was the way in which time was allocated between the two alternatives. A greater proportion of both responses and time were allocated to the lean alternative. In a way, the allocation of behavior makes sense. At the rich alternative, reinforcement only occurs in the presence of the signal. If responding at the rich alternative is restricted to the signaled periods, then more behavior can be allocated to the lean alternative where the availability of reinforcers is unpredictable. It was curious, however, that visit durations at the rich alternative lasted for somewhat extended periods considering that reinforcement only occurred in the presence of the signal. There are few reasons why this might have occurred.

In the discussion of the results for Experiment 1, it was suggested that excessive responding in the absence of the signal might have been the result of preference pulses, which occur after a reinforcer is delivered. Research has shown that the duration and magnitude of preference pulses increase as an alternative becomes richer, and as longer sequences of successive reinforcers are obtained at an alternative (e.g., Baum \& Davison, 2004; Davison \& Baum, 2006; Krageloh, Davison, \& Elliffe, 2005; Landon, Davison, \& Elliffe, 2002). Because it is likely that the rich alternative arranged much longer sequences of successive reinforcers than the lean alternative, preference pulses at the rich alternative would be fairly large and lengthy. Although the run lengths were not excessive at the rich alternative, large preference pulses might have been manifested as longer visits to the lean alternative.

A more plausible explanation for the long visits to the rich alternative is the increased likelihood of reinforcement for staying. The high reinforcement rate at the rich alternative 
increases the probability that multiple reinforcers will become available during relatively brief visits. Obtaining multiple reinforcers per visit is likely to engender longer stays during which responding is most likely restricted to the onset of the signal - the result of which would be fairly lengthy visits and short run lengths.

As in Experiment 1, the present findings extend and support the literature suggesting that fix and sample may be a fundamental aspect of performances on concurrent schedules (Aparicio \& Baum, 2006; Baum \& Aparicio 1999; Baum et al., 1999). The results were also interesting in that signaling reinforcement at the rich alternative produced "reversed" matching that was an outcome of fixing at the lean alternative (preferred) and sampling the rich (non-preferred) alternative.

The present results were also consistent with MacDonall's conceptualization of concurrent schedules as schedules that reinforce staying at one alternative and switching to the other alternative (e.g., MacDonall, 1998, 1999, 2005; MacDonall et al., 2005). At the preferred alternative (rich in the unsignaled conditions and lean in the signaled conditions) increases in run lengths and visit durations corresponded with increases in the proportion of reinforcers obtained by staying. At the non-preferred alternative (lean in the unsignaled conditions and rich in the signaled conditions), most reinforcers were obtained by switching. Considering the way in which reinforcers were obtained, it is not surprising that data were well described by the local model (Equation 6). Whereas fits of the generalized matching law were poor in the signaled conditions, fits of Equation 6 were good for all but one pigeon in both unsignaled and signaled conditions. Values of the AIC statistic were generally lower for Equation 6, indicating that despite the greater number of free parameters, Equation 6 provided a better overall fit to the data. 


\section{General Discussion}

\section{Summary of the Findings}

In both experiments, response and time allocation in the unsignaled conditions was well described by the generalized matching law. For most of the pigeons, estimates of sensitivity were within a typical range (e.g., Baum 1979; Wearden \& Burgess, 1982) despite the fact that a COD was not used. Only one pigeon in each experiment severely undermatched, suggesting that a COD may not be necessary to obtain close approximations to matching. In the signaled conditions, the reinforcement signal was effective at reducing switching, but the behavioral effect depended on which alternative was signaled. In Experiment 1, signaling the availability of reinforcement at the lean alternative increased the allocation of behavior at the rich alternative, which resulted in overmatching. In Experiment 2, signaling reinforcement at the rich alternative shifted the allocation of behavior in favor of the lean alternative, which resulted in negative estimates of sensitivity (i.e., reversed matching).

The present set of experiments was designed to assess whether an ideal fix-and-sample response pattern was an outcome of control by concurrent VI VI schedules. Experiment 1 was designed to create the optimal conditions for an ideal fix-and-sample response pattern by signaling the availability of reinforcement at the lean alternative. Assumptions about the ideal fix-and-sample response pattern were violated by the fact that more behavior was allocated to the lean alternative than was necessary to obtain reinforcers, and by the fact that visit durations were much shorter than expected. Experiment 2 was designed to assess whether or not an ideal fixand-sample pattern would have been an artifact of the reinforcement signal. Because reinforcement was signaled at the rich alternative, reinforcement at the lean alternative could not 
be discriminated. It was expected that responding at the rich alternative would be reduced, but behavior would continue to dwell at that alternative. Otherwise, the allocation of time at both alternatives and the allocation of responses at the lean alternative were expected to be the same in both the unsignaled and signaled conditions. Instead, the allocation of time and responses was shifted in favor of the lean alternative in the signaled conditions.

Little evidence for an ideal fix-and-sample response pattern was found in either experiment. What was found was a less-extreme tendency to fix at the preferred alternative and sample the non-preferred alternative. At the non-preferred alternative, run lengths and visit durations were brief in both the unsignaled and signaled conditions. At the preferred alternative, run lengths and visit durations were extended, particularly in the signaled conditions of Experiment 1. The interesting result of Experiment 2 was that the lean alternative became the preferred alternative when reinforcement at the rich alternative was signaled. The preference for the lean alternative indicates that defining fix and sample simply in terms of the richness and leanness of the alternatives is too narrow.

The way in which reinforcers were obtained corresponded with run lengths and visit durations. Generally speaking, run lengths and visit durations increased as reinforcement for staying increased. Likewise, switching rates generally increased as reinforcement of switching increased. Most of the reinforcers at the non-preferred (i.e., "sampled”) alternative were obtained by switches, and many of the reinforcers at the preferred (i.e., "fixed”) alternative were obtained by stay responses. As such, it is not surprising that the local model (Equation 6) provided a good fit to the data in both experiments. Although Equation 6 is more complex than Equation 3, the AIC statistic indicated that Equation 6 provided a better fit in most cases, suggesting the possibility that Equation 6 may be the preferred model for describing concurrent 
schedule performances.

\section{Theoretical Implications and Future Research}

Herrnstein (1970) argued that the simple matching relation described in Equation 1 (p. 4) had broad implications for the description of a variety of reinforcement schedules. Even when an animal is exposed to a single reinforcement schedule, other sources of extraneous reinforcement are simultaneously available (e.g., grooming, exploring the operant chamber). By this view, the animal allocates behavior among several alternatives, only one of which is the explicitly programmed reinforcement schedule. Hence, Herrnstein concluded that all operant behavior is reinforced according to concurrent schedules, therefore all operant behavior should conform to the matching law. Consistent with this assumption, Herrnstein showed that Equation 1 could be easily adapted to accommodate a variety of different reinforcement schedules, including single schedules.

Herrnstein’s (1970) conceptualization of reinforcement contingencies as instances of concurrent schedules provided a general framework in which all operant behavior can be understood. As such, a thorough understanding of how concurrent schedules control behavior is important. Results from the present two experiments are consistent with research suggesting that the tendency to fix at the preferred alternative and sample the non-preferred alternative might be a fundamental characteristic of responding on concurrent schedules (Aparicio \& Baum, 2006; Baum \& Aparicio, 1999; Baum et al, 1999).

Fix and sample is interesting because it is congruent with MacDonall's conceptualization of concurrent schedules as pairs of schedules that reinforce staying (fixing) at one alternative and switching to (sampling) the other alternative (e.g., MacDonall, 1998, 1999, MacDonall et al., 2006). The present experiments showed that fix and sample is well described by the local model 
of choice (Equation 6). The present experiments also showed that preferences on concurrent schedules could be controlled by more than just the rates of reinforcement. Discrimination of reinforcement had a robust effect on the allocation of responding. When the availability of reinforcement at the lean alternative was signaled, preference for the rich alternative was exaggerated. When the availability of reinforcement at the rich alternative was signaled, preference shifted towards the lean alternative.

The results from Experiments 1 and 2 suggest some potentially useful directions for future research. The generality of the fix-and-sample pattern needs to be more widely established. There are two reasons why fix and sample might have gone unnoticed. First, very few studies have analyzed data at a local level. Instead, studies of matching tend to focus on the global allocations of behavior irrespective of how behavior is allocated per visit to an alternative. Second, most studies of concurrent VI VI schedules use CODs. CODs are likely to mask or discourage fix and sample because they delay reinforcement of switching and engender bursts of responding following the switch (e.g., Shahan \& Lattal, 1998, 2000). Hence, future studies of concurrent VI VI schedules would benefit from not using CODs, and from analyzing responding on a per-visit basis.

It might also be worth further exploring concurrent schedules of signaled reinforcement in an effort to determine why excessive responding occurs at the signaled alternative. In both experiments, pigeons allocated more responses and time than were necessary to obtain reinforcers at the signaled alternative. Excessive responding could have been the result of noise or incomplete control by the signal. It is also possible that reinforcers engender responding such as preference pulses. If so, the influence of preferences pulses should be accounted for if quantitative descriptions of concurrent-schedule performances are to be complete. 
Although the existence of preference pulses is well documented (e.g., Baum \& Davison, 2004; Davison \& Baum, 2006; Krageloh, Davison, \& Elliffe, 2005; Landon, Davison, \& Elliffe, 2002), the effects of signaling reinforcement might enhance studies of them. Signaling reinforcement reduces responding at the signaled alternative to the point where preference pulses might be easier to isolate. Furthermore, signaling reinforcement at the rich alternative would reveal how preferences pulses are affected when the preferred alternative arranges a lower rate of reinforcement. Taken together, the all of the suggestions for future research should help clarify how behavior is allocated at a local level, which might improve our qualitative and quantitative descriptions of the allocation of behavior on concurrent schedules. Improvements in our understanding are important because as Herrnstein (1970) has noted, all operant behavior can be conceptualized in terms of concurrent schedules. 


\section{References}

Aparicio, C. F. \& Baum, W. M. (2006). Fix and sample with rats in the dynamics of choice. Journal of the Experimental Analysis of Behavior, 86, 43-63.

Baum, W. M. (1974). On two types of deviation from the matching law: Bias and undermatching. Journal of the Experimental Analysis of Behavior, 22, 231-242.

Baum, W. M. (1979). Matching, undermatching, and overmatching in studies of choice. Journal of the Experimental Analysis of Behavior, 32, 269-281.

Baum, W. M. (2002). From molecular to molar: A paradigm shift in behavior analysis. Journal of the Experimental Analysis of Behavior, 78, 95-116.

Baum, W. M. \& C. F. Aparicio (1999). Optimality and concurrent variable-interval variable-ratio schedules. Journal of the Experimental Analysis of Behavior, 71, 75-89.

Baum, W. M. \& Davison, M. (2004). Choice in a variable environment: Visit patterns in the dynamics of choice. Journal of Experimental Analysis of Behavior, 81, 85-127.

Baum, W. M., \& Rachlin, H. C. (1969). Choice as time allocation. Journal of the Experimental Analysis of Behavior, 12, 861-874.

Baum, W. M., Schwendiman, J. W., \& Bell, K. E. (1999). Choice, contingency discrimination, and foraging theory. Journal of the Experimental Analysis of Behavior, 71, 355-373.

Brownstein, A. J., \& Pliskoff, S. S. (1968). Some effects of relative reinforcement rate and changeover delay in response-independent concurrent schedules of reinforcement. Journal of the Experimental Analysis of Behavior, 11, 683-688.

Catania, A. C. (1963). Concurrent performances: Reinforcement interaction and response independence. Journal of the Experimental Analysis of Behavior, 6, 253-263. 
Catania, A. C., Silverman, P. J., \& Stubbs, D. A. (1974). Concurrent performances: Stimuluscontrol gradients during schedules of signalled and unsignalled concurrent reinforcement. Journal of the Experimental Analysis of Behavior, 21, 99-107.

Crowley, M. A., \& Donahoe, J. W. (2004). Matching: Its acquisition and generalization. Journal of the Experimental Analysis of Behavior, 82, 143-159.

Davison, M. \& Baum, W.M. (2006). Do conditional reinforcers count? Journal of the Experimental Analysis of Behavior, 86, 269-283.

Davison, M., \& Jenkins, P. E. 1985. Stimulus discriminability, contingency discriminability, and schedule preformance. Animal Learning \& Behavior, 13, 77-84.

Davison, M. \& McCarthy, D. (1988). The matching law: A research review. Hillsdale, NJ: Erlbaum.

Ferster, C. B., \& Skinner, B. F. (1957). Schedules of reinforcement. Upper Saddle River, NJ: Prentice-Hall.

Findley, J. D. (1958). Preference and switching under concurrent scheduling. Journal of the Experimental Analysis of Behavior, 1, 123-144.

Fleshler, M., \& Hoffman, H. S. (1962). A progression for generating variable-interval schedules. Journal of the Experimental Analysis of Behavior, 5, 529-530.

Herrnstein, R. J. (1961). Relative and absolute strength of response as a function of frequency of reinforcement. Journal of the Experimental Analysis of Behavior, 4, 267-272.

Herrnstein, R. J. (1970). On the law of effect. Journal of the Experimental Analysis of Behavior, 13, 243-266.

Herrnstein, R. J. (1997). The matching law: Papers in psychology and economics. (Rachlin, H., \& Laibson, D. I., Eds.). New York: Russell Sage Foundation. 
Herrnstein, R. J., \& Loveland, D. H. (1975). Maximizing and matching on concurrent ratio schedules. Journal of the Experimental Analysis of Behavior, 24, 107-116.

Heyman, G. M. (1979). A Markov model description of changeover probabilities on concurrent variable-interval schedules. Journal of the Experimental Analysis of Behavior, 31, 41-51.

Houston, A. I., \& McNamara, J. (1981). How to maximize reward rate on two variable-interval paradigms. Journal of the Experimental Analysis of Behavior, 35, 367-396.

Krageloh, C. U., Davison, M., \& Elliffe, D. M. (2005). Local preference in concurrent schedules: The effects of reinforcer sequences. Journal of the Experimental Analysis of Behavior, 84, 37-64.

Landon, J., Davison, M., \& Elliffe, D. (2002). Concurrent schedules: Short- and long-term effects of reinforcers. Journal of the Experimental Analysis of Behavior, 77, 257-271.

MacDonall, J. S. (1988). Concurrent variable-ratio schedules: Implications for the generalized matching law. Journal of the Experimental Analysis of Behavior, 50, 55-64.

MacDonall, J. S. (1998). Run length, visit duration, and reinforcers per visit in concurrent performance. Journal of the Experimental Analysis of Behavior, 69, 275-293.

MacDonall, J. S. (1999). A local model of concurrent performance. Journal of the Experimental Analysis of Behavior, 71, 57-74.

MacDonall, J. S. (2000). Synthesizing concurrent interval performances. Journal of the Experimental Analysis of Behavior, 74, 189-206.

MacDonall, J. S. (2003). Reinforcing staying and switching while using a changeover delay. Journal of the Experimental Analysis of Behavior, 79, 219-232.

MacDonall, J. S. (2005). Earning and obtaining reinforcers under concurrent interval scheduling. Journal of the Experimental Analysis of Behavior, 84, 167- 183. 
MacDonall, J. S., Goodell, J., \& Juliano, A. (2006). Momentary maximizing and optimal foraging theories on performance on concurrent VR schedules. Journal of the Experimental Analysis of Behavior, 84, 167- 183.

Madden, G. J., \& Perone, M. (2003). Effects of alternative reinforcement on human behavior: The source does matter. Journal of the Experimental Analysis of Behavior, 79, 193-206.

Marcucella, H., \& Margolius, G. (1978). Time allocation in concurrent schedules: The effect of signalled reinforcement. Journal of the Experimental Analysis of Behavior, 29, 419-430.

McDowell, J. J (2005). On the classic and modern theories of matching. Journal of the Experimental Analysis of Behavior, 84, 111- 127.

Myers, D. L., \& Myers, L. E. (1977). Undermatching: A reappraisal of performance on concurrent variable-interval schedules of reinforcement. Journal of the Experimental Analysis of Behavior, 27, 203-214.

Mullins, E., Agunwamba, C. C., \& Donohoe, A. J. (1982). On the analysis of studies of choice. Journal of the Experimental Analysis of Behavior, 37, 323-327.

Pliskoff, S. S. (1971). Effects of symmetrical and asymmetrical changeover delays on concurrent performances. Journal of the Experimental Analysis of Behavior, 16, 249-256.

Pliskoff, S. S., \& Green, D. (1972). Effects on concurrent performances of a stimulus correlated with reinforcer availability. Journal of the Experimental Analysis of Behavior, 17, 221227.

Shahan, T. A., \& Lattal, K. A. (1998). On the functions of the changeover delay. Journal of the Experimental Analysis of Behavior, 69, 141-160.

Shahan, T. A., \& Lattal, K. A. (2000). Choice, changing over, and reinforcement delays. Journal of the Experimental Analysis of Behavior, 74, 311-330. 
Shull, R. L., Spear, D. J., \& Bryson, A. E. (1981). Delay or rate of food delivery as a determiner of response rate. Journal of the Experimental Analysis of Behavior, 35, 129-143.

Silberberg, A., \& Fantino, E. (1970). Choice, rate of reinforcement, and the changeover delay. Journal of the Experimental Analysis of Behavior, 13, 187-197.

Stubbs, D. A., \& Pliskoff, S. S. (1969). Concurrent responding with fixed relative rate of reinforcement. Journal of the Experimental Analysis of Behavior, 12, 887-895.

Stubbs, D. A., Pliskoff, S. S., \& Reid, H. M. (1977). Concurrent schedules: A quantitative relation between changeover behavior and its consequences. Journal of the Experimental Analysis of Behavior, 27, 85-96.

Wearden, J. H., \& Burgess, I. S. (1982). Matching since Baum (1979). Journal of the Experimental Analysis of Behavior, 38, 339-348.

Wilkie, D. M. (1973). Signalled reinforcement in multiple and concurrent schedules. Journal of the Experimental Analysis of Behavior, 20, 29-36. 
Table A1

\section{Appendix A}

Experiment 1. For each pigeon, the reinforcer ratios [Rnf Ratio (L:R)] and responses per minute (standard deviations in parentheses) for the left and right keys in the unsignaled (U) and signaled (S) conditions. Data are from the last five sessions of each condition.

\begin{tabular}{|c|c|c|c|c|c|c|c|c|c|}
\hline \multirow[b]{2}{*}{ Pigeon } & \multirow{2}{*}{$\begin{array}{c}\text { Rnf } \\
\text { Ratio } \\
\text { (L:R) }\end{array}$} & \multicolumn{4}{|c|}{ Left } & \multicolumn{4}{|c|}{ Right } \\
\hline & & \multicolumn{2}{|c|}{$\mathrm{U}$} & \multicolumn{2}{|c|}{$\mathrm{S}$} & \multicolumn{2}{|c|}{$\overline{\mathrm{U}}$} & \multicolumn{2}{|c|}{ S } \\
\hline \multirow[t]{6}{*}{1024} & $1: 5$ & 6.00 & $\begin{array}{l}(1.86) \\
\end{array}$ & 0.32 & $(0.12)$ & 22.81 & (5.10) & 32.40 & $(1.29)$ \\
\hline & $4: 1$ & 34.28 & (2.09) & 32.85 & (2.51) & 10.61 & (1.27) & 1.11 & $(0.34)$ \\
\hline & 9:1 & 41.60 & (0.85) & 48.75 & (2.70) & 7.50 & (0.55) & 0.14 & $(0.01)$ \\
\hline & 1:10 & 4.70 & (0.88) & 0.81 & (0.33) & 32.14 & (1.95) & 18.50 & (2.34) \\
\hline & $1: 3$ & 6.86 & (0.52) & 0.45 & $(0.06)$ & 25.47 & (0.79) & 16.82 & (1.46) \\
\hline & $2: 1$ & 17.57 & (0.95) & 33.15 & (3.42) & 14.73 & (1.14) & 0.69 & $(0.19)$ \\
\hline \multirow[t]{6}{*}{9980} & 9:1 & 14.23 & (2.64) & 12.15 & (2.43) & 1.40 & (0.16) & 0.61 & $(0.24)$ \\
\hline & 1:10 & 1.72 & $(0.40)$ & 1.02 & $(0.27)$ & 14.14 & (1.02) & 13.50 & (1.23) \\
\hline & $1: 5$ & 2.36 & $(0.31)$ & 0.76 & $(0.22)$ & 10.84 & (1.15) & 15.02 & (1.37) \\
\hline & $4: 1$ & 10.01 & (2.55) & 12.84 & (1.15) & 2.28 & $(0.09)$ & 0.63 & $(0.12)$ \\
\hline & $2: 1$ & 6.08 & (1.62) & 8.49 & $(0.51)$ & 4.19 & $(0.72)$ & 0.71 & $(0.07)$ \\
\hline & 1:3 & 5.49 & $(0.49)$ & 1.03 & $(0.18)$ & 12.28 & (1.80) & 19.40 & (7.48) \\
\hline \multirow[t]{6}{*}{1163} & 1:5 & 6.76 & $(0.51)$ & 6.27 & $(0.87)$ & 50.16 & (3.41) & 69.01 & (4.03) \\
\hline & $4: 1$ & 17.29 & $(0.42)$ & 18.98 & (2.27) & 14.48 & (0.75) & 8.79 & $(0.70)$ \\
\hline & 9:1 & 13.16 & (1.04) & 17.25 & (0.71) & 12.85 & $(0.96)$ & 14.13 & $(0.54)$ \\
\hline & $1: 10$ & 6.82 & (1.58) & 3.96 & (0.68) & 59.54 & (11.50) & 64.09 & (7.01) \\
\hline & $1: 3$ & 8.44 & (1.03) & 1.55 & (0.65) & 21.95 & (1.32) & 46.60 & (4.38) \\
\hline & 2:1 & 12.08 & $(0.82)$ & 19.67 & (3.07) & 15.98 & (1.69) & 2.79 & (0.36) \\
\hline \multirow[t]{6}{*}{6890} & 9:1 & 38.46 & (1.67) & 41.17 & (5.26) & 5.03 & $(0.76)$ & 0.34 & $(0.12)$ \\
\hline & 1:10 & 4.85 & (0.15) & 0.30 & $(0.14)$ & 41.78 & (1.49) & 51.69 & (2.21) \\
\hline & $1: 5$ & 5.92 & $(0.75)$ & 1.13 & $(0.25)$ & 42.96 & (1.88) & 42.81 & (1.99) \\
\hline & 4:1 & 33.62 & (2.93) & 33.85 & (3.58) & 10.05 & (0.89) & 1.95 & $(0.44)$ \\
\hline & $2: 1$ & 28.71 & (2.72) & 26.34 & (1.90) & 18.48 & (0.81) & 0.40 & $(0.03)$ \\
\hline & $1: 3$ & 9.04 & (1.23) & 0.58 & $(0.16)$ & 24.60 & (2.53) & 27.45 & (3.44) \\
\hline
\end{tabular}


Table A2

Experiment 1. For each pigeon, the reinforcer ratios [Rnf Ratio (L:R)], the obtained reinforcers per minute (standard deviations in parentheses) for the left and right keys, and the overall obtained reinforcers per minute. Each measure is shown for the unsignaled $(U)$ and signaled (S) conditions. Data are from the last five sessions of each condition.

\begin{tabular}{|c|c|c|c|c|c|c|c|c|c|c|c|c|c|}
\hline \multirow{3}{*}{$\frac{\text { Pigeon }}{}$} & \multirow{3}{*}{$\begin{array}{c}\text { Rnf } \\
\text { Ratio } \\
\text { (L:R) } \\
1: 5\end{array}$} & \multicolumn{4}{|c|}{ Left } & \multicolumn{4}{|c|}{ Right } & \multicolumn{4}{|c|}{ Overall } \\
\hline & & \multicolumn{2}{|c|}{$\mathrm{U}$} & \multicolumn{2}{|c|}{$S$} & \multicolumn{2}{|c|}{$\mathrm{U}$} & \multicolumn{2}{|c|}{$S$} & \multicolumn{2}{|c|}{$\mathrm{U}$} & \multicolumn{2}{|c|}{$\mathrm{S}$} \\
\hline & & 0.16 & $(0.00)$ & 0.16 & $(0.00)$ & 0.77 & $(0.03)$ & 0.80 & $(0.03)$ & 0.93 & $(0.03)$ & 0.96 & $(0.03)$ \\
\hline & $4: 1$ & 0.76 & $(0.00)$ & 0.77 & $(0.00)$ & 0.19 & $(0.00)$ & 0.19 & $(0.00)$ & 0.95 & $(0.00)$ & 0.97 & $(0.00)$ \\
\hline & 9:1 & 0.86 & $(0.00)$ & 0.88 & $(0.00)$ & 0.10 & $(0.00)$ & 0.10 & $(0.00)$ & 0.96 & (0.01) & 0.98 & $(0.00)$ \\
\hline & $1: 10$ & 0.09 & $(0.00)$ & 0.09 & $(0.00)$ & 0.88 & $(0.04)$ & 0.86 & $(0.04)$ & 0.96 & (0.04) & 0.94 & $(0.04)$ \\
\hline & $1: 3$ & 0.23 & $(0.00)$ & 0.24 & $(0.01)$ & 0.69 & $(0.01)$ & 0.71 & $(0.02)$ & 0.93 & $(0.01)$ & 0.95 & (0.03) \\
\hline & $2: 1$ & 0.65 & $(0.02)$ & 0.65 & $(0.02)$ & 0.32 & $(0.01)$ & 0.32 & $(0.01)$ & 0.97 & (0.03) & 0.97 & $(0.03)$ \\
\hline \multirow[t]{6}{*}{9980} & $9: 1$ & 0.82 & $(0.01)$ & 0.82 & $(0.02)$ & 0.09 & $(0.00)$ & 0.09 & $(0.00)$ & 0.91 & $(0.00)$ & 0.91 & $(0.02)$ \\
\hline & $1: 10$ & 0.08 & $(0.00)$ & 0.09 & $(0.00)$ & 0.81 & $(0.04)$ & 0.87 & $(0.02)$ & 0.89 & (0.04) & 0.95 & $(0.02)$ \\
\hline & $1: 5$ & 0.15 & $(0.00)$ & 0.16 & $(0.00)$ & 0.74 & $(0.01)$ & 0.79 & $(0.01)$ & 0.89 & (0.01) & 0.94 & $(0.02)$ \\
\hline & $4: 1$ & 0.71 & $(0.02)$ & 0.75 & $(0.01)$ & 0.18 & $(0.01)$ & 0.19 & $(0.00)$ & 0.89 & (0.03) & 0.94 & $(0.01)$ \\
\hline & $2: 1$ & 0.58 & $(0.04)$ & 0.63 & $(0.02)$ & 0.29 & $(0.02)$ & 0.32 & $(0.01)$ & 0.87 & $(0.05)$ & 0.94 & $(0.03)$ \\
\hline & $1: 3$ & 0.23 & $(0.01)$ & 0.24 & $(0.01)$ & 0.70 & $(0.02)$ & 0.73 & $(0.01)$ & 0.92 & $(0.02)$ & 0.97 & $(0.02)$ \\
\hline \multirow[t]{6}{*}{1163} & $1: 5$ & 0.18 & $(0.05)$ & 0.16 & $(0.00)$ & 0.79 & $(0.06)$ & 0.83 & $(0.02)$ & 0.97 & $(0.00)$ & 1.00 & $(0.03)$ \\
\hline & $4: 1$ & 0.77 & $(0.00)$ & 0.77 & $(0.01)$ & 0.19 & $(0.00)$ & 0.19 & $(0.00)$ & 0.96 & $(0.00)$ & 0.96 & $(0.01)$ \\
\hline & $9: 1$ & 0.86 & $(0.00)$ & 0.87 & $(0.00)$ & 0.10 & $(0.00)$ & 0.10 & $(0.00)$ & 0.96 & (0.01) & 0.97 & $(0.00)$ \\
\hline & $1: 10$ & 0.09 & $(0.00)$ & 0.09 & $(0.00)$ & 0.86 & $(0.03)$ & 0.89 & $(0.04)$ & 0.95 & (0.03) & 0.98 & $(0.04)$ \\
\hline & $1: 3$ & 0.23 & $(0.00)$ & 0.24 & $(0.00)$ & 0.70 & $(0.01)$ & 0.73 & $(0.01)$ & 0.93 & $(0.02)$ & 0.97 & $(0.01)$ \\
\hline & $2: 1$ & 0.62 & $(0.01)$ & 0.64 & $(0.02)$ & 0.31 & $(0.00)$ & 0.32 & $(0.01)$ & 0.94 & (0.01) & 0.96 & $(0.03)$ \\
\hline \multirow[t]{6}{*}{6890} & 9:1 & 0.86 & $(0.06)$ & 0.88 & $(0.00)$ & 0.10 & $(0.05)$ & 0.10 & $(0.00)$ & 0.96 & $(0.01)$ & 0.98 & $(0.00)$ \\
\hline & $1: 10$ & 0.09 & $(0.00)$ & 0.09 & $(0.00)$ & 0.89 & $(0.03)$ & 0.89 & $(0.01)$ & 0.98 & $(0.04)$ & 0.98 & $(0.01)$ \\
\hline & $1: 5$ & 0.16 & $(0.00)$ & 0.16 & $(0.00)$ & 0.79 & $(0.00)$ & 0.80 & $(0.00)$ & 0.95 & $(0.00)$ & 0.96 & $(0.00)$ \\
\hline & $4: 1$ & 0.77 & $(0.00)$ & 0.78 & $(0.00)$ & 0.19 & $(0.00)$ & 0.19 & $(0.00)$ & 0.96 & $(0.00)$ & 0.97 & $(0.00)$ \\
\hline & $2: 1$ & 0.65 & $(0.01)$ & 0.64 & $(0.02)$ & 0.33 & $(0.00)$ & 0.32 & $(0.01)$ & 0.97 & $(0.02)$ & 0.96 & $(0.02)$ \\
\hline & $1: 3$ & 0.24 & $(0.01)$ & 0.24 & $(0.01)$ & 0.72 & $(0.03)$ & 0.72 & $(0.02)$ & 0.96 & $(0.04)$ & 0.97 & $(0.03)$ \\
\hline
\end{tabular}


Table A3

Experiment 1. For each pigeon, the reinforcer ratios [Rnf Ratio (L:R)], the total time (minus reinforcement time) in seconds allocated to the left and right keys, the total number of responses emitted on the left and right keys, and the total number of switches to the left and right keys. Each measure is shown for the unsignaled $(U)$ and signaled $(S)$ conditions. Data are summed across the last five sessions of each condition.

\begin{tabular}{|c|c|c|c|c|c|c|c|c|c|c|c|c|c|}
\hline \multirow[b]{3}{*}{ Pigeon } & \multirow{3}{*}{$\begin{array}{c}\text { Rnf } \\
\text { Ratio } \\
\text { (L:R) }\end{array}$} & \multicolumn{4}{|c|}{ Time (sec) } & \multicolumn{4}{|c|}{ Responses } & \multicolumn{4}{|c|}{ Switches } \\
\hline & & \multicolumn{2}{|c|}{ Left } & \multicolumn{2}{|c|}{ Right } & \multicolumn{2}{|c|}{ Left } & \multicolumn{2}{|c|}{ Right } & \multicolumn{2}{|c|}{ Left } & \multicolumn{2}{|c|}{ Right } \\
\hline & & $\mathrm{U}$ & $S$ & $\mathrm{U}$ & $\mathrm{S}$ & $\mathrm{U}$ & $S$ & $\mathrm{U}$ & $S$ & $\mathrm{U}$ & $S$ & $\mathrm{U}$ & $S$ \\
\hline \multirow[t]{6}{*}{ "1024 } & $101: 5$ & "1978.99 & 174.55 & 13573.31 & 149925.56 & 1541 & 81 & (5907 & 8159 & 880 & 48 & "883 & 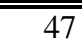 \\
\hline & $4: 1$ & 10169.96 & 15021.25 & 5583.65 & 464.35 & 9002 & 8475 & 2786 & 286 & 1329 & 134 & 1329 & 135 \\
\hline & 9:1 & 12180.02 & 15200.95 & 3477.98 & 132.66 & 10858 & 12456 & 1957 & 34 & 953 & 32 & 949 & 27 \\
\hline & $1: 10$ & 957.98 & 303.07 & 12763.44 & 13753.37 & 1077 & 190 & 7349 & 4326 & 411 & 93 & 413 & 95 \\
\hline & $1: 3$ & 3120.83 & 293.55 & 12452.22 & 14925.78 & 1781 & 113 & 6611 & 4269 & 1064 & 86 & 1066 & 88 \\
\hline & $2: 1$ & 8040.79 & 14310.56 & 6809.47 & 509.61 & 4347 & 8189 & 3646 & 169 & 1370 & 93 & 1368 & 93 \\
\hline \multirow[t]{6}{*}{9980} & $9: 1$ & 14203.89 & 15397.85 & 2251.30 & 1031.11 & 3903 & 3312 & 384 & 166 & 377 & 110 & 373 & 108 \\
\hline & $1: 10$ & 1959.72 & 1195.42 & 12899.48 & 12653.29 & 426 & 235 & 3493 & 3114 & 374 & 227 & 377 & 231 \\
\hline & $1: 5$ & 3917.27 & 1031.34 & 12235.54 & 14273.69 & 634 & 193 & 2920 & 3825 & 607 & 190 & 608 & 192 \\
\hline & $4: 1$ & 13882.02 & 14995.58 & 2956.16 & 915.25 & 2788 & 3403 & 640 & 166 & 601 & 160 & 603 & 158 \\
\hline & $2: 1$ & 12213.37 & 14231.42 & 4378.63 & 1028.14 & 1660 & 2157 & 1150 & 180 & 943 & 173 & 941 & 172 \\
\hline & $1: 3$ & 4683.89 & 1343.23 & 10853.02 & 13515.45 & 1419 & 254 & 3176 & 4795 & 1088 & 240 & 1089 & 240 \\
\hline \multirow[t]{6}{*}{1163} & $1: 5$ & 4285.81 & 2742.71 & 11198.03 & 11680.87 & 1745 & 1513 & 12943 & 16563 & 1511 & 1455 & 1512 & 1455 \\
\hline & $4: 1$ & 12115.35 & 13631.32 & 3465.73 & 2025.16 & 4491 & 4949 & 3759 & 2294 & 2983 & 2102 & 2980 & 2098 \\
\hline & $9: 1$ & 11738.00 & 10529.66 & 3902.58 & 4982.71 & 3429 & 4460 & 3350 & 3653 & 3046 & 3576 & 3043 & 3575 \\
\hline & $1: 10$ & 2477.79 & 1365.81 & 11430.47 & 12150.08 & 1575 & 888 & 13717 & 14425 & 1234 & 862 & 1235 & 864 \\
\hline & $1: 3$ & 4830.65 & 708.94 & 10585.35 & 14088.26 & 2172 & 383 & 5640 & 11501 & 1815 & 366 & 1817 & 367 \\
\hline & $2: 1$ & 10768.87 & 13879.48 & 4615.84 & 1191.54 & 3097 & 4937 & 4098 & 700 & 2422 & 621 & 2421 & 618 \\
\hline \multirow[t]{6}{*}{6890} & $9: 1$ & 13741.99 & 15102.34 & 1894.39 & 256.10 & 10023 & 10536 & 1310 & 88 & 871 & 66 & 871 & 63 \\
\hline & $1: 10$ & 1554.93 & 119.46 & 11928.98 & 13407.75 & 1089 & 67 & 9401 & 11654 & 706 & 35 & 706 & 37 \\
\hline & $1: 5$ & 2179.55 & 526.00 & 13058.16 & 14528.98 & 1505 & 284 & 10911 & 10742 & 992 & 229 & 994 & 231 \\
\hline & $4: 1$ & 11998.15 & 14285.47 & 3623.39 & 1150.88 & 8751 & 8704 & 2616 & 502 & 1519 & 323 & 1520 & 321 \\
\hline & $2: 1$ & 8736.11 & 14579.89 & 6048.67 & 428.64 & 7079 & 6592 & 4555 & 101 & 2238 & 86 & 2240 & 87 \\
\hline & $1: 3$ & 4442.41 & 456.82 & 10563.69 & 14484.62 & 2264 & 144 & 6174 & 6829 & 1483 & 74 & 1487 & 75 \\
\hline
\end{tabular}


Table A4

Experiment 1. For each pigeon, the reinforcer ratios [Rnf Ratio $(L: R)]$, the total number of reinforcers obtained by staying at the left and right keys (stay reinforcers), and the total number of reinforcers obtained by switching to the left and right keys (switch reinforcers). Each measure is shown for the unsignaled $(U)$ and signaled $(S)$ conditions. Data are summed across the last five sessions of each condition.

\begin{tabular}{|c|c|c|c|c|c|c|c|c|c|}
\hline \multirow[b]{3}{*}{ Pigeon } & \multirow{3}{*}{$\begin{array}{c}\text { Rnf } \\
\text { Ratio } \\
\text { (L:R) }\end{array}$} & \multicolumn{4}{|c|}{ Stay Reinforcers } & \multicolumn{4}{|c|}{ Switch Reinforcers } \\
\hline & & \multicolumn{2}{|c|}{ Left } & \multicolumn{2}{|c|}{ Right } & \multicolumn{2}{|c|}{ Left } & \multicolumn{2}{|c|}{ Right } \\
\hline & & $\mathrm{U}$ & $\mathrm{S}$ & $\mathrm{U}$ & $\mathrm{S}$ & $\mathrm{U}$ & $\mathrm{S}$ & $\mathrm{U}$ & $\mathrm{S}$ \\
\hline \multirow[t]{6}{*}{1024} & $1: 5$ & 1 & 2 & 136 & 199 & 39 & 38 & 64 & 1 \\
\hline & $4: 1$ & 103 & 193 & 1 & 0 & 97 & 7 & 49 & 50 \\
\hline & $9: 1$ & 158 & 223 & 0 & 0 & 67 & 2 & 25 & 25 \\
\hline & $1: 10$ & 1 & 0 & 173 & 187 & 19 & 20 & 27 & 13 \\
\hline & $1: 3$ & 1 & 0 & 112 & 175 & 59 & 60 & 68 & 5 \\
\hline & $2: 1$ & 56 & 153 & 19 & 1 & 104 & 7 & 61 & 79 \\
\hline \multirow[t]{6}{*}{9980} & $9: 1$ & 168 & 204 & 0 & 1 & 57 & 21 & 25 & 24 \\
\hline & $1: 10$ & 0 & 0 & 145 & 161 & 20 & 20 & 55 & 39 \\
\hline & $1: 5$ & 0 & 0 & 102 & 177 & 40 & 40 & 98 & 23 \\
\hline & $4: 1$ & 120 & 184 & 0 & 0 & 80 & 16 & 50 & 50 \\
\hline & $2: 1$ & 42 & 146 & 2 & 3 & 118 & 14 & 78 & 77 \\
\hline & $1: 3$ & 2 & 3 & 73 & 151 & 58 & 57 & 107 & 29 \\
\hline \multirow[t]{6}{*}{1163} & $1: 5$ & 0 & 3 & 130 & 137 & 47 & 37 & 73 & 63 \\
\hline & $4: 1$ & 32 & 69 & 3 & 3 & 168 & 131 & 47 & 47 \\
\hline & 9:1 & 3 & 11 & 0 & 2 & 222 & 214 & 25 & 23 \\
\hline & $1: 10$ & 0 & 0 & 128 & 169 & 20 & 20 & 72 & 31 \\
\hline & $1: 3$ & 0 & 4 & 62 & 174 & 60 & 56 & 118 & 6 \\
\hline & $2: 1$ & 8 & 128 & 2 & 2 & 152 & 32 & 78 & 78 \\
\hline \multirow[t]{6}{*}{6890} & $9: 1$ & 177 & 222 & 0 & 0 & 48 & 3 & 25 & 25 \\
\hline & $1: 10$ & 1 & 1 & 152 & 196 & 19 & 19 & 48 & 4 \\
\hline & $1: 5$ & 0 & 0 & 151 & 188 & 40 & 40 & 49 & 12 \\
\hline & $4: 1$ & 103 & 179 & 4 & 3 & 97 & 21 & 46 & 47 \\
\hline & $2: 1$ & 60 & 157 & 4 & 2 & 100 & 3 & 76 & 78 \\
\hline & $1: 3$ & 1 & 1 & 71 & 178 & 59 & 59 & 109 & 2 \\
\hline
\end{tabular}


Table B1

\section{Appendix B}

Experiment 2. For each pigeon, the reinforcer ratios [Rnf Ratio (L:R)] and responses per minute (standard deviations in parentheses) for the left and right keys in the unsignaled (U) and signaled (S) conditions. Data are from the last five sessions of each condition.

\begin{tabular}{|c|c|c|c|c|c|c|c|c|c|}
\hline \multirow[b]{2}{*}{ Pigeon } & \multirow{2}{*}{$\begin{array}{c}\text { Rnf } \\
\text { Ratio } \\
\text { (L:R) }\end{array}$} & \multicolumn{4}{|c|}{ Left } & \multicolumn{4}{|c|}{ Right } \\
\hline & & \multicolumn{2}{|c|}{$\mathrm{U}$} & \multicolumn{2}{|c|}{$\mathrm{S}$} & \multicolumn{2}{|c|}{$\mathrm{U}$} & \multicolumn{2}{|c|}{$S$} \\
\hline \multirow[t]{6}{*}{1034} & $11: 5$ & 8.77 & $(1.07)$ & 19.24 & $(0.93)$ & 31.57 & $(6.02)$ & 1.49 & $(0.19)$ \\
\hline & 4:1 & 21.86 & (2.22) & 5.09 & $(0.81)$ & 9.18 & (1.47) & 16.27 & (1.55) \\
\hline & $9: 1$ & 29.60 & (1.54) & 7.00 & (0.88) & 5.38 & (0.78) & 9.47 & (1.13) \\
\hline & 1:10 & 6.19 & (0.66) & 10.45 & (0.98) & 24.20 & (1.36) & 1.73 & $(0.30)$ \\
\hline & $1: 3$ & 9.77 & (0.33) & 26.99 & (1.68) & 26.96 & (1.48) & 2.20 & $(0.29)$ \\
\hline & 2:1 & - & - & 5.17 & $(0.44)$ & - & - & 24.17 & (2.77) \\
\hline \multirow[t]{6}{*}{9297} & $9: 1$ & 40.71 & (1.41) & 1.03 & $(0.09)$ & 3.44 & $(0.67)$ & 4.13 & (1.17) \\
\hline & 1:10 & 3.02 & $(0.45)$ & 5.34 & $(0.90)$ & 39.39 & (5.92) & 1.28 & $(0.27)$ \\
\hline & 1:5 & 4.80 & $(0.36)$ & 15.13 & (3.07) & 39.55 & (4.27) & 2.20 & (0.43) \\
\hline & 4:1 & 21.77 & (3.09) & 1.27 & $(0.16)$ & 9.39 & $(0.67)$ & 21.29 & (2.26) \\
\hline & $2: 1$ & 13.63 & (1.60) & 1.25 & (0.37) & 11.64 & (1.48) & 22.66 & (2.58) \\
\hline & $1: 3$ & 8.76 & (1.46) & 14.29 & (2.89) & 29.89 & (3.01) & 0.77 & $(0.03)$ \\
\hline \multirow[t]{6}{*}{2417} & $1: 5$ & 19.14 & (2.04) & 3.27 & $(0.34)$ & 6.14 & $(0.42)$ & 4.78 & (0.73) \\
\hline & $4: 1$ & 6.17 & (0.64) & 4.00 & (0.53) & 12.51 & (2.51) & 2.13 & $(0.16)$ \\
\hline & 9:1 & 7.52 & (0.67) & 7.07 & (0.65) & 9.27 & $(0.75)$ & 2.19 & $(0.27)$ \\
\hline & 1:10 & 15.26 & $(0.44)$ & 3.07 & (0.30) & 8.95 & $(0.73)$ & 3.85 & $(0.45)$ \\
\hline & $1: 3$ & 14.69 & (1.49) & 5.62 & $(0.42)$ & 12.68 & $(0.99)$ & 6.74 & $(0.45)$ \\
\hline & $2: 1$ & 11.07 & $(0.89)$ & 7.25 & (1.13) & 13.68 & (1.37) & 5.39 & (0.74) \\
\hline \multirow[t]{6}{*}{1146} & $9: 1$ & 3.27 & $(0.51)$ & 6.30 & $(0.60)$ & 14.27 & (1.32) & 0.81 & $(0.02)$ \\
\hline & $1: 10$ & 14.62 & (2.02) & 0.78 & $(0.03)$ & 3.03 & (1.13) & 2.63 & $(0.70)$ \\
\hline & 1:5 & 16.23 & (1.73) & 0.92 & $(0.04)$ & 0.81 & $(0.12)$ & 4.18 & $(0.64)$ \\
\hline & $4: 1$ & 3.08 & $(0.40)$ & 2.11 & $(0.40)$ & 12.56 & (1.70) & 0.87 & $(0.03)$ \\
\hline & $2: 1$ & 4.29 & $(0.57)$ & 5.42 & $(0.65)$ & 13.17 & $(0.77)$ & 0.75 & $(0.02)$ \\
\hline & $1: 3$ & 13.68 & $(0.68)$ & 0.65 & $(0.02)$ & 4.15 & $(0.29)$ & 4.25 & (1.12) \\
\hline
\end{tabular}


Table B2

Experiment 2. For each pigeon, the reinforcer ratios [Rnf Ratio (L:R)], the obtained reinforcers per minute (standard deviations in parentheses) for the left and right keys, and the overall obtained reinforcers per minute. Each measure is shown for the unsignaled $(U)$ and signaled (S) conditions. Data are from the last five sessions of each condition.

\begin{tabular}{|c|c|c|c|c|c|c|c|c|c|c|c|c|c|}
\hline \multirow{3}{*}{$\frac{\text { Pigeon }}{}$} & \multirow{3}{*}{$\begin{array}{c}\begin{array}{c}\text { Rnf } \\
\text { Ratio } \\
(\mathrm{L}: \mathrm{R})\end{array} \\
1: 5\end{array}$} & \multicolumn{4}{|c|}{ Left } & \multicolumn{4}{|c|}{ Right } & \multicolumn{4}{|c|}{ Overall } \\
\hline & & \multicolumn{2}{|c|}{$\mathrm{U}$} & \multicolumn{2}{|c|}{$S$} & \multicolumn{2}{|c|}{$\mathrm{U}$} & \multicolumn{2}{|c|}{$S$} & \multicolumn{2}{|c|}{$\mathrm{U}$} & \multicolumn{2}{|c|}{$S$} \\
\hline & & 0.15 & $\overline{(0.00)}$ & 0.16 & (0.00) & 0.78 & $\overline{~(0.01)}$ & 0.80 & $(0.00)$ & 0.94 & 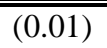 & 0.95 & $\overline{(0.01)}$ \\
\hline & $4: 1$ & 0.75 & (0.01) & 0.77 & $(0.00)$ & 0.19 & $(0.00)$ & 0.19 & $(0.00)$ & 0.94 & $(0.01)$ & 0.97 & $(0.00)$ \\
\hline & $9: 1$ & 0.85 & $(0.00)$ & 0.87 & $(0.01)$ & 0.09 & $(0.00)$ & 0.10 & $(0.00)$ & 0.95 & $(0.00)$ & 0.97 & $(0.01)$ \\
\hline & $1: 10$ & 0.09 & $(0.00)$ & 0.09 & $(0.00)$ & 0.87 & $(0.03)$ & 0.86 & $(0.04)$ & 0.96 & (0.03) & 0.95 & $(0.04)$ \\
\hline & $1: 3$ & 0.24 & $(0.00)$ & 0.24 & $(0.01)$ & 0.71 & $(0.02)$ & 0.71 & $(0.02)$ & 0.94 & $(0.02)$ & 0.95 & $(0.02)$ \\
\hline & $2: 1$ & --- & --- & 0.64 & $(0.02)$ & --- & --- & 0.32 & $(0.01)$ & --- & --- & 0.96 & $(0.02)$ \\
\hline \multirow[t]{6}{*}{9297} & $9: 1$ & 0.86 & $(0.01)$ & 0.84 & $(0.01)$ & 0.10 & $(0.00)$ & 0.09 & $(0.00)$ & 0.95 & $(0.02)$ & 0.94 & $(0.01)$ \\
\hline & $1: 10$ & 0.08 & $(0.00)$ & 0.08 & $(0.00)$ & 0.85 & $(0.02)$ & 0.85 & (0.01) & 0.94 & $(0.03)$ & 0.94 & $(0.01)$ \\
\hline & $1: 5$ & 0.16 & $(0.00)$ & 0.16 & $(0.00)$ & 0.79 & $(0.02)$ & 0.79 & $(0.01)$ & 0.95 & $(0.03)$ & 0.95 & $(0.01)$ \\
\hline & $4: 1$ & 0.77 & $(0.01)$ & 0.77 & $(0.00)$ & 0.19 & $(0.00)$ & 0.19 & $(0.00)$ & 0.96 & $(0.00)$ & 0.96 & $(0.00)$ \\
\hline & $2: 1$ & 0.64 & (0.01) & 0.63 & $(0.01)$ & 0.32 & $(0.01)$ & 0.31 & $(0.00)$ & 0.96 & $(0.02)$ & 0.94 & $(0.02)$ \\
\hline & $1: 3$ & 0.24 & $(0.00)$ & 0.24 & $(0.01)$ & 0.72 & $(0.01)$ & 0.73 & $(0.03)$ & 0.96 & $(0.02)$ & 0.97 & $(0.03)$ \\
\hline \multirow[t]{6}{*}{2417} & $1: 5$ & 0.80 & $(0.03)$ & 0.86 & $(0.01)$ & 0.15 & $(0.03)$ & 0.10 & $(0.00)$ & 0.95 & $(0.00)$ & 0.95 & $(0.01)$ \\
\hline & $4: 1$ & 0.08 & $(0.00)$ & 0.09 & $(0.00)$ & 0.85 & $(0.04)$ & 0.87 & $(0.01)$ & 0.94 & $(0.04)$ & 0.96 & $(0.01)$ \\
\hline & $9: 1$ & 0.16 & $(0.00)$ & 0.16 & $(0.00)$ & 0.78 & $(0.01)$ & 0.81 & $(0.01)$ & 0.93 & $(0.01)$ & 0.97 & $(0.02)$ \\
\hline & $1: 10$ & 0.76 & $(0.00)$ & 0.75 & $(0.01)$ & 0.19 & $(0.00)$ & 0.19 & $(0.00)$ & 0.95 & $(0.00)$ & 0.94 & $(0.01)$ \\
\hline & $1: 3$ & 0.63 & $(0.01)$ & 0.63 & $(0.01)$ & 0.32 & $(0.01)$ & 0.31 & $(0.01)$ & 0.95 & $(0.02)$ & 0.94 & $(0.02)$ \\
\hline & $2: 1$ & 0.23 & $(0.00)$ & 0.24 & $(0.01)$ & 0.70 & $(0.01)$ & 0.72 & $(0.02)$ & 0.93 & $(0.01)$ & 0.95 & $(0.02)$ \\
\hline \multirow[t]{6}{*}{1146} & $9: 1$ & 0.15 & $(0.05)$ & 0.16 & $(0.00)$ & 0.78 & $(0.05)$ & 0.80 & $(0.02)$ & 0.92 & $(0.01)$ & 0.96 & $(0.02)$ \\
\hline & $1: 10$ & 0.73 & $(0.03)$ & 0.75 & $(0.02)$ & 0.18 & $(0.01)$ & 0.19 & $(0.00)$ & 0.91 & $(0.03)$ & 0.93 & $(0.02)$ \\
\hline & $1: 5$ & 0.74 & $(0.07)$ & 0.86 & $(0.01)$ & 0.08 & $(0.01)$ & 0.10 & $(0.00)$ & 0.83 & $(0.07)$ & 0.95 & $(0.01)$ \\
\hline & $4: 1$ & 0.08 & $(0.00)$ & 0.08 & $(0.00)$ & 0.83 & (0.03) & 0.85 & (0.03) & 0.92 & (0.03) & 0.93 & $(0.03)$ \\
\hline & $2: 1$ & 0.23 & (0.01) & 0.24 & $(0.01)$ & 0.69 & $(0.02)$ & 0.71 & $(0.02)$ & 0.92 & (0.03) & 0.94 & $(0.02)$ \\
\hline & $1: 3$ & 0.61 & $(0.02)$ & 0.62 & $(0.01)$ & 0.30 & $(0.01)$ & 0.31 & $(0.01)$ & 0.91 & $(0.03)$ & 0.93 & $(0.02)$ \\
\hline
\end{tabular}


Table B3

Experiment 2. For each pigeon, the reinforcer ratios [Rnf Ratio (L:R)], the total time (minus reinforcement time) in seconds allocated to the left and right keys, the total number of responses emitted on the left and right keys, and the total number of switches to the left and right keys. Each measure is shown for the unsignaled $(U)$ and signaled (S) conditions. Data are summed across the last five sessions of each condition.

\begin{tabular}{|c|c|c|c|c|c|c|c|c|c|}
\hline \multirow[b]{3}{*}{ Pigeon } & \multirow{3}{*}{$\begin{array}{l}\text { Rnf } \\
\text { Ratio } \\
(\mathrm{L}: \mathrm{R})\end{array}$} & \multicolumn{4}{|c|}{ Time (sec) } & \multicolumn{4}{|c|}{ Responses } \\
\hline & & \multicolumn{2}{|c|}{ Left } & \multicolumn{2}{|c|}{ Right } & \multicolumn{2}{|c|}{ Left } & \multicolumn{2}{|c|}{ Right } \\
\hline & & $\mathrm{U}$ & $S$ & $\mathrm{U}$ & $\mathrm{S}$ & $\mathrm{U}$ & $\mathrm{S}$ & $\mathrm{U}$ & $S$ \\
\hline \multirow[t]{6}{*}{1034} & $1: 5$ & 3484.32 & 12954.03 & 11880.37 & 2159.92 & 2244 & 4847 & 8074 & 375 \\
\hline & $4: 1$ & 11809.26 & 3445.49 & 4155.10 & 12068.82 & 5811 & 1316 & 2437 & 4207 \\
\hline & 9:1 & 13292.34 & 3232.76 & 2534.98 & 12298.64 & 7808 & 1812 & 1419 & 2453 \\
\hline & $1: 10$ & 2767.44 & 6721.43 & 11028.75 & 7201.95 & 1421 & 2427 & 5561 & 401 \\
\hline & $1: 3$ & 3784.17 & 10298.77 & 11466.53 & 4886.74 & 2483 & 6830 & 6850 & 555 \\
\hline & $2: 1$ & --- & 1727.38 & --- & 13329.60 & --- & 1296 & --- & 6066 \\
\hline \multirow[t]{6}{*}{9297} & 9:1 & 13311.09 & 6955.97 & 2456.45 & 9056.32 & 10695 & 276 & 902 & 1103 \\
\hline & $1: 10$ & 1666.95 & 8284.06 & 12400.62 & 5833.03 & 706 & 1257 & 9241 & 300 \\
\hline & $1: 5$ & 3151.20 & 11525.09 & 11960.58 & 3643.04 & 1207 & 3819 & 9978 & 555 \\
\hline & $4: 1$ & 10548.69 & 1738.15 & 5072.65 & 13862.63 & 5665 & 329 & 2445 & 5534 \\
\hline & $2: 1$ & 9610.68 & 2020.56 & 5373.63 & 13347.09 & 3399 & 319 & 2904 & 5797 \\
\hline & $1: 3$ & 5590.25 & 13903.03 & 9465.59 & 997.53 & 2198 & 3536 & 7495 & 192 \\
\hline \multirow[t]{6}{*}{2417} & $1: 5$ & 12576.28 & 8411.16 & 3296.31 & 7360.44 & 5065 & 860 & 1623 & 1255 \\
\hline & $4: 1$ & 3162.63 & 9392.38 & 10957.72 & 4383.89 & 1458 & 920 & 2921 & 489 \\
\hline & $9: 1$ & 4608.50 & 11396.59 & 10791.55 & 3432.16 & 1931 & 1749 & 2380 & 542 \\
\hline & $1: 10$ & 11400.20 & 7550.19 & 4341.30 & 8449.59 & 4004 & 818 & 2346 & 1026 \\
\hline & $1: 3$ & 8870.31 & 5324.25 & 6260.38 & 9962.48 & 3704 & 1433 & 3198 & 1719 \\
\hline & $2: 1$ & 4632.17 & 8179.83 & 10805.34 & 6887.12 & 2847 & 1818 & 3519 & 1352 \\
\hline \multirow[t]{6}{*}{1146} & 9:1 & 2574.46 & 11387.44 & 13652.30 & 3626.57 & 884 & 1575 & 3861 & 202 \\
\hline & $1: 10$ & 14181.57 & 1811.24 & 2374.07 & 14273.88 & 4048 & 208 & 824 & 701 \\
\hline & $1: 5$ & 17443.55 & 4380.06 & 884.25 & 11334.58 & 4953 & 241 & 246 & 1095 \\
\hline & $4: 1$ & 907.75 & 6716.28 & 13508.78 & 7459.23 & 741 & 497 & 3023 & 204 \\
\hline & $2: 1$ & 1493.65 & 12501.45 & 14099.41 & 2744.70 & 1115 & 1377 & 3418 & 191 \\
\hline & $1: 3$ & 9953.90 & 2006.88 & 5812.57 & 13482.50 & 3595 & 167 & 1089 & 1094 \\
\hline
\end{tabular}

\begin{tabular}{rrrrr}
\hline \multicolumn{4}{c}{ Switches } \\
\cline { 2 - 2 } \cline { 5 - 5 } Left & \multicolumn{2}{c}{ Right } \\
\hline \hline 1485 & $\mathrm{~S}$ & & $\mathrm{U}$ & $\mathrm{S}$ \\
\hline 1251 & 465 & & 1485 & 288 \\
845 & 260 & & 844 & 260 \\
1069 & 219 & & 1071 & 222 \\
1697 & 419 & & 1699 & 420 \\
--- & 455 & & --- & 456 \\
& & & & \\
807 & 146 & & 806 & 146 \\
565 & 165 & & 568 & 165 \\
1139 & 189 & & 1137 & 192 \\
2288 & 267 & & 2288 & 268 \\
2550 & 261 & & 2551 & 262 \\
1697 & 175 & & 1699 & 178 \\
& & & & \\
1350 & 800 & & 1349 & 798 \\
1414 & 453 & & 1416 & 455 \\
1893 & 488 & & 1896 & 487 \\
2275 & 764 & & 2272 & 764 \\
2772 & 1392 & & 2773 & 1388 \\
2820 & 1240 & & 2822 & 1242 \\
841 & 156 & & 843 & 158 \\
804 & 183 & & 803 & 182 \\
230 & 178 & & 228 & 176 \\
693 & 94 & & 693 & 97 \\
1093 & 163 & & 1095 & 162 \\
967 & 142 & & 965 & 141 \\
\hline & & &
\end{tabular}


Table B4

Experiment 2. For each pigeon, the reinforcer ratios [Rnf Ratio (L:R)], the total number of reinforcers obtained by staying at the left and right keys (stay reinforcers), and the total number of reinforcers obtained by switching to the left and right keys (switch reinforcers). Each measure is shown for the unsignaled $(U)$ and signaled $(S)$ conditions. Data are summed across the last five sessions of each condition.

\begin{tabular}{|c|c|c|c|c|c|c|c|c|c|}
\hline \multirow[b]{3}{*}{ Pigeon } & \multirow{3}{*}{$\begin{array}{c}\text { Rnf } \\
\text { Ratio } \\
\text { (L:R) }\end{array}$} & \multicolumn{4}{|c|}{ Stay Reinforcers } & \multicolumn{4}{|c|}{ Switch Reinforcers } \\
\hline & & \multicolumn{2}{|c|}{ Left } & \multicolumn{2}{|c|}{ Right } & \multicolumn{2}{|c|}{ Left } & \multicolumn{2}{|c|}{ Right } \\
\hline & & $\mathrm{U}$ & $\mathrm{S}$ & $\mathrm{U}$ & $\mathrm{S}$ & $\mathrm{U}$ & $\mathrm{S}$ & $\mathrm{U}$ & $\mathrm{S}$ \\
\hline \multirow[t]{6}{*}{$\begin{array}{l}1034 \\
\end{array}$} & $1: 5$ & 1 & 31 & 102 & 20 & 39 & 9 & 998 & 180 \\
\hline & 4:1 & 97 & 43 & 1 & 38 & 103 & 157 & 49 & 12 \\
\hline & $9: 1$ & 151 & 42 & 0 & 17 & 74 & 183 & 25 & 8 \\
\hline & $1: 10$ & 0 & 9 & 104 & 73 & 20 & 11 & 96 & 127 \\
\hline & $1: 3$ & 0 & 38 & 68 & 30 & 60 & 22 & 112 & 150 \\
\hline & 2:1 & --- & 11 & --- & 58 & --- & 149 & --- & 22 \\
\hline \multirow[t]{6}{*}{9297} & $9: 1$ & 161 & 93 & 1 & 10 & 64 & 132 & 24 & 15 \\
\hline & $1: 10$ & 0 & 8 & 149 & 73 & 20 & 12 & 51 & 127 \\
\hline & $1: 5$ & 0 & 33 & 114 & 45 & 40 & 7 & 86 & 155 \\
\hline & $4: 1$ & 78 & 25 & 0 & 42 & 122 & 175 & 50 & 8 \\
\hline & $2: 1$ & 22 & 17 & 2 & 71 & 138 & 143 & 78 & 9 \\
\hline & $1: 3$ & 4 & 55 & 68 & 13 & 56 & 5 & 112 & 167 \\
\hline \multirow[t]{6}{*}{2417} & 1:5 & 112 & 36 & 1 & 2 & 99 & 189 & 38 & 23 \\
\hline & $4: 1$ & 0 & 4 & 47 & 22 & 20 & 16 & 153 & 178 \\
\hline & 9:1 & 0 & 22 & 12 & 30 & 40 & 18 & 188 & 170 \\
\hline & $1: 10$ & 49 & 31 & 0 & 0 & 151 & 169 & 50 & 50 \\
\hline & $1: 3$ & 14 & 10 & 3 & 1 & 146 & 150 & 77 & 79 \\
\hline & $2: 1$ & 0 & 7 & 0 & 42 & 60 & 53 & 180 & 138 \\
\hline \multirow[t]{6}{*}{1146} & $9: 1$ & 0 & 31 & 140 & 42 & 40 & 9 & 70 & 158 \\
\hline & 1:10 & 132 & 20 & 0 & 40 & 68 & 180 & 50 & 10 \\
\hline & 1:5 & 200 & 54 & 0 & 16 & 25 & 171 & 25 & 9 \\
\hline & $4: 1$ & 0 & 10 & 132 & 106 & 20 & 10 & 68 & 94 \\
\hline & $2: 1$ & 0 & 50 & 105 & 29 & 60 & 10 & 75 & 151 \\
\hline & $1: 3$ & 81 & 21 & 0 & 66 & 79 & 139 & 80 & 14 \\
\hline
\end{tabular}


Table 1

Experiment 1. The ratio of reinforcers arranged on the left and right keys [Rnf Ratio $(L: R)]$, the number of reinforcers per session (Rnf per Session), and for each pigeon, the order of conditions and the number of sessions in each condition. For each pigeon, the order of conditions is arranged in two columns; a column for the unsignaled conditions (U) and a column for the signaled conditions $(S)$.

\begin{tabular}{|c|c|c|c|c|c|c|c|c|c|c|c|c|c|c|c|c|c|}
\hline \multirow{4}{*}{$\begin{array}{c}\text { Rnf } \\
\text { Ratio } \\
\text { (L:R) }\end{array}$} & \multirow{4}{*}{$\begin{array}{c}\text { Rnf } \\
\text { per } \\
\text { Session }\end{array}$} & \multicolumn{16}{|c|}{ Pigeon } \\
\hline & & \multicolumn{4}{|c|}{1024} & \multicolumn{4}{|c|}{9980} & \multicolumn{4}{|c|}{1163} & \multicolumn{4}{|c|}{6890} \\
\hline & & \multicolumn{2}{|c|}{ Order } & \multicolumn{2}{|c|}{ Sessions } & \multicolumn{2}{|c|}{ Order } & \multicolumn{2}{|c|}{ Sessions } & \multicolumn{2}{|c|}{ Order } & \multicolumn{2}{|c|}{ Sessions } & \multicolumn{2}{|c|}{ Order } & \multicolumn{2}{|c|}{ Sessions } \\
\hline & & $\mathrm{U}$ & $\mathrm{S}$ & $\mathrm{U}$ & $\mathrm{S}$ & $\mathrm{U}$ & $\mathrm{S}$ & $\mathrm{U}$ & $\mathrm{S}$ & $\mathrm{U}$ & $\mathrm{S}$ & $\bar{U}$ & $\mathrm{~S}$ & $\bar{U}$ & $\mathrm{~S}$ & $\mathrm{U}$ & $\mathrm{S}$ \\
\hline $2: 1$ & 48 & 12 & 11 & 15 & 32 & 9 & 10 & 18 & 15 & 12 & 11 & 15 & 15 & 9 & 10 & 15 & 30 \\
\hline $4: 1$ & 50 & 4 & 3 & 15 & 15 & 8 & 7 & 15 & 40 & 4 & 3 & 15 & 25 & 8 & 7 & 15 & 15 \\
\hline $9: 1$ & 50 & 5 & 6 & 15 & 15 & 1 & 2 & 21 & 15 & 5 & 6 & 16 & 15 & 1 & 2 & 15 & 15 \\
\hline $1: 3$ & 48 & 9 & 10 & 15 & 15 & 12 & 11 & 17 & 26 & 9 & 10 & 15 & 17 & 12 & 11 & 27 & 15 \\
\hline $1: 5$ & 48 & 1 & 2 & 21 & 15 & 5 & 6 & 20 & 20 & 1 & 2 & 15 & 15 & 5 & 6 & 15 & 15 \\
\hline $1: 10$ & 44 & 8 & 7 & 15 & 15 & 4 & 3 & 20 & 15 & 8 & 7 & 15 & 15 & 4 & 3 & 15 & 21 \\
\hline
\end{tabular}


Table 2

Experiment 1. Results of the linear regression analyses shown in Figure 1. Included in the table is the slope, intercept, proportion of explained variance $\left(r^{2}\right)$, and standard errors of the estimates of the slope and intercept (Slope SE and Intercept SE) in the unsignaled (U) and signaled (S) conditions. The top of the table shows results for response allocation, and the bottom shows results for time allocation.

\begin{tabular}{|c|c|c|c|c|c|c|c|c|c|c|}
\hline \multirow[b]{2}{*}{ Pigeon } & \multicolumn{2}{|c|}{ Slope } & \multicolumn{2}{|c|}{ Intercept } & \multicolumn{2}{|c|}{$r^{2}$} & \multicolumn{2}{|c|}{ Slope SE } & \multicolumn{2}{|c|}{ Intercept $S E$} \\
\hline & $\mathrm{U}$ & $\mathrm{S}$ & $\mathrm{U}$ & $\mathrm{S}$ & $\mathrm{U}$ & $S$ & $\mathrm{U}$ & $\mathrm{S}$ & $\mathrm{U}$ & $\mathrm{S}$ \\
\hline \multicolumn{11}{|c|}{ Responses } \\
\hline 1024 & 0.82 & 2.42 & -0.06 & 0.26 & 0.98 & 0.90 & 0.06 & 0.40 & 0.04 & 0.29 \\
\hline 9980 & 0.96 & 1.60 & 0.03 & 0.09 & 0.99 & 0.89 & 0.06 & 0.29 & 0.04 & 0.21 \\
\hline 1163 & 0.54 & 0.99 & -0.35 & -0.36 & 0.89 & 0.67 & 0.10 & 0.35 & 0.07 & 0.25 \\
\hline 6890 & 0.96 & 2.42 & -0.06 & 0.07 & 0.99 & 0.92 & 0.05 & 0.36 & 0.04 & 0.26 \\
\hline \multicolumn{11}{|c|}{ Time } \\
\hline 1024 & 0.85 & 2.33 & -0.24 & 0.08 & 0.99 & 0.92 & 0.02 & 0.34 & 0.02 & 0.25 \\
\hline 9980 & 0.87 & 1.47 & 0.09 & 0.14 & 0.99 & 0.89 & 0.05 & 0.26 & 0.04 & 0.19 \\
\hline 1163 & 0.67 & 1.01 & 0.03 & -0.05 & 0.95 & 0.65 & 0.08 & 0.37 & 0.05 & 0.27 \\
\hline 6890 & 0.90 & 2.14 & -0.03 & 0.02 & 0.99 & 0.93 & 0.05 & 0.30 & 0.04 & 0.22 \\
\hline
\end{tabular}


Table 3

Experiment 1. Results of the multiple linear regression analyses shown in Figure 9. Included in the table are the slopes for obtaining reinforcers (obtained) and earning reinforcers (earned), the intercept, proportion of explained variance $\left(r^{2}\right)$, and standard errors of the estimates of the slopes and intercept (Slope SE and Intercept SE) in the unsignaled (U) and signaled (S) conditions. The top of the table shows results for response allocation, and the bottom shows results for time allocation.

\begin{tabular}{|c|c|c|c|c|c|c|c|c|c|c|c|c|c|c|}
\hline \multirow[b]{2}{*}{ Pigeon } & \multicolumn{2}{|c|}{ Obtained } & \multicolumn{2}{|c|}{ Earned } & \multicolumn{2}{|c|}{ Intercept } & \multicolumn{2}{|c|}{$r^{2}$} & \multicolumn{2}{|c|}{ Obtained $S E$} & \multicolumn{2}{|c|}{ Earned $S E$} & \multicolumn{2}{|c|}{ Intercept $S E$} \\
\hline & U & $\mathrm{S}$ & $\mathrm{U}$ & $\mathrm{S}$ & $\mathrm{U}$ & $S$ & $\mathrm{U}$ & $\mathrm{S}$ & $\mathrm{U}$ & $\mathrm{S}$ & $\mathrm{U}$ & $\mathrm{S}$ & $\mathrm{U}$ & $\mathrm{S}$ \\
\hline \multicolumn{15}{|c|}{ Responses } \\
\hline 1024 & 0.19 & -0.04 & 0.55 & 1.23 & 0.01 & 0.08 & 0.99 & 0.99 & 0.02 & 0.19 & 0.11 & 0.18 & 0.02 & 0.12 \\
\hline 9980 & 0.16 & 0.14 & 1.10 & 1.07 & -0.03 & -0.12 & 0.99 & 0.99 & 0.03 & 0.09 & 0.20 & 0.17 & 0.03 & 0.06 \\
\hline 1163 & 0.24 & 0.32 & 0.42 & 0.73 & -0.10 & -0.08 & 0.93 & 0.96 & 0.04 & 0.07 & 0.28 & 0.17 & 0.13 & 0.12 \\
\hline 6890 & 0.21 & 0.24 & 0.68 & 1.04 & -0.04 & 0.00 & 0.99 & 0.99 & 0.05 & 0.18 & 0.24 & 0.16 & 0.04 & 0.11 \\
\hline \multicolumn{15}{|c|}{ Time } \\
\hline 1024 & 0.12 & 0.17 & 0.91 & 1.01 & -0.11 & -0.09 & 0.98 & 0.99 & 0.07 & 0.08 & 0.35 & 0.07 & 0.07 & 0.05 \\
\hline 9980 & 0.23 & 0.12 & 0.37 & 0.97 & 0.05 & -0.04 & 0.99 & 0.99 & 0.04 & 0.04 & 0.27 & 0.09 & 0.04 & 0.03 \\
\hline 1163 & 0.27 & 0.32 & 0.18 & 0.78 & 0.21 & 0.24 & 0.99 & 0.96 & 0.02 & 0.08 & 0.13 & 0.19 & 0.06 & 0.13 \\
\hline 6890 & 0.18 & 0.24 & 0.70 & 0.90 & 0.02 & 0.05 & 0.99 & 0.99 & 0.06 & 0.17 & 0.28 & 0.15 & 0.05 & 0.10 \\
\hline
\end{tabular}


Table 4

Experiment 1. For each pigeon, values of Akaike Information Criterion (AIC) for Equation 3 ( $p$. 4) and Equation 6 (p.13). For both equations, values of AIC are shown for the unsignaled (U) and signaled $(S)$ conditions. The top half of the table shows values for response allocation, and the bottom half shows values for time allocation.

\begin{tabular}{cccccc}
\hline & \multicolumn{2}{c}{ Unsignaled } & & \multicolumn{2}{c}{ Signaled } \\
\cline { 2 - 5 } \cline { 4 - 6 } Pigeon & Equation 3 & Equation 6 & & Equation 3 & Equation 6 \\
\hline \hline 1024 & -26.59 & -38.34 & & -2.67 & -13.14 \\
9980 & -26.40 & -30.23 & & -6.70 & -23.32 \\
1163 & -19.90 & -20.86 & & -4.24 & -15.03 \\
6890 & -27.52 & -26.96 & -4.12 & -14.12 \\
\hline \multicolumn{5}{c}{ Time } \\
\hline 1024 & -36.56 & -24.69 & -4.53 & -23.66 \\
9980 & -27.75 & -26.74 & -7.87 & -31.49 \\
1163 & -22.82 & -30.54 & -3.55 & -14.00 \\
6890 & -27.55 & -24.39 & -6.03 & -14.76 \\
\hline
\end{tabular}


Table 5

Experiment 2. The ratio of reinforcers arranged on the left and right keys [Rnf Ratio $(L: R)]$, the number of reinforcers per session (Rnf per Session), and for each pigeon, the order of conditions and the number of sessions in each condition. For each pigeon, the order of conditions is arranged in two columns; a column for the unsignaled conditions (U) and a column for the signaled conditions (S).

\begin{tabular}{|c|c|c|c|c|c|c|c|c|c|c|c|c|c|c|c|c|c|}
\hline \multirow{4}{*}{$\begin{array}{c}\text { Rnf } \\
\text { Ratio } \\
\text { (L:R) }\end{array}$} & \multirow{4}{*}{$\begin{array}{c}\text { Rnf } \\
\text { per } \\
\text { Session } \\
\end{array}$} & \multicolumn{16}{|c|}{ Pigeon } \\
\hline & & \multicolumn{4}{|c|}{1034} & \multicolumn{4}{|c|}{9297} & \multicolumn{4}{|c|}{2417} & \multicolumn{4}{|c|}{1146} \\
\hline & & \multicolumn{2}{|c|}{ Order } & \multicolumn{2}{|c|}{ Sessions } & \multicolumn{2}{|c|}{ Order } & \multicolumn{2}{|c|}{ Sessions } & \multicolumn{2}{|c|}{ Order } & \multicolumn{2}{|c|}{ Sessions } & \multicolumn{2}{|c|}{ Order } & \multicolumn{2}{|c|}{ Sessions } \\
\hline & & $\mathrm{U}$ & $\mathrm{S}$ & $\bar{U}$ & $\mathrm{~S}$ & $\mathrm{U}$ & $\mathrm{S}$ & $\mathrm{U}$ & $\mathrm{S}$ & $\mathrm{U}$ & $\mathrm{S}$ & $\bar{U}$ & $\mathrm{~S}$ & $\bar{U}$ & $\mathrm{~S}$ & $\mathrm{U}$ & $\mathrm{S}$ \\
\hline $2: 1$ & 48 & - & 11 & - & 17 & 9 & 10 & 15 & 23 & 9 & 10 & 29 & 15 & 12 & 11 & 15 & 15 \\
\hline $4: 1$ & 50 & 4 & 3 & 15 & 21 & 8 & 7 & 19 & 23 & 8 & 7 & 15 & 15 & 4 & 3 & 15 & 20 \\
\hline $9: 1$ & 50 & 5 & 6 & 15 & 32 & 1 & 2 & 20 & 26 & 1 & 2 & 16 & 19 & 5 & 6 & 18 & 15 \\
\hline $1: 3$ & 48 & 9 & 10 & 15 & 33 & 12 & 11 & 15 & 28 & 12 & 11 & 16 & 15 & 9 & 10 & 15 & 15 \\
\hline $1: 5$ & 48 & 1 & 2 & 21 & 22 & 5 & 6 & 15 & 15 & 5 & 6 & 16 & 15 & 1 & 2 & 15 & 26 \\
\hline $1: 10$ & 44 & 8 & 7 & 16 & 42 & 4 & 3 & 15 & 21 & 4 & 3 & 15 & 21 & 8 & 7 & 15 & 35 \\
\hline
\end{tabular}


Table 6

Experiment 2. Results of the linear regression analyses shown in Figure 1. Included in the table is the slope, intercept, proportion of explained variance $\left(r^{2}\right)$, and standard errors of the estimates of the slope and intercept (Slope SE and Intercept SE) in the unsignaled $(U)$ and signaled $(S)$ conditions. The top of the table shows results for response allocation, and the bottom shows results for time allocation.

\begin{tabular}{|c|c|c|c|c|c|c|c|c|c|c|}
\hline \multirow[b]{2}{*}{ Pigeon } & \multicolumn{2}{|c|}{ Slope } & \multicolumn{2}{|c|}{ Intercept } & \multicolumn{2}{|c|}{$r^{2}$} & \multicolumn{2}{|c|}{ Slope $S E$} & \multicolumn{2}{|c|}{ Intercept $S E$} \\
\hline & $\mathrm{U}$ & $\mathrm{S}$ & $\mathrm{U}$ & $\mathrm{S}$ & $\mathrm{U}$ & $\mathrm{S}$ & $\mathrm{U}$ & $\mathrm{S}$ & $\mathrm{U}$ & $\mathrm{S}$ \\
\hline \multicolumn{11}{|c|}{ Responses } \\
\hline 1034 & 0.71 & -0.86 & 0.00 & 0.23 & 0.98 & 0.68 & 0.06 & 0.30 & 0.05 & 0.21 \\
\hline 9297 & 1.05 & -1.15 & -0.12 & -0.12 & 0.97 & 0.66 & 0.09 & 0.41 & 0.06 & 0.30 \\
\hline 2417 & 0.36 & -0.29 & 0.08 & 0.08 & 0.87 & 0.78 & 0.07 & 0.08 & 0.05 & 0.06 \\
\hline 1146 & 1.02 & -0.85 & 0.19 & -0.03 & 0.96 & 0.73 & 0.10 & 0.26 & 0.07 & 0.19 \\
\hline \multicolumn{11}{|c|}{ Time } \\
\hline 1034 & 0.72 & -0.53 & 0.00 & -0.08 & 0.98 & 0.62 & 0.06 & 0.24 & 0.05 & 0.19 \\
\hline 9297 & 0.76 & -0.64 & -0.02 & -0.04 & 0.97 & 0.40 & 0.06 & 0.39 & 0.05 & 0.28 \\
\hline 2417 & 0.64 & -0.24 & 0.04 & 0.10 & 0.98 & 0.47 & 0.05 & 0.13 & 0.03 & 0.09 \\
\hline 1146 & 1.26 & -0.61 & -0.02 & -0.21 & 0.96 & 0.52 & 0.13 & 0.29 & 0.09 & 0.21 \\
\hline
\end{tabular}


Table 7

Experiment 2. Results of the multiple linear regression analyses shown in Figure 9. Included in the table are the slopes for obtaining reinforcers (obtained) and earning reinforcers (earned), the intercept, proportion of explained variance $\left(r^{2}\right)$, and standard errors of the estimates of the slopes and intercept (Slope SE and Intercept SE) in the unsignaled (U) and signaled (S) conditions. The top of the table shows results for response allocation, and the bottom shows results for time allocation.

\begin{tabular}{|c|c|c|c|c|c|c|c|c|c|c|c|c|c|c|}
\hline \multirow[b]{2}{*}{ Pigeon } & \multicolumn{2}{|c|}{ Obtained } & \multicolumn{2}{|c|}{ Earned } & \multicolumn{2}{|c|}{ Intercept } & \multicolumn{2}{|c|}{$r^{2}$} & \multicolumn{2}{|c|}{ Obtained $S E$} & \multicolumn{2}{|c|}{ Earned $S E$} & \multicolumn{2}{|c|}{ Intercept $S E$} \\
\hline & $\mathrm{U}$ & $\mathrm{S}$ & $\mathrm{U}$ & $\mathrm{S}$ & $\mathrm{U}$ & $\mathrm{S}$ & $\mathrm{U}$ & $\mathrm{S}$ & $\mathrm{U}$ & $\mathrm{S}$ & $\mathrm{U}$ & $\mathrm{S}$ & $\mathrm{U}$ & $\mathrm{S}$ \\
\hline \multicolumn{15}{|c|}{ Responses } \\
\hline 1034 & 0.14 & -0.03 & 1.20 & 1.12 & -0.08 & 0.33 & 1.00 & 0.94 & 0.00 & 0.12 & 0.05 & 0.25 & 0.01 & 0.33 \\
\hline 9297 & 0.23 & -0.22 & 1.12 & 1.14 & -0.07 & -0.08 & 0.99 & 0.99 & 0.04 & 0.02 & 0.28 & 0.04 & 0.05 & 0.02 \\
\hline 2417 & 0.17 & 0.05 & 0.31 & 0.67 & -0.02 & 0.04 & 0.91 & 0.89 & 0.04 & 0.09 & 0.22 & 0.31 & 0.06 & 0.06 \\
\hline 1146 & 0.07 & -0.18 & 1.19 & 0.86 & 0.03 & 0.11 & 0.99 & 0.97 & 0.02 & 0.09 & 0.08 & 0.17 & 0.02 & 0.09 \\
\hline \multicolumn{15}{|c|}{ Time } \\
\hline 1034 & 0.19 & 0.08 & 0.66 & 1.04 & -0.03 & -0.09 & 1.00 & 0.99 & 0.07 & 0.04 & 0.08 & 0.08 & 0.08 & 0.03 \\
\hline 9297 & 0.17 & 0.02 & 0.74 & 1.05 & 0.01 & 0.00 & 0.98 & 0.99 & 0.03 & 0.03 & 0.24 & 0.07 & 0.05 & 0.04 \\
\hline 2417 & 0.22 & 0.13 & -0.06 & 0.87 & -0.02 & 0.03 & 0.93 & 0.70 & 0.05 & 0.16 & 0.32 & 0.56 & 0.09 & 0.11 \\
\hline 1146 & 0.12 & 0.02 & 0.13 & 1.03 & -0.20 & -0.02 & 0.96 & 0.99 & 0.13 & 0.03 & 0.59 & 0.06 & 0.13 & 0.03 \\
\hline
\end{tabular}


Table 8

Experiment 2. For each pigeon, values of Akaike Information Criterion (AIC) for Equation 3 ( $p$. 4) and Equation 6 (p. 13). For both equations, values of AIC are shown for the unsignaled (U) and signaled $(S)$ conditions. The top half of the table shows values for response allocation, and the bottom half shows values for time allocation.

\begin{tabular}{|c|c|c|c|c|}
\hline \multirow[b]{2}{*}{ Pigeon } & \multicolumn{2}{|c|}{ Unsignaled } & \multicolumn{2}{|c|}{$\begin{array}{c}\text { Signaled } \\
\end{array}$} \\
\hline & Equation 3 & Equation 6 & Equation 3 & Equation $\theta$ \\
\hline \multicolumn{5}{|c|}{ Responses } \\
\hline 1034 & -20.88 & -48.73 & -6.52 & -14.66 \\
\hline 9297 & -21.15 & -23.07 & -2.36 & -35.08 \\
\hline 2417 & -24.79 & -24.72 & -22.21 & -24.67 \\
\hline 1146 & -19.15 & -38.50 & -7.79 & -18.07 \\
\hline \multicolumn{5}{|c|}{ Time } \\
\hline 1034 & -20.85 & -42.90 & -7.74 & -28.81 \\
\hline 9297 & -24.87 & -24.64 & -3.11 & -27.24 \\
\hline 2417 & -28.30 & -20.03 & -16.15 & -17.49 \\
\hline 1146 & -16.18 & -14.56 & -6.43 & -32.24 \\
\hline
\end{tabular}



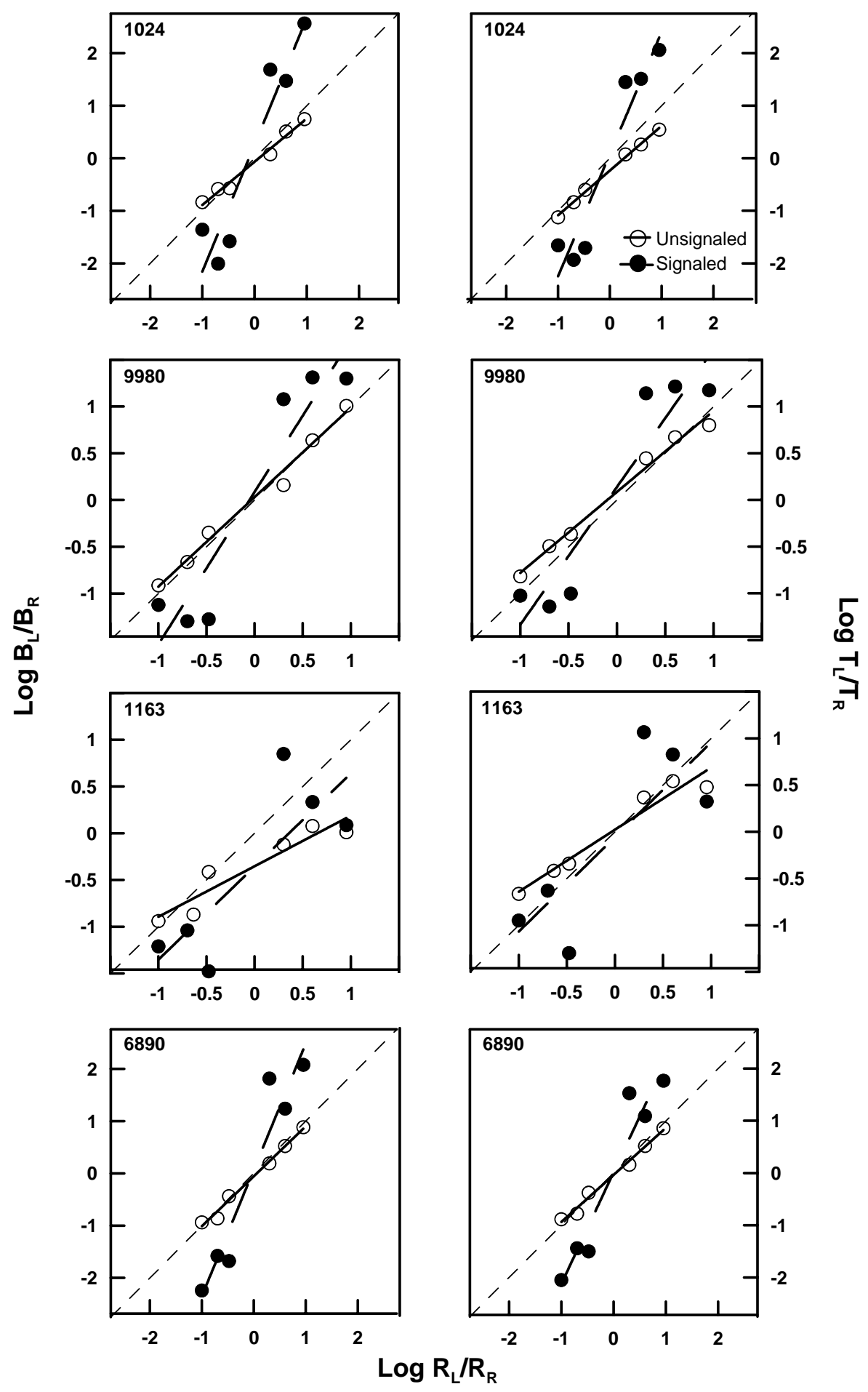

Figure 1. Experiment 1. The logarithms (base 10) of the response ratios $\left(\mathrm{B}_{\mathrm{L}} / \mathrm{B}_{\mathrm{R}}\right.$; left column) and time ratios $\left(T_{L} / T_{R}\right.$; right column) plotted as a function of the logarithm of the reinforcer ratios $\left(R_{L} / R_{R}\right)$. Open circles depict data from the unsignaled conditions and filled circles depict data from the signaled conditions. The dashed diagonal line depicts matching of the behavior ratios and reinforcer ratios. Solid lines are the least-squares regression lines for the unsignaled conditions, and heavy dashes are the regression lines for the signaled conditions. 

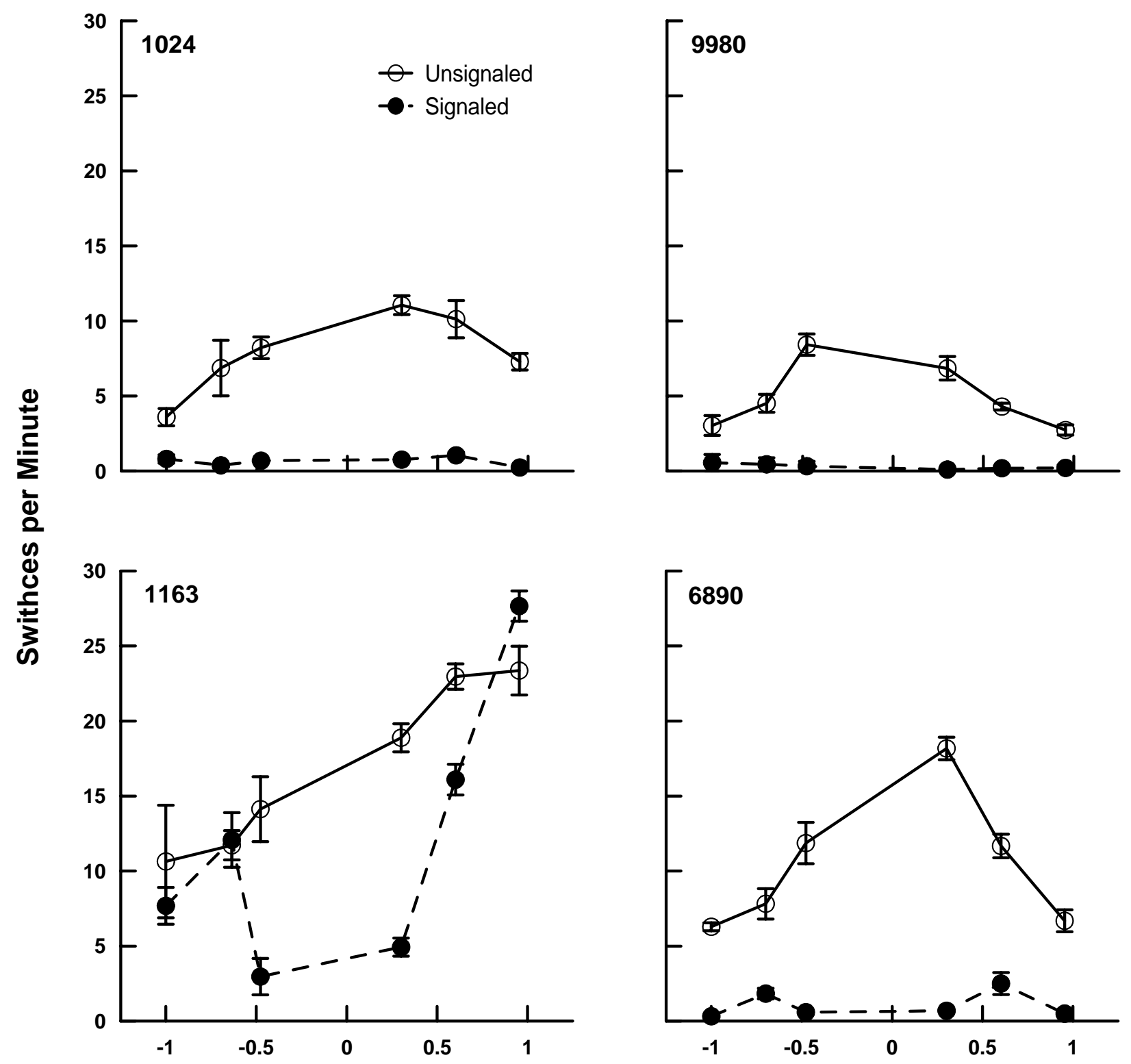

\section{$\log R_{L} / R_{R}$}

Figure 2. Experiment 1. Mean switches per minute as a function of the log reinforcer ratios. Open circles depict data from the unsignaled conditions and filled circles depict data from the signaled conditions. Error bars extend one standard deviation above and below the mean. 


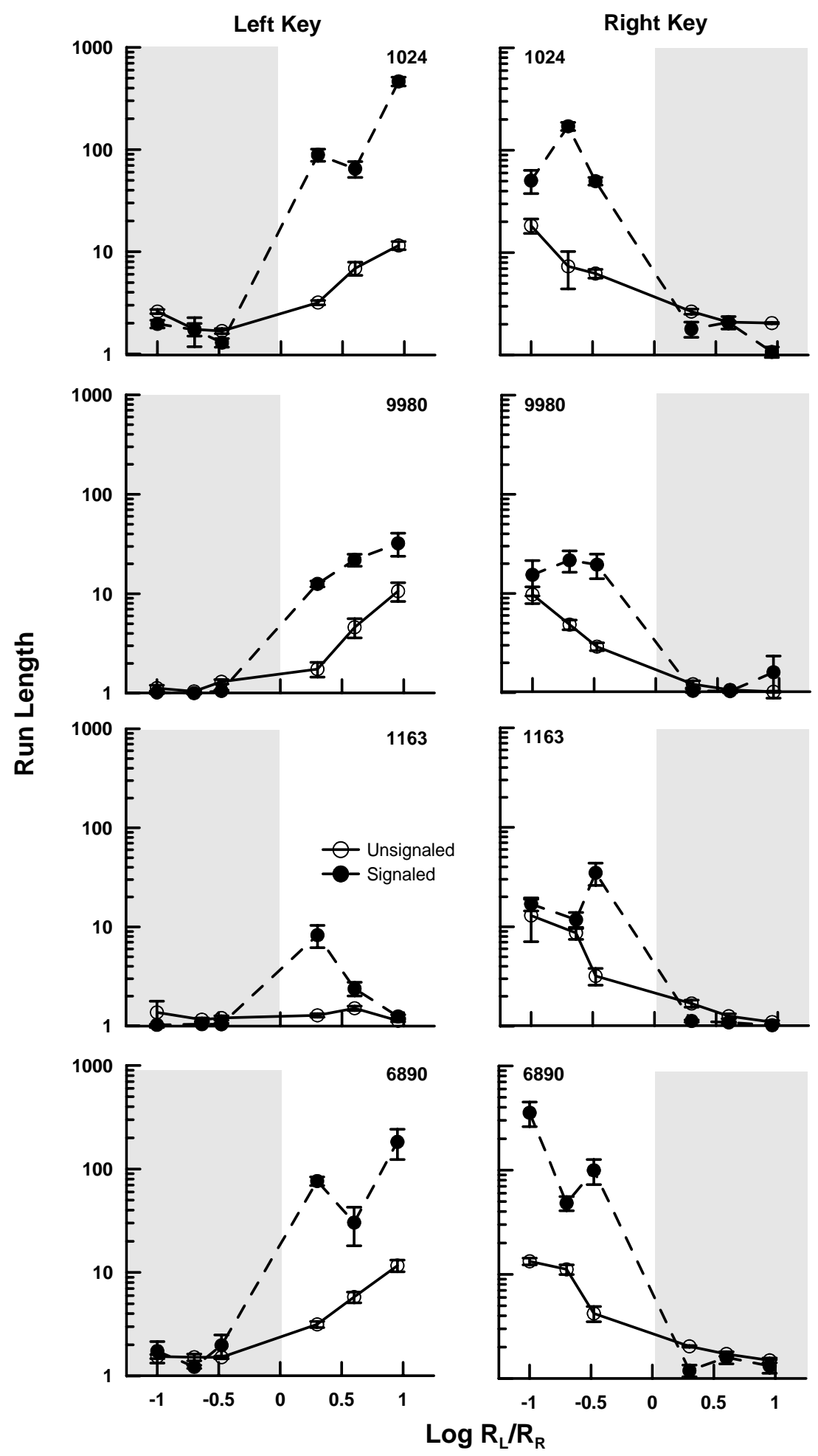

Figure 3. Experiment 1. Mean run lengths as a function of the log reinforcer ratios. Open circles depict data from the unsignaled conditions and filled circles depict data from the signaled conditions. Error bars extend one standard deviation above and below the mean. The left column shows run lengths on the left key and the right column shows run lengths on the right key. Shaded regions indicate conditions in which the key was the lean alternative. 


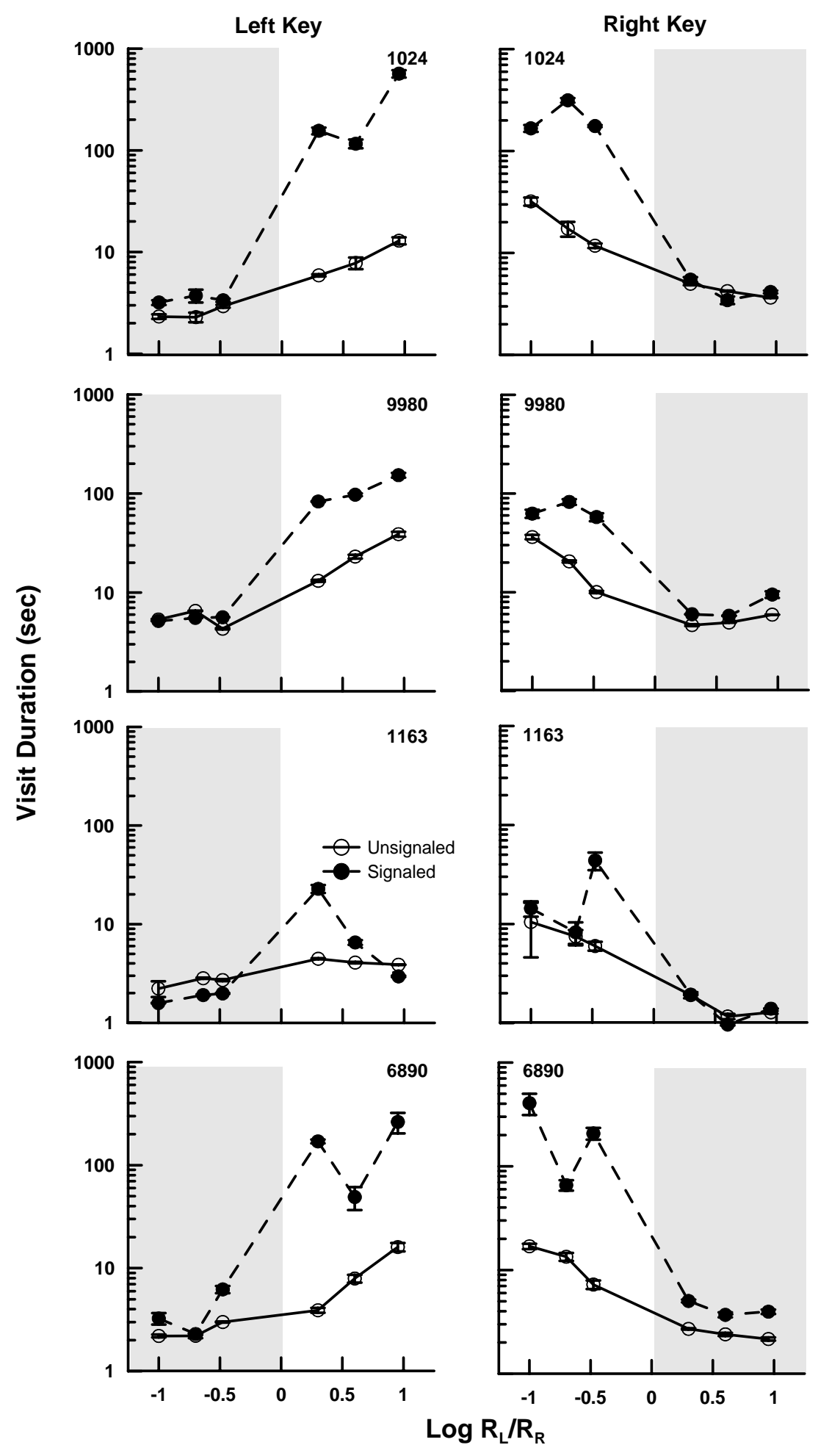

Figure 4. Experiment 1. Mean visit durations (in seconds) as a function of the log reinforcer ratios. Other details are as in Figure 3. 

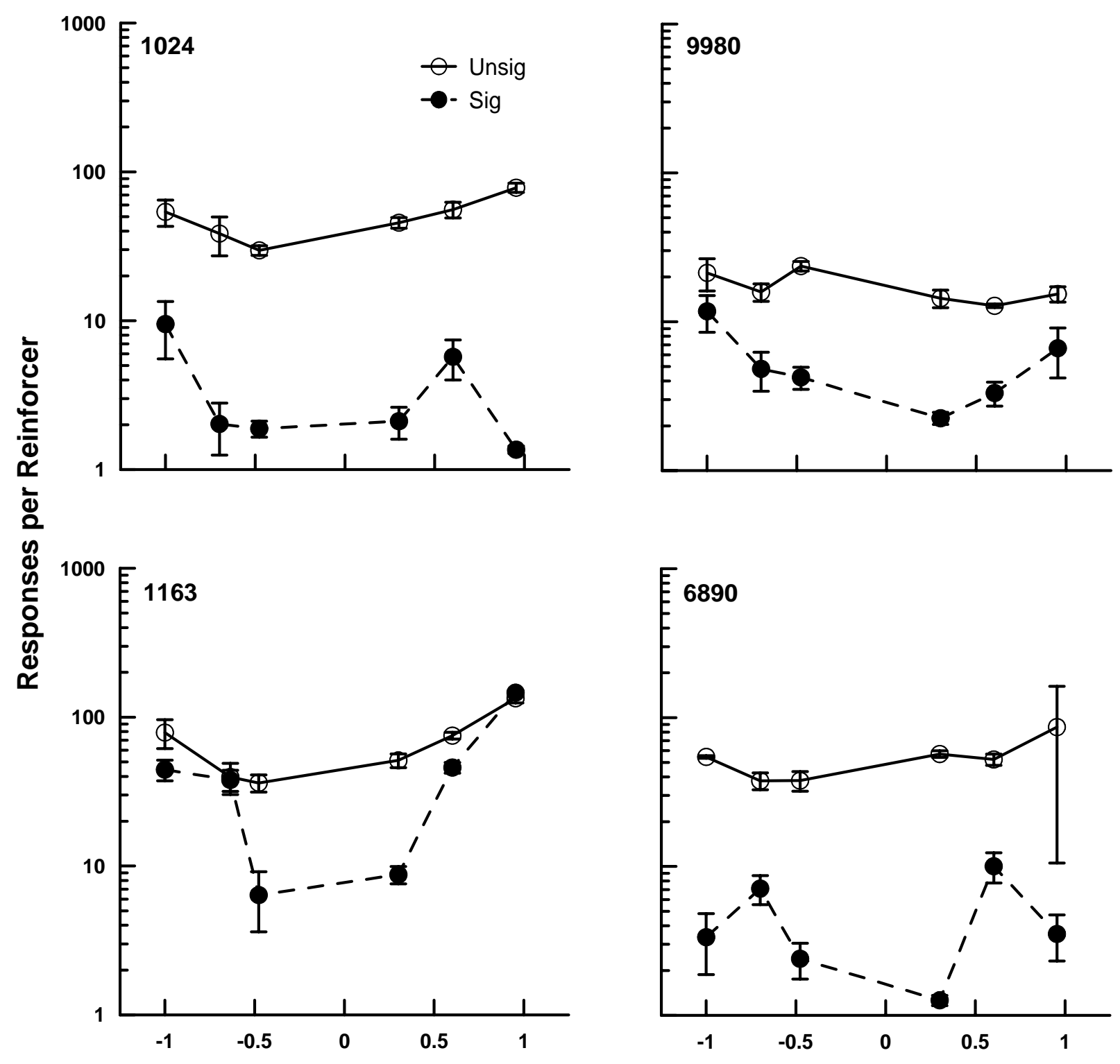

$\log R_{L} / R_{R}$

Figure 5. Experiment 1. The mean number of responses per reinforcer at the lean alternative as a function of the log reinforcer ratio. Open circles depict data from the unsignaled conditions and filled circles depict data from the signaled conditions. Error bars extend one standard deviation above and below the mean. 


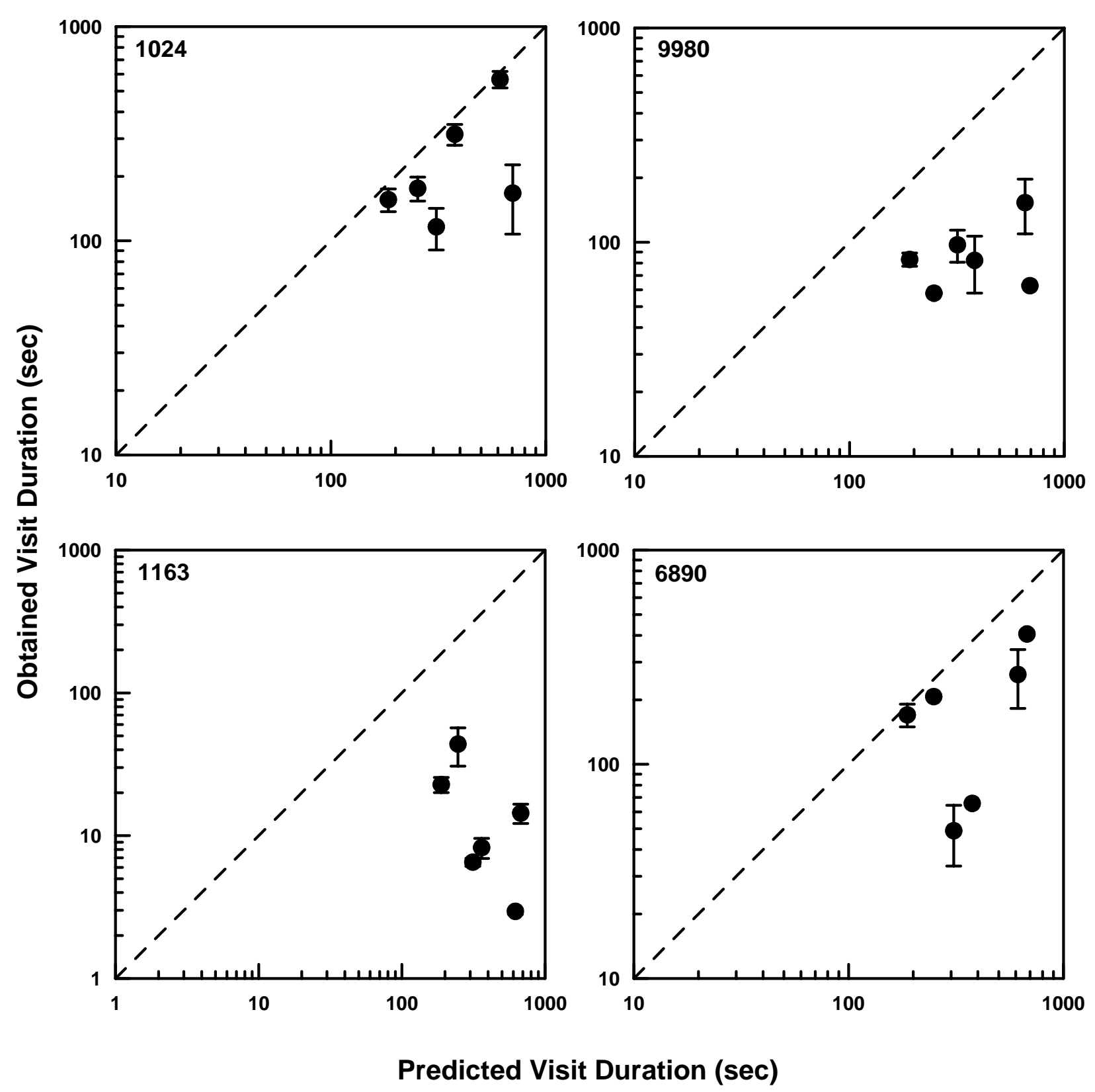

Figure 6. Experiment 1. For the signaled conditions, the mean obtained visit durations (in seconds) as a function of the predicted visit durations. The dashed diagonal line depicts the point where obtained and predicted visit durations are equal. 


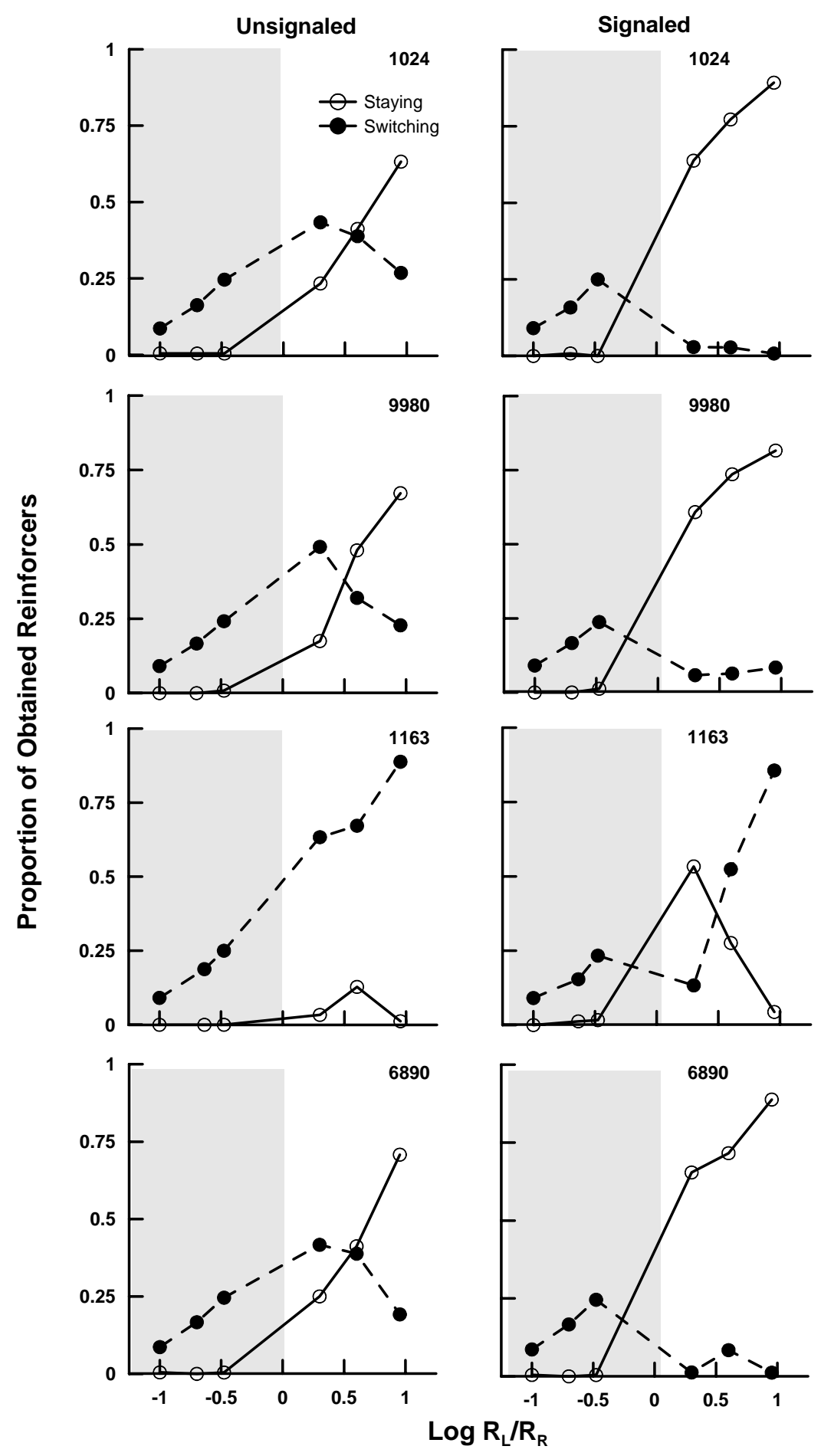

Figure 7. Experiment 1. The proportion of reinforcers obtained for staying at the left key (open circles) and switching to the left key (filled circles). Data are plotted as a function of the log reinforcer ratios. The left column shows data from the unsignaled conditions and the right column shows data from the signaled conditions. Shaded regions indicate conditions in which the left key was the lean alternative. 


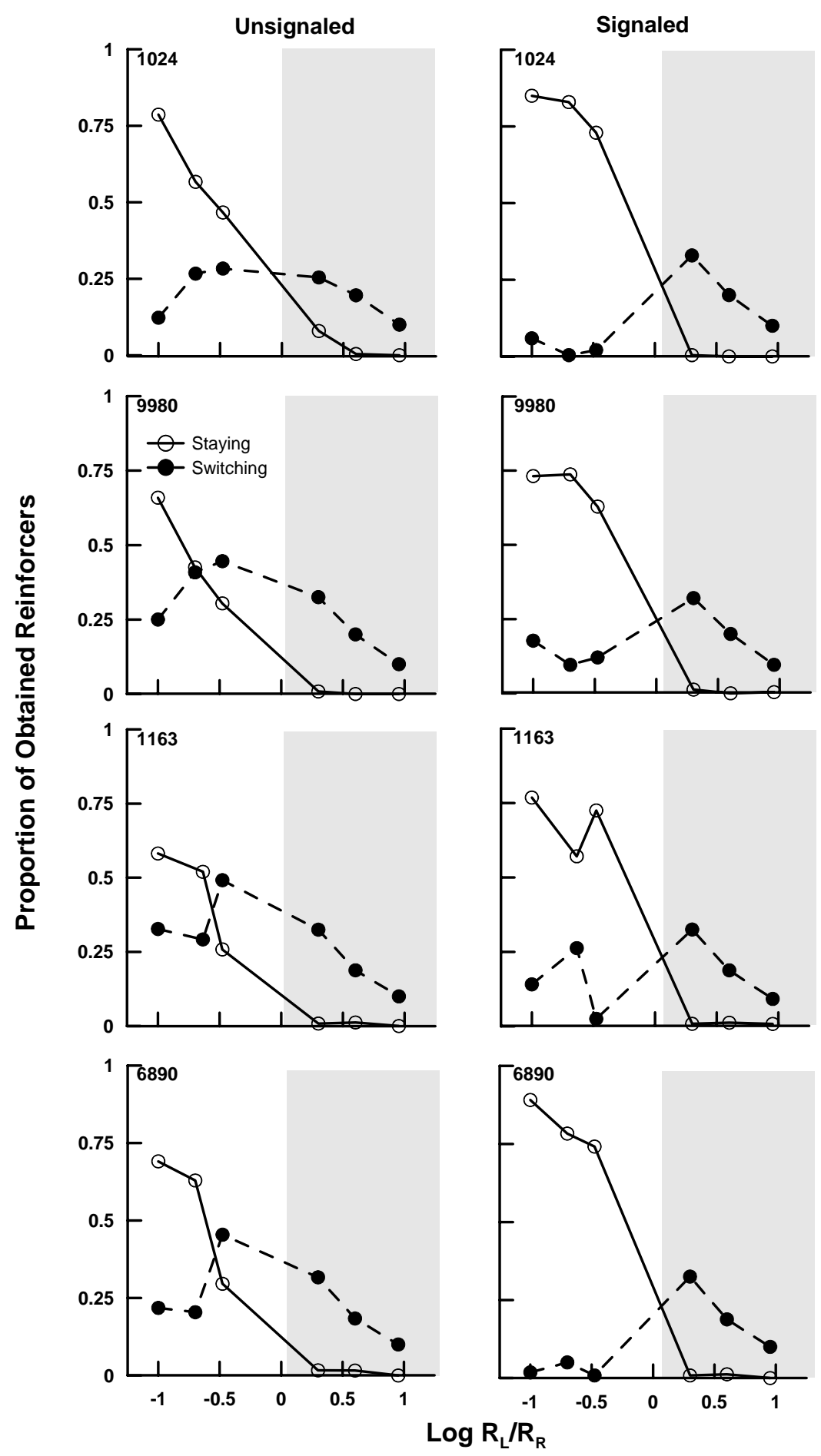

Figure 8. Experiment 1. The proportion of reinforcers obtained for staying at the right key and switching to the right key. Other details are as in Figure 7. 


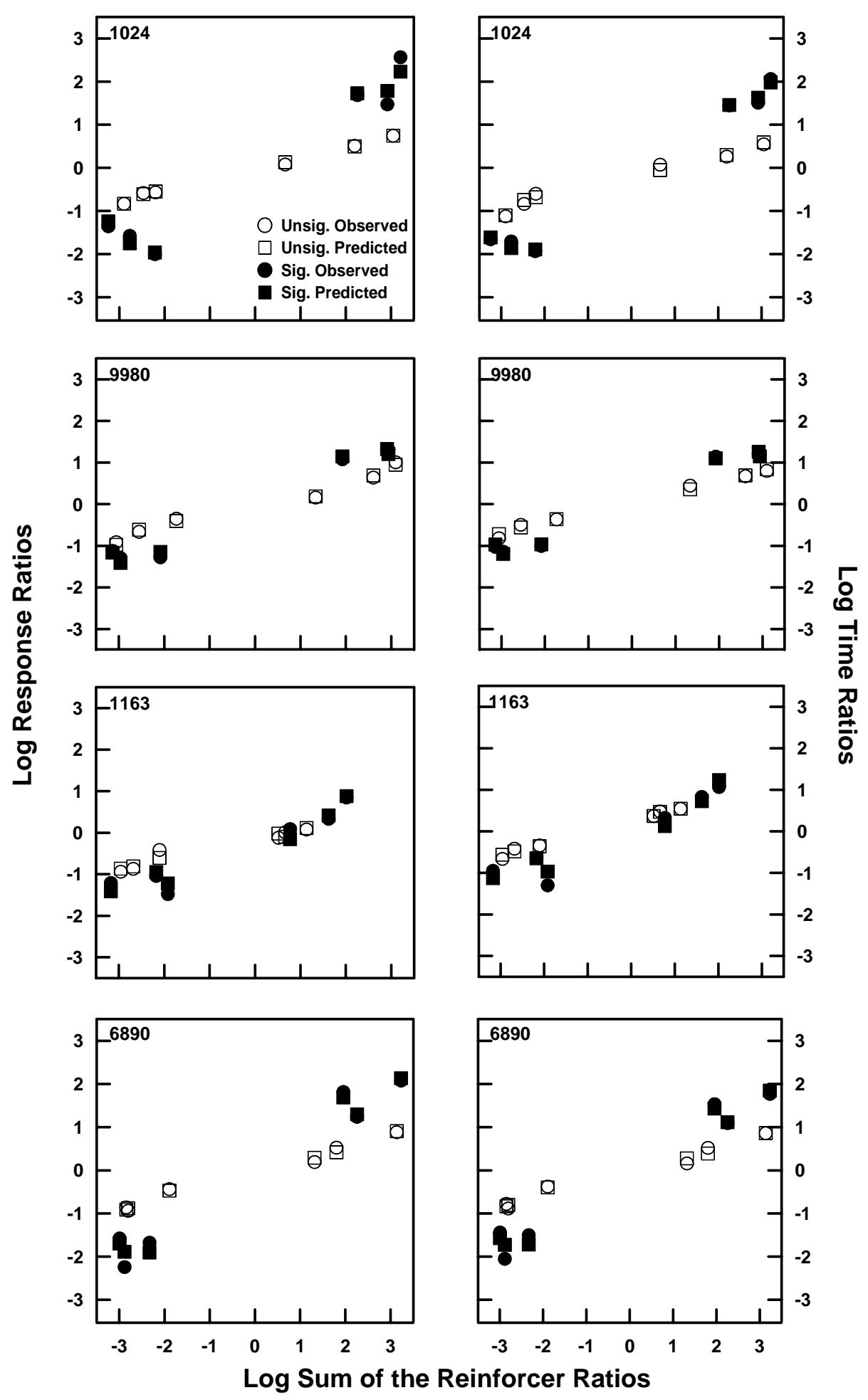

Figure 9. Experiment 1. Fits of Equation 6 (p. 13). The logarithms (base 10) of the response ratios (left column) and time ratios (right column) plotted as a function of the sum of the logarithm of the ratios for obtaining reinforcers and earning reinforcers. Circles depict observed behavior ratios and squares depict predicted behavior ratios. Open symbols depict data from the unsignaled conditions and filled symbols depict data from the signaled conditions. 

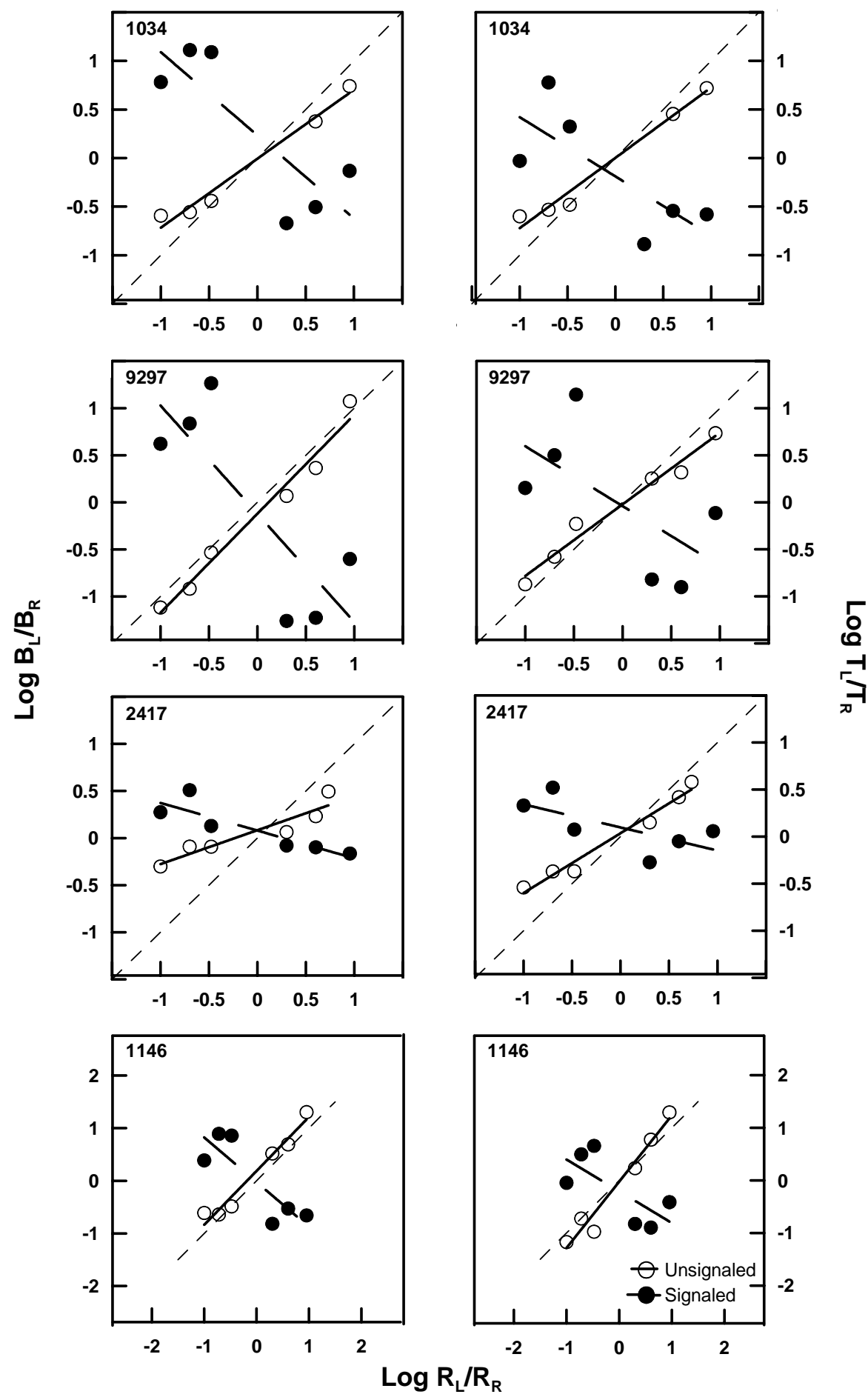

Figure 10. Experiment 2. The logarithms (base 10) of the response ratios $\left(\mathrm{B}_{\mathrm{L}} / \mathrm{B}_{\mathrm{R}}\right.$; left column) and time ratios $\left(T_{L} / T_{R}\right.$; right column) plotted as a function of the logarithm of the reinforcer ratios $\left(R_{L} / R_{R}\right)$. Open circles depict data from the unsignaled conditions and filled circles depict data from the signaled conditions. The dashed diagonal line depicts matching of the behavior ratios and reinforcer ratios. Solid lines are the least-squares regression lines for the unsignaled conditions, and heavy dashes are the regression lines for the signaled conditions. 

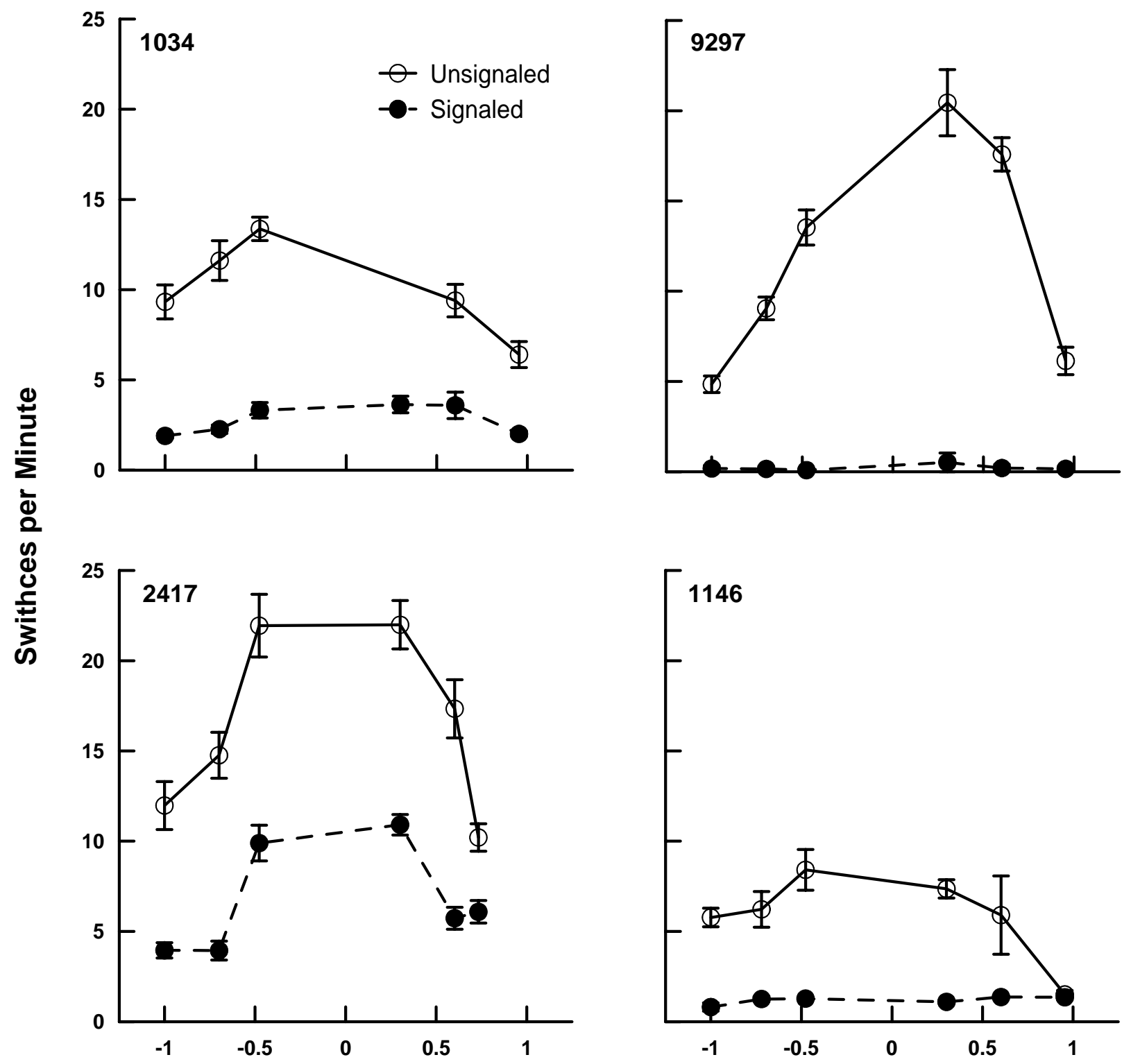

\section{$\log R_{L} / R_{R}$}

Figure 11. Experiment 2. Mean switches per minute as a function of the log reinforcer ratios. Open circles depict data from the unsignaled conditions and filled circles depict data from the signaled conditions. Error bars extend one standard deviation above and below the mean. 


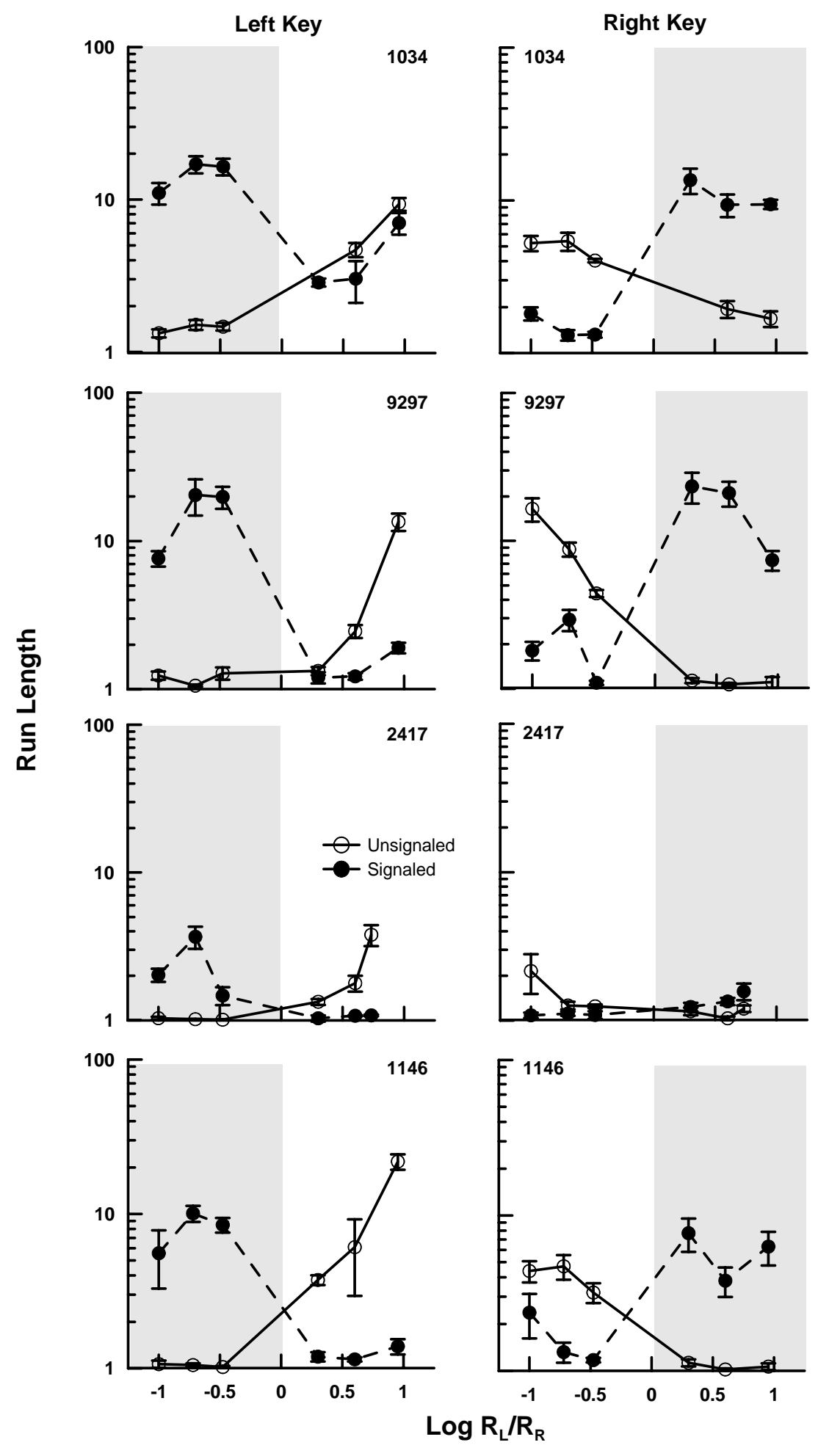

Figure 12. Experiment 2. Mean run lengths as a function of the log reinforcer ratios. Open circles depict data from the unsignaled conditions and filled circles depict data from the signaled conditions. Error bars extend one standard deviation above and below the mean. The left column shows run lengths on the left key and the right column shows run lengths on the right key. Shaded regions indicate conditions in which the key was the lean alternative. 


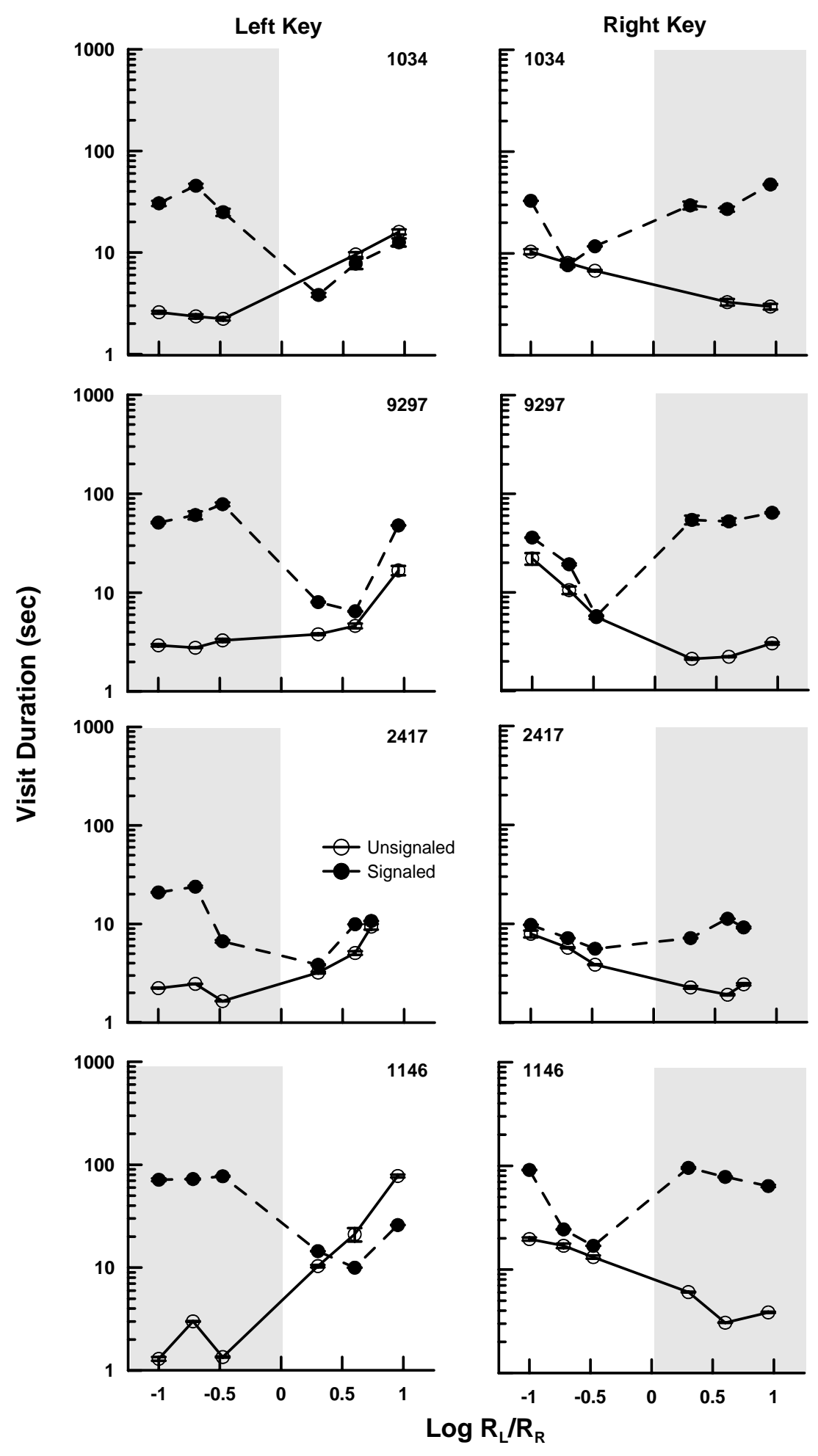

Figure 13. Experiment 2. Mean visit durations (in seconds) as a function of the log reinforcer ratios. Other details are as in Figure 12. 

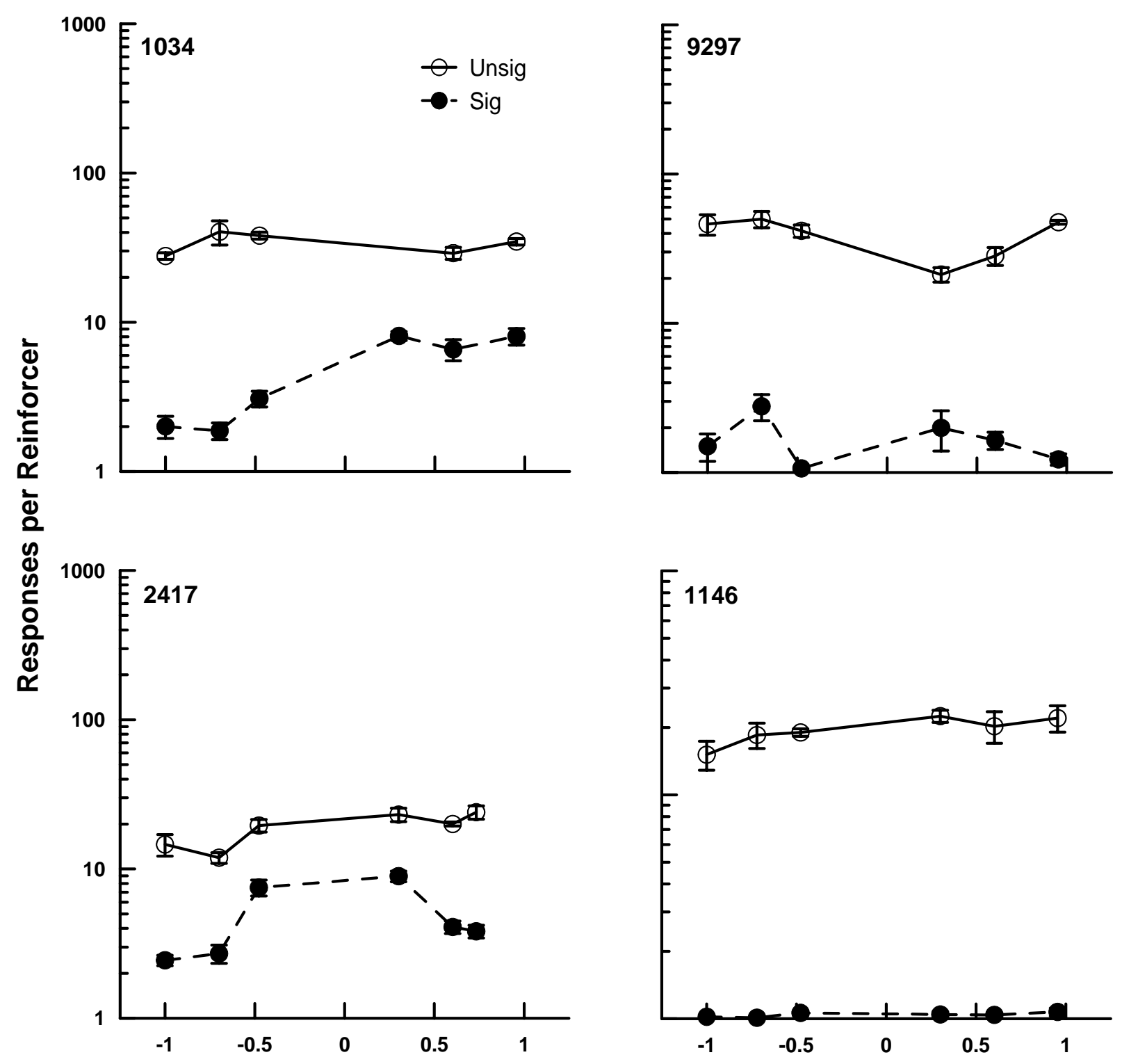

\section{$\log \mathbf{R}_{\mathrm{L}} / \mathbf{R}_{\mathbf{R}}$}

Figure 14. Experiment 2. The mean number of responses per reinforcer at the rich alternative as a function of the log reinforcer ratio. Open circles depict data from the unsignaled conditions and filled circles depict data from the signaled conditions. Error bars extend one standard deviation above and below the mean. 


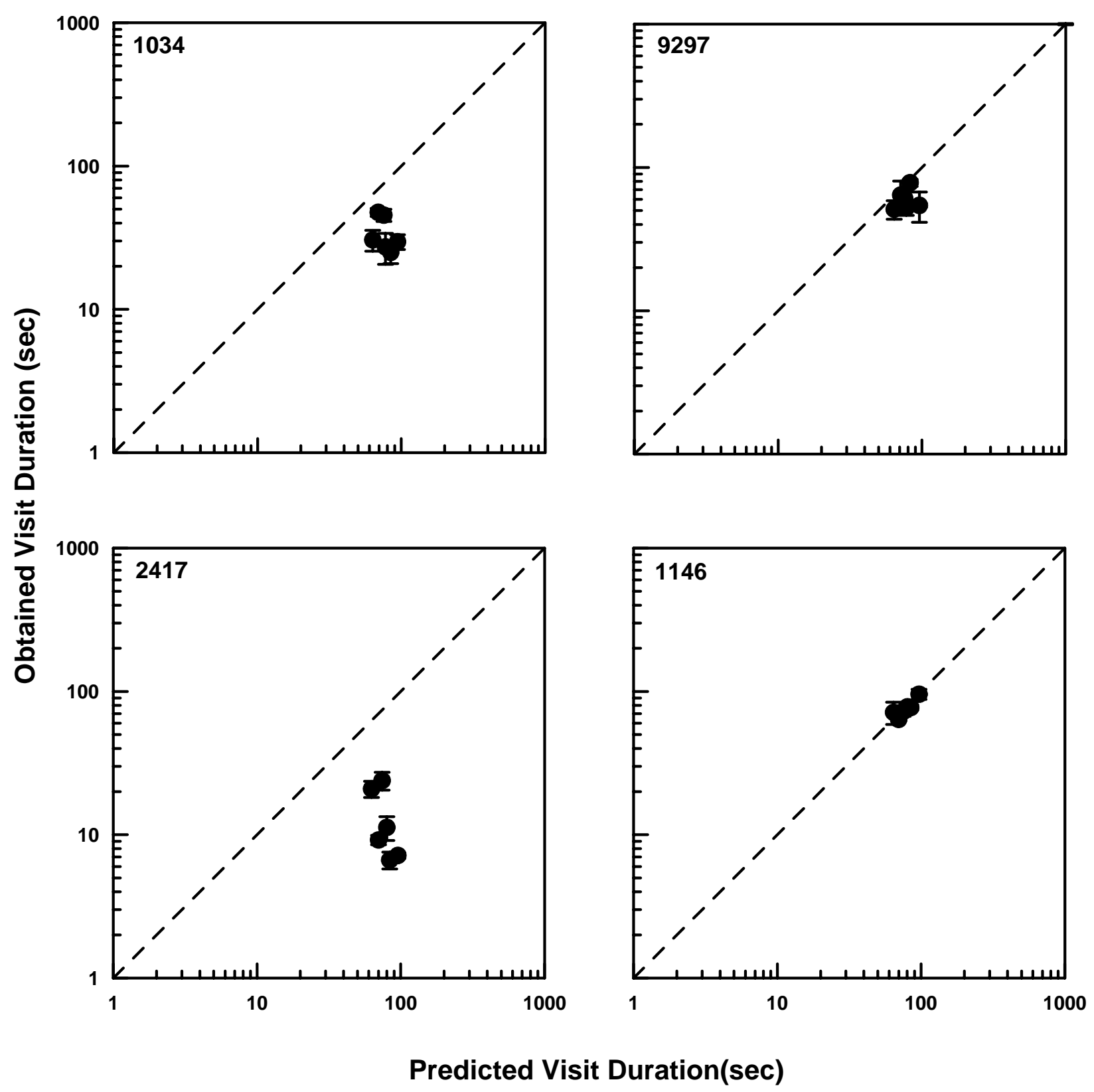

Figure 15. Experiment 2. For the signaled conditions, the mean obtained visit durations (in seconds) as a function of the predicted visit durations. The dashed diagonal line depicts the point where obtained and predicted visit durations are equal. 


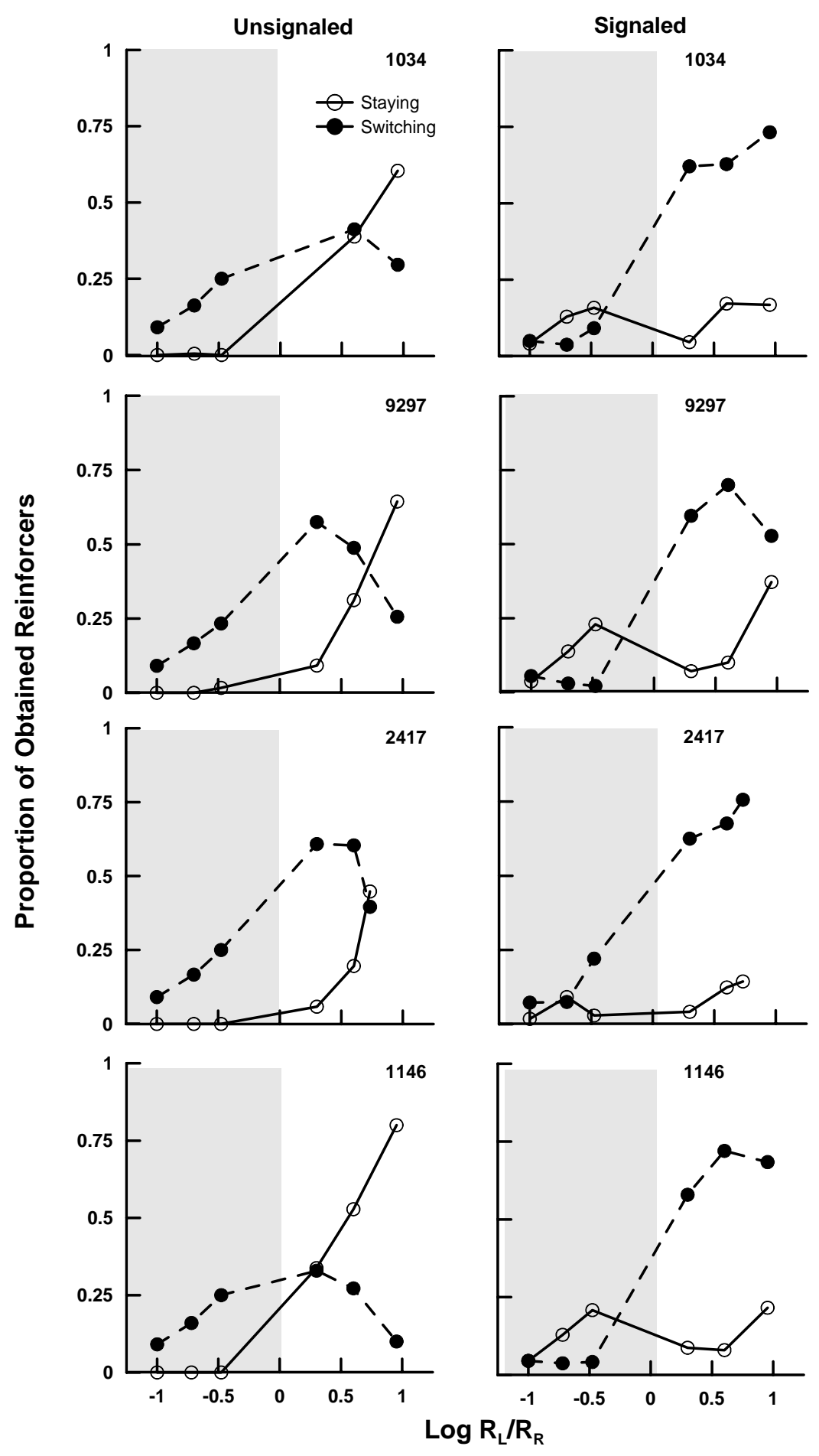

Figure 16. Experiment 2. The proportion of reinforcers obtained for staying the left key (open circles) and switching to the left key (filled circles). Data are plotted as a function of the log reinforcer ratios. The left column shows data from the unsignaled conditions and the right column shows data from the signaled conditions. Shaded regions indicate conditions in which the left key was the lean alternative. 

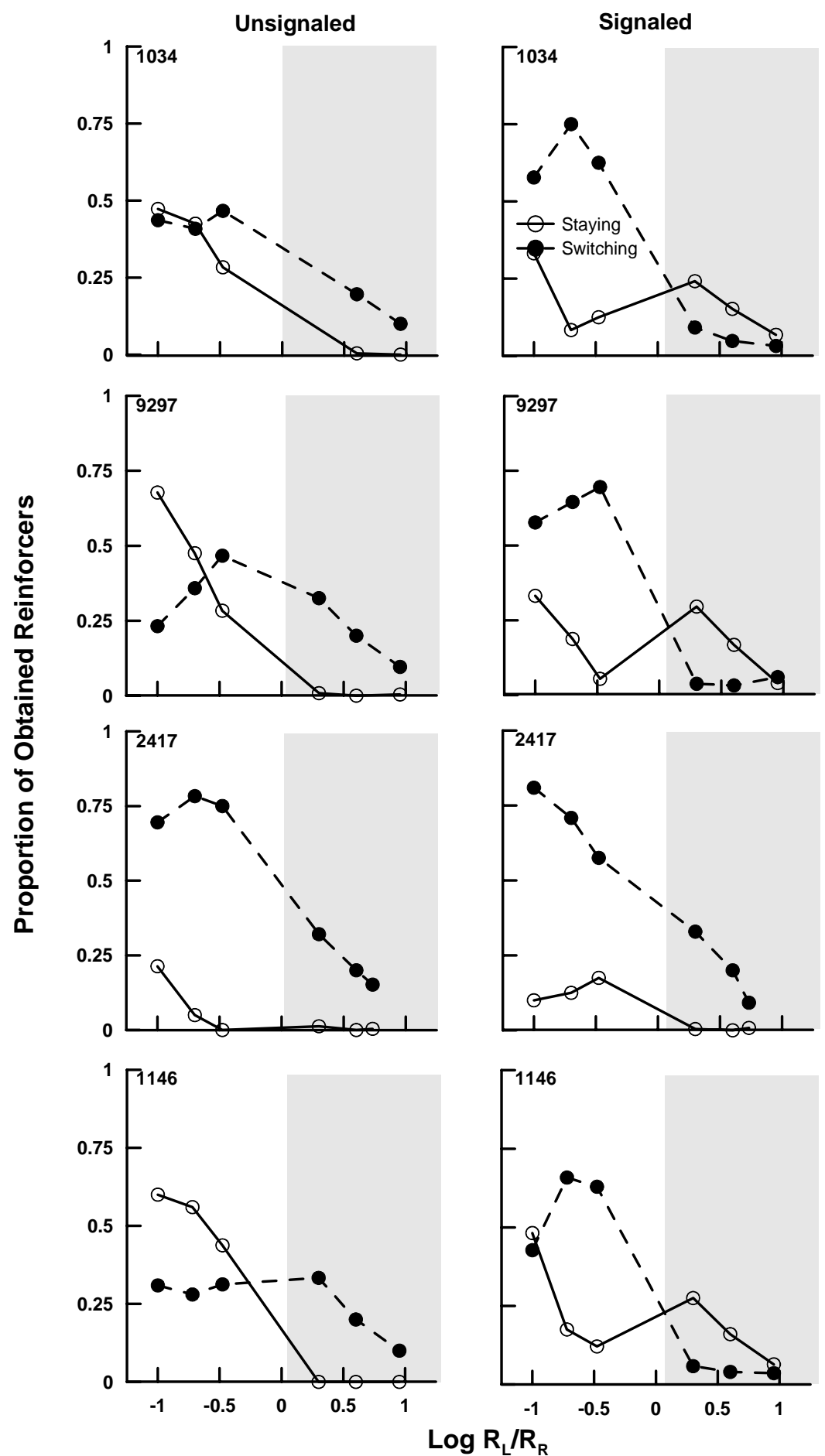

Figure 17. Experiment 2. The proportion of reinforcers obtained for staying at the right key and switching to the right key. Other details are as in Figure 16. 

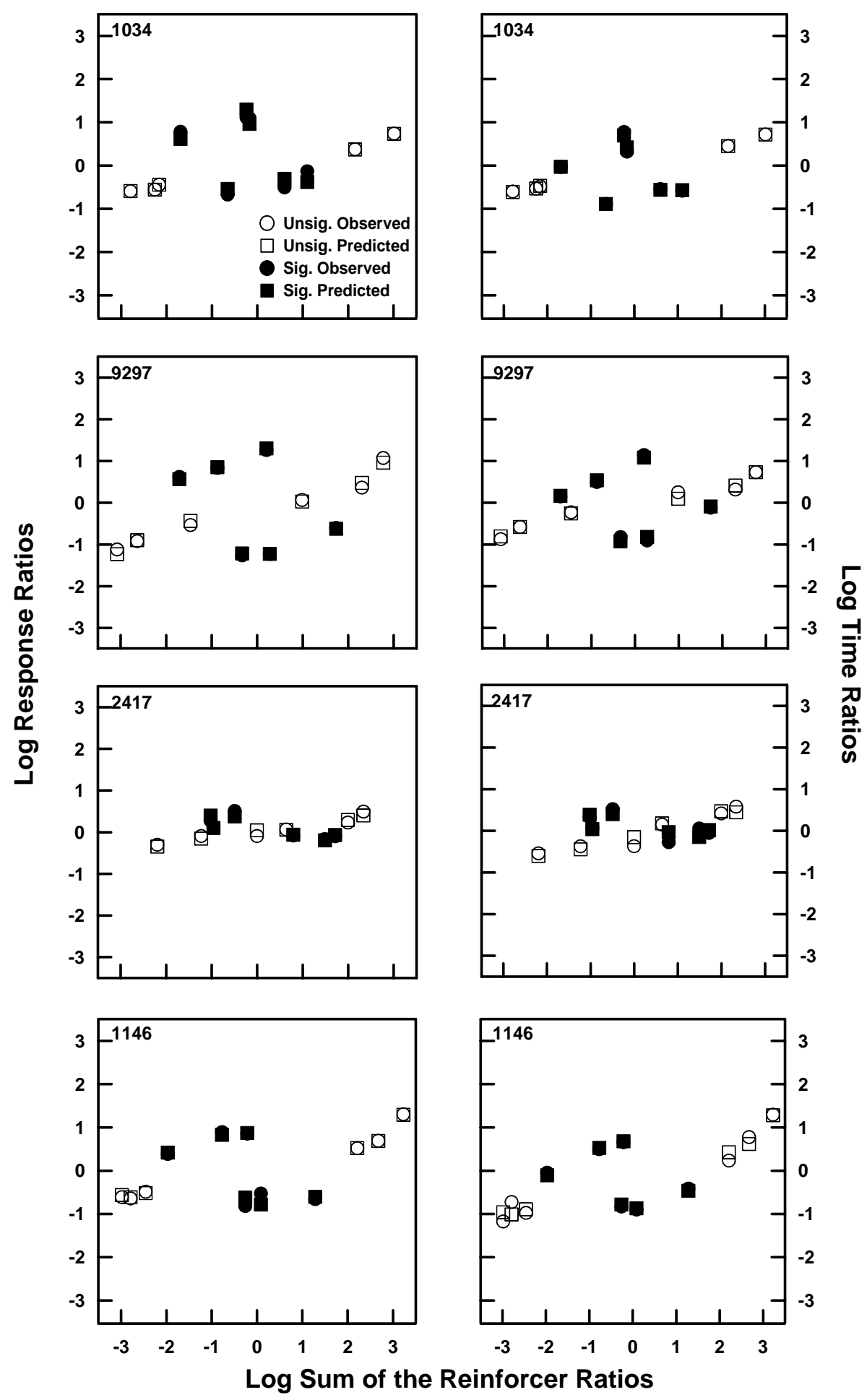

Figure 18. Experiment 2. Fits of Equation 6 (p. 13). The logarithms (base 10) of the response ratios (left column) and time ratios (right column) plotted as a function of the sum of the logarithm of the ratios for obtaining reinforcers and earning reinforcers. Circles depict observed behavior ratios and squares depict predicted behavior ratios. Open symbols depict data from the unsignaled conditions and filled symbols depict data from the signaled conditions. 